BANCA D'ITALIA

E U R O S I S T E M A

Temi di discussione

(Working Papers)

Public debt expansions and the dynamics of the household borrowing constraint

by António Antunes and Valerio Ercolani 



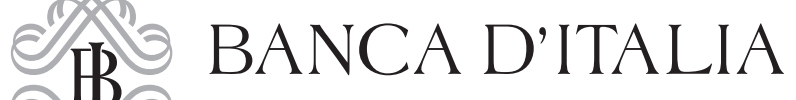

E UROS I S T E MA

\section{Temi di discussione}

(Working Papers)

Public debt expansions and the dynamics of the household borrowing constraint

by António Antunes and Valerio Ercolani

Number 1268 - March 2020 
The papers published in the Temi di discussione series describe preliminary results and are made available to the public to encourage discussion and elicit comments.

The views expressed in the articles are those of the authors and do not involve the responsibility of the Bank.

Editorial Board: Federico Cingano, Marianna Riggi, Monica Andini, Audinga Baltrunaite, Marco Bottone, Davide Delle Monache, Sara Formai, Francesco Franceschi, Salvatore lo Bello, Juho Taneli Makinen, luca Metelli, Mario Pietrunti, Marco Savegnago.

Editorial Assistants: Alessandra Giammarco, Roberto Marano.

ISSN 1594-7939 (print)

ISSN 2281-3950 (online)

Printed by the Printing and Publishing Division of the Bank of Italy 


\title{
PUBLIC DEBT EXPANSIONS AND THE DYNAMICS OF THE HOUSEHOLD BORROWING CONSTRAINT ${ }^{*}$
}

\author{
by António Antunes ${ }^{* *}$ and Valerio Ercolani ${ }^{* * *}$
}

\begin{abstract}
Contrary to a well-established view, public debt expansions may tighten the household borrowing constraint over time. Within an incomplete-markets model featuring an endogenous borrowing limit, we show that plausible debt-financed fiscal policies generate such tightening through an increase in the interest rate. The tightening makes constrained agents deleverage and reinforces the precautionary saving motive of the unconstrained. This appetite for assets affects factor prices and this, in some cases, amplifies the households' reactions to the policies. For example, the tightening can substantially magnify the government spending multiplier by strengthening the typical negative wealth effect on labor supply induced by the fiscal stimulus. Moreover, the tightening affects political support for the policies mainly through price effects.
\end{abstract}

JEL Classification: E21, E44, E62, H60.

Keywords: endogenous borrowing constraint, government debt, fiscal policies and multipliers, heterogeneous households, incomplete markets.

DOI: $10.32057 / 0 . T D .2020 .1268$

\section{Contents}

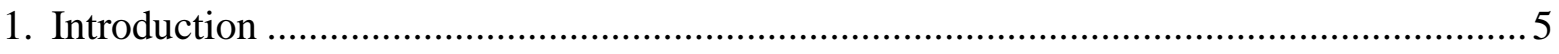

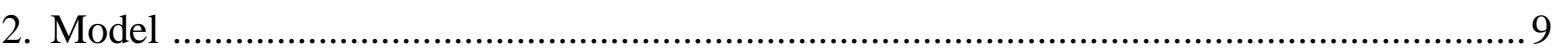

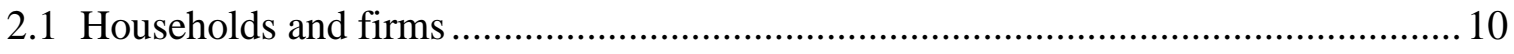

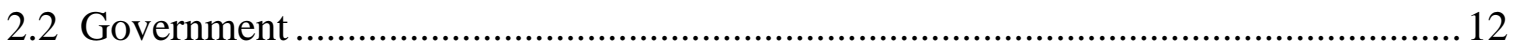

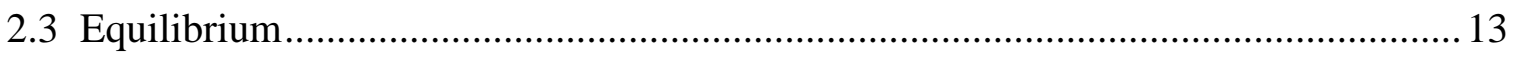

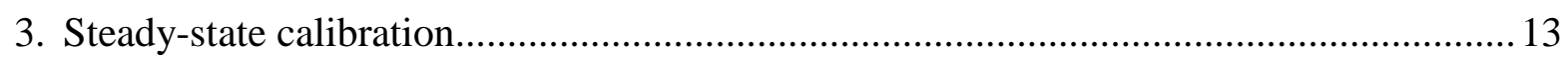

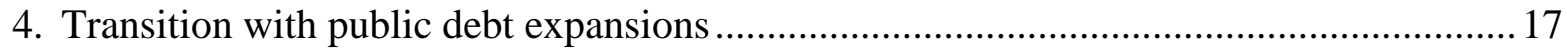

4.1 The dynamics of the borrowing limit, prices and aggregates................................. 17

4.2 Dynamics at the individual level and consequences for the aggregates ....................2 21

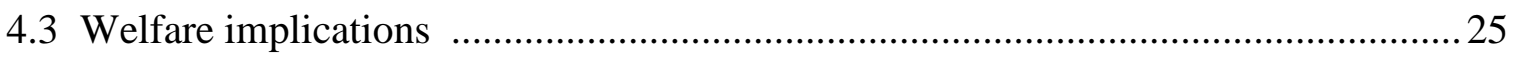

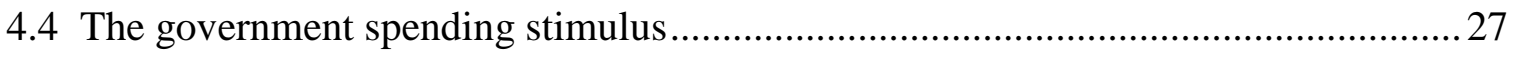

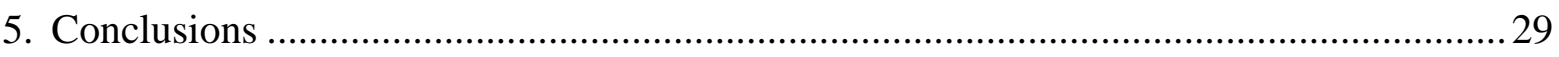

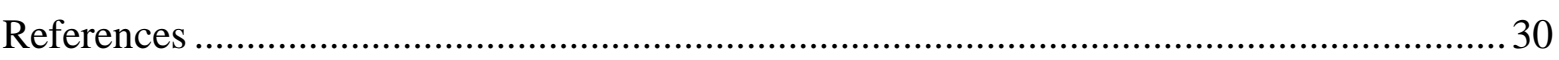

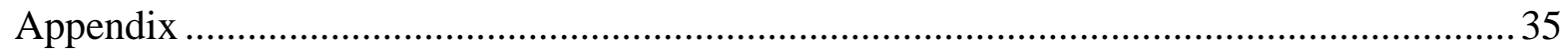

\footnotetext{
${ }^{*}$ This paper is forthcoming at Review of Economic Dynamics.

** Bank of Portugal, Department of Economic Studies; NOVA SBE.

*** Bank of Italy, Directorate General for Economics, Statistics and Research.
} 



\section{Introduction ${ }^{1}$}

Policies have the potential to influence credit markets and, in particular, the households' ability to either borrow or lend. In this paper, we explicitly consider the endogeneity of the household borrowing constraint and show that this channel accounts for a sizeable part of the effects in output, credit and welfare of typical fiscal policies entailing public debt expansions.

It is well known that government debt expansions significantly influence the households' financial conditions (Woodford, 1990; Aiyagari and McGrattan, 1998; Angeletos et al., 2016; Röhrs and Winter, 2015, among others). ${ }^{2}$ For example, Aiyagari and McGrattan (1998) put forward the view that, within an economy where households face borrowing constraints and the precautionary saving motive is active, public debt can act as if it loosened the household borrowing constraint. That is, higher levels of public debt result in higher interest rates, making assets more attractive to hold and, hence, enhancing households' self-insurance possibilities.

An increase in the interest rate contributes to a "loosening" of the borrowing limit, but it also makes borrowing more costly, generating ceteris paribus an actual tightening in the borrowing constraint. Virtually any endogenous borrowing constraint has the property of being proportional to the inverse of the borrowing cost, as are the cases of the natural borrowing limit in Aiyagari (1994) and of the constraint with collateral in Kiyotaki and Moore (1997). This property is supported by empirical evidence. Figure 1 shows a negative correlation between the evolution of the uncollateralized household borrowing limit estimated by Fulford (2015) and the interest rate on credit card plans over the 2000s in the U.S., which implies that increases in the interest rate are associated with a tightening of this limit. The short-term risk-free interest rate produces a similar picture and a slightly less negative correlation (see Section A in the appendix for details). Maddaloni and Peydró (2011) also find a significant correlation between proxies for borrowing constraints, such as credit standards, and interest rates. ${ }^{3}$

We perform our analysis within a general equilibrium, incomplete-markets, flexible prices model with physical capital and a neoclassical labor market which relies on the early contribution of Bewley (1977). Households are heterogeneous in terms of wealth and productivity,

\footnotetext{
${ }^{1}$ This paper is forthcoming at Review of Economic Dynamics. An earlier version of the paper circulated under the title "Debt-financed fiscal policies and the dynamics of the household borrowing constraint". We particulary thank Pedro Teles and Gianluca Violante for their comments during different stages of the project. We are also grateful to Mark Aguiar, Pedro Amaral, George-Marios Angeletos, Marco Bassetto, Pedro Brinca, Craig Burnside, Francesco Carli, Dean Corbae, Isabel Correia, Luca dei Federichi, Giulia Feserini, Jonathan Heathcote, João Victor Issler, Pat Kehoe, Tim Kehoe, Jesper Lindé, Fabrizio Mattesini, Ellen McGrattan, Ettore Panetti, Morten Ravn, Sérgio Rebelo and João Valle e Azevedo for useful suggestions. We thank participants of all seminars and conferences in which this paper was presented. The views expressed are those of the authors and do not necessarily represent those of Bank of Portugal, Bank of Italy or the Eurosystem. All errors are ours.

${ }^{2}$ Holmstrom and Tirole (1998) focus on the productive sector of the economy and study how the governmentsupplied assets influence the firms' financing problem.

${ }^{3}$ Using surveys to commercial banks (including the Bank Lending Survey for the Eurosystem), Maddaloni and Peydró (2011) show that credit standards applied to households and firms become tighter when short-term interest rates increase, both in the U.S. and in the euro area. The authors primarily focus on the effect of shortterm nominal interest rates, interpreted as a proxy for monetary policy, on these credit standards. However, such evidence can also be extended to real rates since, in their computations, the effect of inflation is controlled for.
} 


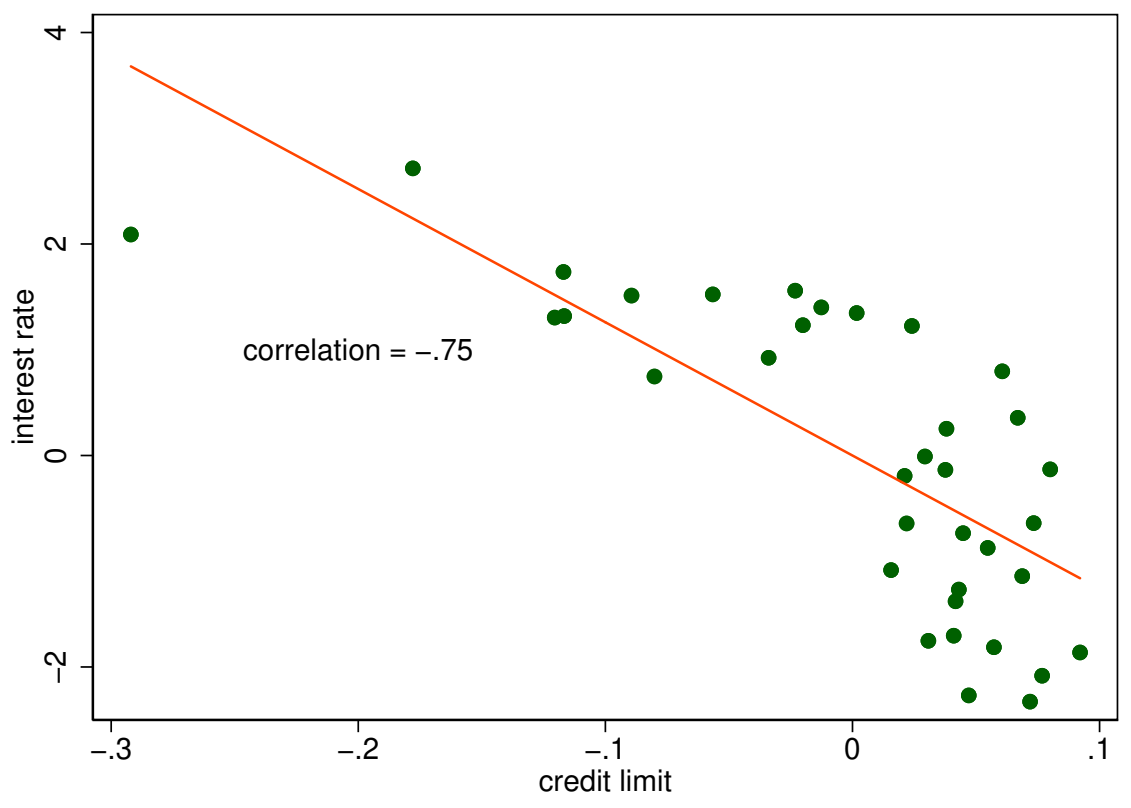

Figure 1: The borrowing limit and the interest rate for the U.S., in real terms, demeaned. The log of the quarterly series of the borrowing limit is taken from Fulford (2015). The series of the quarterly real rate is calculated as the difference between the rate charged by commercial banks on credit card plans and the quarterly average of monthly inflation expressed in annual terms, both taken from the FRED database. The time period is 1999q1-2007q4. The reported Pearson's correlation coefficient between the two variables is significant at $1 \%$. The straight line represents a linear fit to the two variables.

and the wealth distribution evolves endogenously. In order to self-insure against the occurrence of bad productivity shocks, they borrow or lend without using collateral. We endogeneize the borrowing constraint by considering limited commitment for the repayment obligations of the households. In particular, in case of default they are permanently excluded from intertemporal trade, thus entering an autarky regime. We assume that honoring its own debt is at least as good as defaulting. Within our incomplete-markets environment and consistently with the empirical evidence, the temptation of declaring bankruptcy - measured by the relative value of autarky vis-à-vis the value of honoring debt commitments - decreases as the household's labor income increases.

We calibrate the stationary distribution of our model at quarterly frequency for the U.S. economy. We then study the transition of the economy due to transitory public debt expansions that finance stylized but realistic spending policies. On one hand, we analyze a policy of transfers amounting to $1 \%$ of steady-state output and evenly distributed across households. The aggregate profile for transfers follows the one estimated by Leeper et al. (2010). On the other hand, the debt expansion finances an increase in purchases of goods and services, the so-called government spending stimulus, similar to that set in the American Recovery and Reinvestment Act (ARRA). The two policies have a certain degree of persistence over time and entail future increases in taxation to repay the debt. To the best of our knowledge, our work is the first that studies the transition associated to public debt expansions within a framework in which the households' wealth distribution evolves endogenously and the borrowing constraints 
emerge as an equilibrium outcome.

An increase in public debt impacts positively the interest rate. All else equal, the option to stay in the market becomes relatively worse than going to autarky for the borrowers, giving them a higher incentive to default. Lenders will therefore be less willing to provide funds in the credit market. This will endogenously tighten the household borrowing constraint, which means that the maximum quantity that households can borrow becomes smaller. Because of the tightening, constrained agents are forced to deleverage, while the unconstrained save more for precautionary purposes. The appetite for assets generates a downward pressure on the interest rate that dampens the abovementioned tightening. Eventually, the borrowing limit tightens by roughly $0.5-1 \%$ of steady-state output across the two simulated policies and its dynamics is very persistent over time.

The tightening induces households to cut consumption and work harder, though we show that the magnitude of the households' reactions heavily depends on which region of the wealth distribution the household pertains to. For example, constrained agents react on average five times more than the unconstrained.

On top of the tightening, the two fiscal policies may generate opposite reactions. For example, in what concerns output dynamics the purchases policy fosters labor supply which generates a positive output multiplier. The dynamics of the borrowing constraint, identified by its pure movement and price effects (lower interest and higher wage rates), amplifies the output reaction: the impact multiplier of our baseline model with the endogenous borrowing constraint is roughly 0.9 , while the multiplier generated by the model in which the constraint is exogenously kept at its steady-state level is close to 0.65. In contrast, the transfers policy allows agents to work less, thus generating a contraction in output. In this case the tightening dampens the output fall.

In other dimensions the two policies produce similar outcomes; for instance, they both crowd out credit and physical capital. Over a five-year horizon an average of $20 \%$ of the fall in credit is explained by the tightening.

The endogenous borrowing limit plays an important role also in determining the welfare effects generated by the fiscal policies. In the case of the transfers policy the dynamics of the borrowing limit significantly influences political support. In the baseline model, the majority of agents (roughly four fifths) supports the policy, whereas in the fixed constraint version of the model such support is far from majoritarian. This is mainly due to the price effects induced by the tightening along the transition path.

Finally, we perform a crisis experiment by studying how the debt expansions influence the dynamics of an economy experiencing a credit crisis characterized by falling credit and output. The fiscal policies contribute to a further tightening in the borrowing limit and reinforce the fall in credit, whereas their effect on output is not substantial.

An important lesson can be drawn from these results. Constrained agents react the most to the tightening but it is the reaction of the unconstrained that allows it to produce sizeable aggregate effects. Indeed, the unconstrained - which constitute roughly $90 \%$ of the population- 
react non-trivially to both the shift of the borrowing limit and the price effects that it generates. Between half and two thirds of the effects generated by the tightening are due to its price effects.

There is a recent stream of the literature that studies the effects of (i) taxes and monetary transfers and of (ii) government consumption within incomplete-markets frameworks. For example, Heathcote (2005), Ábrahám and Cárceles-Poveda (2010), Oh and Reis (2012), Kaplan and Violante (2014), Huntley and Michelangeli (2014) and McKay and Reis (2016) belong to the first class of papers, while Challe and Ragot (2011), Brinca et al. (2016) and Ercolani and Pavoni (2019) belong to the second. In particular, our paper is tightly linked to Heathcote (2005) and Challe and Ragot (2011). The first paper primarily shows how the consideration of a binding exogenous borrowing limit breaks the Ricardian equivalence, as a debt-financed transfers policy allows wealth-poor agents to consume more, thus affecting the interest rate. The second paper, using a model where households face collateralized borrowing constraints but the wealth distribution is not a state variable, shows that a government spending stimulus may crowd in private consumption, depending on the extent to which the fiscal policy enhances self-insurance possibilities. Unlike these papers, we focus on the endogeneity of the borrowing constraint and by how much this endogeneity influences the effects of the policies. ${ }^{4}$ To some extent our work is also related to Ábrahám and Cárceles-Poveda (2010), who address the effects of revenue-neutral tax reforms in an economy encompassing endogenous borrowing limits with limited commitment. They show that these borrowing constraints significantly influence the effects of the reforms. Their paper, unlike ours, does not contribute to the debate about the effects of public debt expansions on the tightness of the household borrowing constraint. Moreover, they use an analytical framework similar to ours but without endogenous labor supply. Our results show that labor significantly interacts with the dynamics of the borrowing constraint. For details, see Section 4.4 and Section E.4 in the appendix.

There is also the well-established stream of the literature that studies government spending stimuli within general equilibrium models, with complete markets and representative agent(s). The seminal contribution is that of Baxter and King (1993). Galí et al. (2007), Hall (2009), Fernández-Villaverde (2010), Christiano et al. (2011), Eggertsson and Krugman (2012), Corsetti et al. (2013), Bilbiie et al. (2013) and Rendahl (2016) study the effects of fiscal policies in the presence of various financial frictions. We see two contributions to this literature. First, unlike these papers our framework of analysis allows us to study how the combination of borrowing constraints, wealth heterogeneity and market incompleteness influences the households' reaction to public debt expansions. Second, part of this literature stresses how specific channels, such as price stickiness and nominal rates constrained at zero, are able to generate larger government spending multipliers. We isolate an additional mechanism-the tightening in the borrowing limit - that is able to amplify the output reaction to a government spending stimulus even within a fully flexible prices environment.

\footnotetext{
${ }^{4}$ As for Challe and Ragot (2011), it is worth noting that the study of the dynamics of the borrowing limit is not their principal interest because they set the borrowing limit to zero in all their benchmark simulations. In a robustness exercise, they show that the stimulus may reduce the agents' ability to borrow. However they cannot investigate the interaction between their ad hoc borrowing limit and the evolution of the wealth distribution. We show that this interaction is crucial in shaping the effects of the fiscal policies.
} 
Finally, our work is also related to those papers studying the effects of a credit crunch, within frameworks of heterogeneous agents and incomplete markets, as, among others, Guerrieri and Lorenzoni (2017), Buera and Moll (2015), Huo and Ríos-Rull (2015) and Kehoe et al. (2016). We contribute to this literature by studying the interactions between the dynamics of the borrowing constraint and debt-financed fiscal policies.

The paper is structured as follows. Section 2 presents the model. Section 3 presents the results for the stationary distribution. Section 4 reports the transitional dynamics of the economy generated by the government debt expansions. Section 5 concludes.

\section{Model}

Our model belongs to the long-standing tradition of incomplete-markets models like, for example, Bewley (1977), Huggett (1993) and Aiyagari (1994). Specifically, we consider a general equilibrium model with capital and a neoclassical labor market in which households differ by their wealth and productivity. Households choose their labor effort and level of consumption. They save or borrow using uncollateralized credit.

In the spirit of Kehoe and Levine (1993), Zhang (1997) and Alvarez and Jermann (2000), we endogeneize the borrowing constraint by allowing households to default on their debt, in which case they go to autarky permanently. Lenders will then make sure that the value of honoring debt by borrowers is not less than that of defaulting. ${ }^{5}$

Notice two important features of this type of constraints. First, unlike in a complete-markets setting (Kehoe and Levine, 1993; Alvarez and Jermann, 2000), and consistently with the data, using these constraints in an incomplete-markets framework makes the willingness of declaring default decreasing with the level of household's labor income. Second, unlike the standard natural borrowing limit of Aiyagari (1994), this type of constraint allows us to generate a realistic credit-to-output ratio and share of constrained households. The details of both characteristics are spelled out in Section 3. One should note that in this model credit constraints ensure no defaults in equilibrium and prevent households from saving in autarky. While these channelsdefaults in equilibrium and saving in autarky - can be important, allowing for them would significantly complicate our analysis. In the following sections, we will nonetheless compare our model results to those one would arguably obtain had these mechanisms been considered.

We also model a fiscal authority that can collect lump-sum, capital and labor taxes. It issues debt with the same return as physical capital to finance either transfers or purchases. Within our framework, the Ricardian equivalence does not hold even if the financing operates through a mix between debt and lump-sum taxation. This is because the borrowing constraint used in our model is typically tighter than the natural borrowing limit (see Chapther 9 of Ljungqvist and Sargent, 2004, for a detailed argument).

\footnotetext{
${ }^{5}$ Kehoe and Levine (1993) and Alvarez and Jermann (2000) study the properties of the equilibrium allocation in models characterized by limited-commitment borrowing constraints, in the presence of a complete set of state-contingent securities. Furthermore, Zhang (1997), Ábrahám and Cárceles-Poveda (2010) and Antunes and Cavalcanti (2013) use these types of constraints within incomplete-markets models.
} 


\subsection{Households and firms}

There is a continuum of infinitely lived and ex ante identical households with measure one. We use a standard neoclassical instantaneous utility function of the following type:

$$
u(c, n)=\frac{c^{1-\sigma}-1}{1-\sigma}-\chi \frac{n^{1+\psi}}{1+\psi}
$$

where $c$ and $n$ are consumption and labor, respectively. The individual state vector is defined as $x=(a, z)$, where $a$ and $z$ are asset holdings and productivity, respectively. Process $z$ is finite-state Markov with support $\mathcal{Z}$ and transition probability matrix $\Pi$, whose element $\pi_{i j}$ is defined as $\operatorname{Pr}\left(z^{\prime}=z_{j} \mid z=z_{i}\right)$ and $z_{k}$ is the $k^{\text {th }}$ element of $\mathcal{Z}$. We shall henceforth use the usual notation where $x^{\prime}$ denotes the value of variable $x$ in the next period.

The household problem in recursive form can be written as follows:

$$
v(x, \theta)=\max _{c, n, a^{\prime}} u(c, n)+\beta \mathbf{E}\left[v\left(x^{\prime}, \theta^{\prime}\right) \mid z\right]
$$

subject to

$$
\begin{aligned}
c+a^{\prime} & =\left(1+r\left(1-\tau_{k} \mathcal{I}_{a \geq 0}\right)\right) a+w n z\left(1-\tau_{w}\right)+\operatorname{Tr}-\Gamma \\
v\left(x^{\prime}, \theta^{\prime}\right) & \geq \underline{v}\left(z^{\prime}, \theta^{\prime}\right), \quad \text { all } z^{\prime} \in B(z) \\
\underline{v}(z, \theta) & =\max _{n} u\left(\gamma w n z\left(1-\tau_{w}\right)+\operatorname{Tr}-\Gamma, n\right)+\beta \mathbf{E}\left[\underline{v}\left(z^{\prime}, \theta^{\prime}\right) \mid z\right] \\
\theta^{\prime} & =H(\theta) .
\end{aligned}
$$

In these expressions, $\mathcal{I}_{a \geq 0}$ is an indicator function that equals 1 if $a \geq 0$, and 0 otherwise. $B(z)=\{\xi \in \mathcal{Z}: \Pi(z, \xi)>0\}$ is the set of possible next-period idiosyncratic states given that the current state is $z$. $\theta$ is the measure of households, defined in a set of possible asset holdings and idiosyncratic shocks. It subsumes all relevant aggregate variables taken as given by the household. $H(\theta)$ is the forecasting function used by households in predicting next period's measure. Variable Tr represents transfers from the government to households, while $\Gamma$ are lump-sum taxes. We need to distinguish among these two variables to allow for the coexistence of an exogenous policy of lump-sum transfers to households and a rule-based lump-sum tax. The net return on capital, or the borrowing cost, is $r$ and the wage rate for labor efficiency units is $w$. Capital income is taxed at rate $\tau_{k}$ and labor income is taxed at rate $\tau_{w}$.

In this economy borrowers can default on their one-period maturity debt but lenders do not enter credit contracts that will not be fully repaid. The assumed timing is the following. When the agent enters the period, it learns its productivity realization and decides whether to default or not. In the affirmative case, it reneges on all its existing debt, is excluded from future participation in capital and credit markets, and suffers a permanent pecuniary cost due to stigma; otherwise, the agent keeps access to borrowing and saving. Given its feasibility set, the agent then optimally decides how much to work and consume, and its asset holdings in the next period. Equation (2) represents the participation constraint of lenders; it states that 
lenders make sure that borrowers will fully repay their loans by guaranteeing that it is never in the household's best interest to default no matter what happens in the next period. Equation (3) defines the value of being in autarky, $\underline{v}(z, \theta)$; in its expression, $\gamma$ is one minus a pecuniary cost of having tainted credit status, as in Chatterjee et al. (2007).

Since $v\left(x^{\prime}, \theta^{\prime}\right)$ is non decreasing in $a^{\prime}$ while $\underline{v}\left(z^{\prime}, \theta^{\prime}\right)$ is independent of $a^{\prime}$, equation (2) defines a set of endogenous lower bounds on borrowing conditional on each level of $z^{\prime}$. Formally, we define $\underline{\hat{a}}\left(z^{\prime}, \theta^{\prime}\right)$ as the lowest, or most negative, possible asset level conditional on each level of $z^{\prime}: 6$

$$
\underline{\hat{a}}\left(z^{\prime}, \theta^{\prime}\right)=\inf \left\{a^{\prime} \in \mathbb{R}: v\left(a^{\prime}, z^{\prime}, \theta^{\prime}\right) \geq \underline{v}\left(z^{\prime}, \theta^{\prime}\right)\right\} .
$$

For each current level of idiosyncratic productivity, $z$, the lender will pick the tightest constraint among those associated to next period's possible levels of productivity:

$$
\underline{a}_{z}\left(\theta^{\prime}\right)=\sup \left\{\underline{\hat{a}}\left(z^{\prime}, \theta^{\prime}\right): z^{\prime} \in B(z)\right\} \text {. }
$$

In practice, as we will see in Section 3, given the characteristics of our calibrated transition matrix $\Pi$ the relevant endogenous borrowing limit is unique and generated by inequality (2) parameterized in the lowest $z$, which corresponds to the tightest among the borrowing limits in $(5)$.

A representative firm with production function $Y=A K^{\alpha} N^{1-\alpha}$ chooses efficient labor, $N$, and capital, $K$, taking factor prices as given, according to:

$$
\begin{aligned}
r^{K} & =\alpha A\left(\frac{N}{K}\right)^{1-\alpha}, \text { where } r=r^{K}-\delta \\
w & =(1-\alpha) A\left(\frac{K}{N}\right)^{\alpha},
\end{aligned}
$$

where $A$ is total factor productivity (TFP).

An alternative to our framework is developed by Chatterjee et al. (2007). Their model embeds incomplete financial markets, endogenous borrowing spreads, and defaults in equilibrium. In order to generate sufficiently strong motives to default, they introduce serially uncorrelated expense shocks related to divorce and health issues. Lenders recover the borrowed amount only in expectation. Debt contracts are specified by a face value to be repaid at maturity and a discount factor conditional on current productivity and the face value of the contract. One possible borrowing limit in this framework is the largest amount of resources that the agent can obtain in the current period by borrowing. ${ }^{7}$ This quantity is well-defined because lenders will not be willing to enter a contract whose face value is not compensated by a sufficiently small discount factor; this means that in equilibrium the discount factor depends negatively on the default probability of the loan and on the risk-free interest rate. While very well attuned

\footnotetext{
${ }^{6}$ Notice that while our notation defines the borrowing constraint as the most negative asset level, the borrowing limit used to draw Figure 1 in Section 1 follows the definition of Fulford (2015) which identifies the limit with a positive number. More details are given in Section A of the appendix.

${ }^{7}$ This is the $B_{2}$ limit in Chatterjee et al. (2007).
} 
to the study of consumer default and its dynamics, their model does not have elastic labor supply, a feature difficult to implement and which is relevant in our paper. In addition, the configuration of the debt contract and the timing of defaults are also relevant for the outcome. Unlike Chatterjee et al. (2007) and other models with endogenous defaults (Arellano, 2008; Athreya et al., 2015), our model features a debt contract defined in terms of its face value in the current period and an interest rate to be paid at maturity along with the principal (for similar formulations see Calvo, 1988; Ábrahám and Cárceles-Poveda, 2010; Antunes and Cavalcanti, 2013). Depending on model assumptions, defaults can generate multiple equilibria- one with high interest rate and high probability of default, and the other with low interest rate and low probability of default — which would be a considerable complication of our framework. A final reason why our model does not feature equilibrium defaults is that one of the targets of this analysis is understanding how credit, specifically unsecured credit, reacts to certain fiscal policies and, in turn, to the induced shift of the borrowing constraint. In order to generate a sufficiently large amount of credit one would probably need to rely on very large expense shocks with low probability, thus generating a large number of what in Chatterjee et al. (2007) are deemed "involuntary" defaults, or a very low individual discount factor.

\subsection{Government}

We will assume a fiscal sector similar to Uhlig (2010). We consider the gap to finance in each period as the following variable,

$$
D=G+\operatorname{Tr}+(1+r) B-\tau_{k} r \int_{a \geq 0} a d \theta-\tau_{w} w N
$$

where $B$ and $G$ are current government debt and purchases of goods and services, respectively. We assume that $D$ is to be financed through lump-sum taxes, $\Gamma$, and newly issued debt. It follows that:

$$
D=\Gamma+B^{\prime}
$$

There is a fiscal rule whereby lump-sum taxes are imposed based on the difference between the steady-state level of the gap to finance, $\bar{D}$, and its current level, $D$, so that when this difference is zero lump-sum taxes remain at their steady-state level, $\bar{\Gamma}$. Formally,

$$
\Gamma-\bar{\Gamma}=\phi(D-\bar{D})
$$

If $\phi$ is one, then all the gap is financed through lump-sum taxes. If $\phi$ is close to zero but large enough so as to ensure stability of the debt level, then the gap is largely financed through issuing debt, with taxation being postponed into the future. The second case is of great interest to us; our simulations will therefore be conditioned on very low levels of $\phi .^{8}$

\footnotetext{
${ }^{8}$ We use only lump-sum taxation in the fiscal rule so as to avoid changes in the tax rates interacting with the channel under scrutiny. However, in a robustness exercise we show that financing the debt expansion with labor taxes hardly changes our quantitative results (see robustness exercises mentioned in Section 4.2).
} 


\subsection{Equilibrium}

The steady-state equilibrium in this economy is standard. Given a transition matrix $\Pi$ for idiosyncratic productivity, a set of government policies $\left(\tau_{k}, \tau_{w}, \operatorname{Tr}, G\right)$, a fiscal rule summarized by $\phi$, and assuming that any deviation to default is not coordinated among households, we define a recursive competitive equilibrium as a belief system $H$, a pair of prices $(r, w)$, a measure defined over the set of possible states $\theta$, values for government debt, lump-sum tax and gap to finance $(B, \Gamma, D)$, a pair of value functions $v(x, \theta)$ and $\underline{v}(z, \theta)$, and individual policy functions $\left(a^{\prime}, c, n\right)=(a(x, \theta), c(x, \theta), n(x, \theta))$, such that:

1. Each agent solves the optimization problem (1);

2. Firms maximize profits according to (6) and (7);

3. The government balances its budget according to (8) and (9);

4. All markets clear:

$$
\begin{aligned}
K^{\prime}+B^{\prime} & =\int a(x, \theta) d \theta \\
N & =\int n(x, \theta) z d \theta \\
\int c(x, \theta) d \theta+K^{\prime}+G & =(1-\delta) K+A K^{\alpha} N^{1-\alpha} ;
\end{aligned}
$$

5. The belief system $H$ is consistent with the aggregate law of motion implied by the individual policy functions;

6. The measure $\theta$ is constant over time.

The definition of an equilibrium with a transition follows naturally from the previous one although at the cost of a heavier notation, so we economize on space and omit it. Briefly, as will be stressed in Section 4 our transition is triggered by the unexpected introduction of a perfectly credible and deterministic change in the trajectory of either government transfers or purchases, along with a fiscal rule. We assume that in the transition agents can perfectly foresee the evolution of aggregate variables, including the borrowing limits, thus making sure that off-equilibrium paths are not observed. Aggregate uncertainty is therefore not considered in this analysis.

\section{Steady-state calibration}

In this section, we discuss the steady-state calibration of the model. ${ }^{9}$ We calibrate the model at quarterly frequency and present the relevant calibration targets in Table 1.

The idiosyncratic productivity is modeled in most of the literature by a persistent $\operatorname{AR}(1)$ process, as in Krueger and Perri (2005), sometimes coupled with a white noise component, as

\footnotetext{
${ }^{9}$ Full details about the computational procedure are given in Section B of the appendix.
} 
in Storesletten et al. (2004). In these papers labor supply is exogenous. Hence, we borrow the time-varying component of labor productivity from Floden and Lindé (2001), who use endogenous labor supply,

$$
\log \left(z_{t}\right)=\rho \log \left(z_{t-1}\right)+\eta_{t},
$$

where $\rho$ defines the persistence of the process and $\eta_{t}$ is a serially uncorrelated and normally distributed perturbation with variance $\sigma_{\eta}^{2}$. The parameters $\rho$ and $\sigma_{\eta}^{2}$ are set so as to match the yearly autocorrelation and variance of the labor productivity process, which are 0.9136 and 0.0426, respectively (as estimated by Floden and Lindé, 2001). In order to discretize the productivity process, we use the Rouwenhorst method (Kopecky and Suen, 2010) with 7 levels of productivity.

The implied transition probability matrix, $\Pi$, is characterized by non-zero entries everywhere. This implies that, whatever the productivity of the household in a given period, it can have the lowest productivity in the next period (possibly with a very small probability). Therefore, the only borrowing limit such that all households will want to pay back their debt irrespective of the productivity shock that hits them is the tightest among the limits defined in (5); this implies that the borrowing limit is parameterized in the lowest productivity level, $z_{1} \in \mathcal{Z}$. We define this borrowing limit to be $\underline{a}\left(\theta^{\prime}\right)=\underline{\hat{a}}_{z_{1}}\left(\theta^{\prime}\right)$. In case some elements of matrix $\Pi$ are zero it is possible that the borrowing limit is not unique but, even in that case, the limit associated with the lowest productivity level will still be very relevant. The intuition is the following. An agent with the lowest productivity dissaves and eventually becomes credit constrained at $\underline{\hat{a}}_{z_{1}}\left(\theta^{\prime}\right)$. When the agent experiences a positive productivity shock its motive to dissave typically becomes weaker or is even reversed; at the same time, a new fall to the lowest productivity level would force it to deleverage again, something the agent dislikes. This means that the borrowing limit associated to low productivity levels that imply dissaving in the vicinity of $\underline{\hat{a}}_{z_{1}}\left(\theta^{\prime}\right)$ cannot be too far from that level. ${ }^{10}$

Figure 2 shows a graphical representation of constraint $\underline{a}\left(\theta^{\prime}\right)$ together with a set of value functions. Specifically, the figure depicts pairs of value functions associated with the three lowest levels of $z$, as formalized in (4), as a function of assets. According to equation (3), the autarky value functions are flat, whereas the equilibrium value functions have a positive slope. The borrowing constraint is found at the intersection between the equilibrium and the autarky value functions parameterized by the lowest level of productivity, $z_{1}$; this is represented by the vertical line in the figure. The reaction of these value functions to the fiscal policies will determine the new position of the borrowing constraint.

Quantitatively, the resulting borrowing limit is such that a household average income can borrow up to roughly $50 \%$ of its yearly total income. ${ }^{11}$ The steady-state value of the borrowing limit is obtained indirectly by matching the actual credit-to-output ratio. Since in our model

\footnotetext{
${ }^{10}$ Rounding the elements of $\Pi$ to the third decimal place and normalizing the remaining values so that about half of the entries are zero produces essentially the same wealth distribution because the strictest borrowing limit - as in our baseline - will still be the only relevant one.

${ }^{11}$ If we wanted to express the borrowing limit in percentage of the quarterly income, the number would become roughly $200 \%$, which is the value reported in the x-axis of Figure 2.
} 
there is only unsecured credit, we calibrate the credit in the model using data for total revolving credit. ${ }^{12}$ As in Antunes and Cavalcanti (2013), we target a credit-to-output ratio of 7.7\%, which is the average pre-crisis period, fixing $\gamma$ at 0.9516 .

Recall that our model does not feature post-default saving. It can be shown that introducing the possibility of saving after default would hardly change the position of the borrowing limit, and consequently our results, because the agents with low income that determine the limit would not save after default anyway; simulations with these results are available upon request.

Table 2 compares some of the model-generated targets with their actual values for the U.S. economy. Given the calibrated level for credit, our economy is characterized by roughly $8 \%$ of agents at the borrowing constraint - which we label "constrained agents" — and a total of roughly $21 \%$ of borrowers; these values are close to their actual counterparties (Jappelli, 1990; Ábrahám and Cárceles-Poveda, 2010; Kaplan et al., 2014). ${ }^{13}$ Unconstrained agents represent about $92 \%$ of the population: $79 \%$ of the population hold a non-negative level of assets, while $13 \%$ of the population hold negative assets, that is, are borrowers. The table also reports the model wealth distribution. The model does a reasonable job in mimicking the profile of the U.S. wealth distribution but is far from delivering a perfect match. As already noted in several papers (Quadrini and Ríos-Rull, 1997; Floden and Lindé, 2001; Castañeda et al., 2003), models with plausible parameterizations of income processes and risk aversion have problems generating asset and income distributions which are as skewed as in U.S. data.

Using the standard natural borrowing limit instead of our participation constraint would yield values for the credit-to-output ratio and the percentage of households at the constraint considerably far from their actual values. The first measure would be around $30 \%$ and the percentage of constrained households would be virtually nil. This is due to the way the natural limit is implemented; it is computed so that households would consume zero at the constraint, conditional on a long string of realizations of the worst productivity shock.

Figure 2 provides an interesting insight about the type of household that would be more tempted to default, which is in fact in line with the empirical evidence. It can be seen that, as the household's productivity increases, both the equilibrium and autarky value functions move up; however, the equilibrium value function moves up by more than the autarky value function. Hence, the temptation to declare default, that is, to choose autarky relative to honoring debt commitments, decreases with the household's productivity, for any level of asset holdings. This is due to the incompleteness of the financial market: ceteris paribus, a high income household would loose more by defaulting than a low income household, since the opportunity cost of a permanent preclusion from self-insurance is higher for the former.

\footnotetext{
${ }^{12}$ Credit in the model is the aggregated amount of negative net wealth.

${ }^{13}$ Constrained agents are a subset of borrowers. As explained in Section B of the appendix, we use a grid for the asset holdings in our computations. We define agents to be constrained if they seat in the grid points within a eye-ball around the borrowing limit with a radius of $5 \%$ of its absolute value. This typically corresponds to households seating in the two grid points nearest to the borrowing limit. Kaplan et al. (2014) estimate that in the U.S. the share of the poor hand-to-mouth consumers is about $10 \%$ of the population during the 2000s. Although these poor hand-to-mouth agents are not directly comparable with our constrained agents, they share relevant characteristics: both types of agents neither possess collateralized wealth nor can they smooth consumption optimally.
} 
Table 1: Steady-state calibration.

\begin{tabular}{ccl}
\hline \hline Parameter & Value & Observation/Target \\
\hline$A$ & 1 & Normalization \\
$\alpha$ & 0.36 & Share of capital in production \\
$\delta$ & 0.025 & Capital-to-output ratio of 2.6 (yearly) \\
$\sigma$ & 2 & Standard in the literature \\
$\psi$ & 0.67 & Frisch elasticity of 1.5 \\
$\beta$ & 0.9901 & Real interest rate of 1\% \\
$\rho$ & 0.977 & Floden and Lindé (2001) \\
$\sigma_{\eta}$ & 0.11 & Floden and Lindé (2001) \\
$\chi$ & 0.4 & Average labor supply normalized to 1 \\
$\tau_{w}$ & 0.27 & Domeij and Heathcote (2004) \\
$\tau_{k}$ & 0.4 & Domeij and Heathcote (2004) \\
$\gamma$ & 0.9516 & Credit-to-output ratio is 7.7\% (yearly) \\
$G / Y$ & 0.2008 & Public debt-to-output ratio is 60\% (yearly) \\
\hline \hline
\end{tabular}

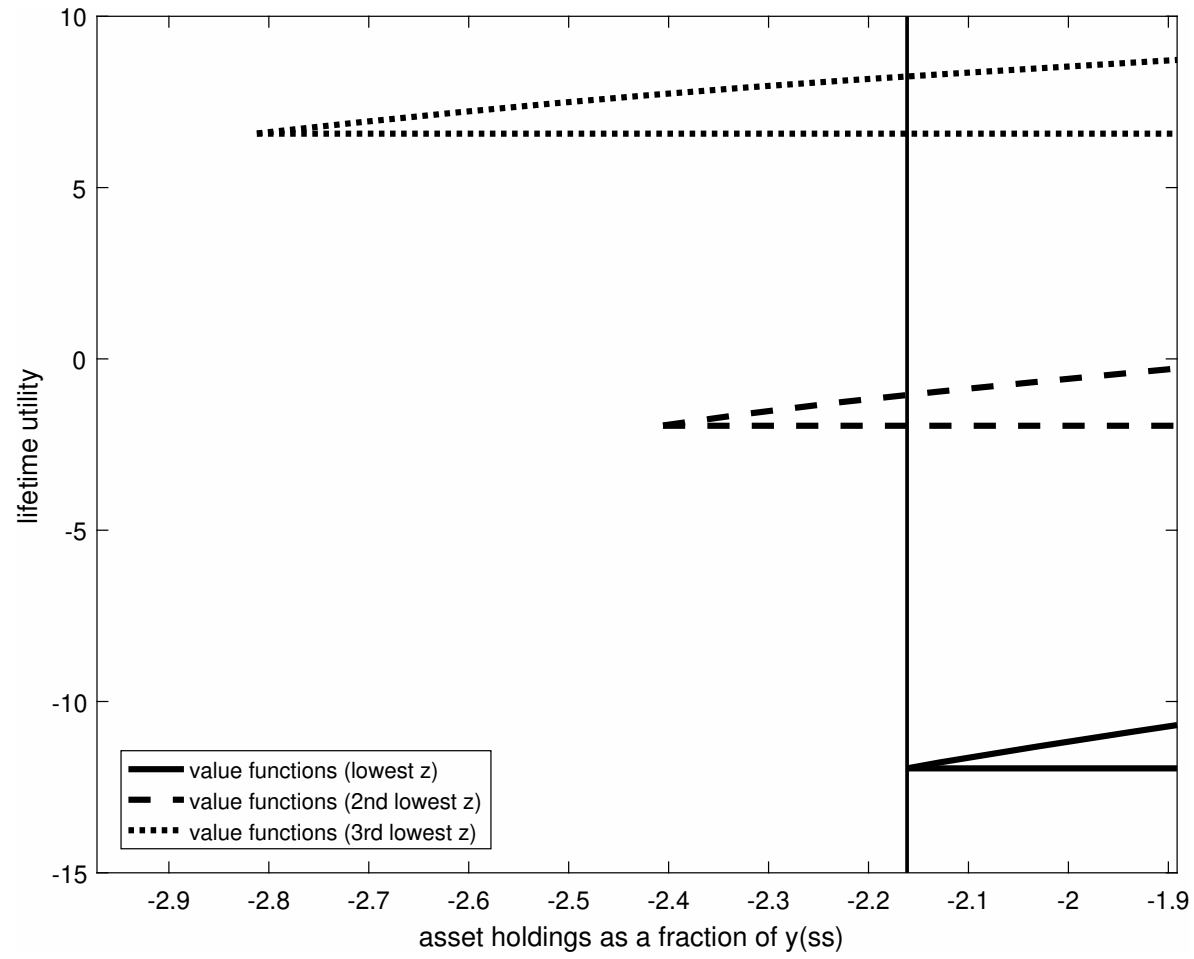

Figure 2: Selected pairs of value functions and the borrowing limit in the steady state. The flat lines correspond to the value functions in autarky, $\underline{v}(z, \theta)$, for different levels of productivity. The lines with positive slope refer to the equilibrium value functions, $v(x, \theta)$, for different levels of productivity. The relevant borrowing limit, $\underline{a}(\theta)$, is identified by the vertical line. $\mathrm{y}(\mathrm{ss})$ stands for steady-state output. 
Table 2: Distribution of wealth in the U.S. economy vis-à-vis the model. All values in percentage. Total credit is relative to output; the number of borrowers and hand-to-mouth households is relative to total population. Data are from Castañeda et al. (2003) for wealth quintiles and the Gini index, Ábrahám and Cárceles-Poveda (2010) for the number of borrowers, and Kaplan et al. (2014) for the number of poor hand-to-mouth households.

\begin{tabular}{|c|c|c|c|c|c|c|c|}
\hline & \multicolumn{3}{|c|}{ Borrowers } & \multicolumn{4}{|c|}{ Wealth distribution } \\
\hline & Total credit & Borrowers & $\begin{array}{l}\text { Hand-to- } \\
\text { mouth }\end{array}$ & Gini & Bottom $60 \%$ & Top $40 \%$ & Top $20 \%$ \\
\hline Data & 7.7 & 24 & $8-13$ & 78 & 6.7 & 93.3 & 79.5 \\
\hline Model & 7.7 & 21 & 8 & 63 & 12.2 & 87.8 & 61.0 \\
\hline
\end{tabular}

We target a steady-state public debt-to-output ratio of $60 \%$ in yearly terms by setting the government consumption-to-output ratio $G / Y$ to $20 \%$ and transfers $\operatorname{Tr}$ and $\Gamma$ to zero, given the tax rates. This value for public debt was roughly the U.S. federal debt level before the Great Recession.

Section C of the appendix depicts the agents' policy functions for consumption and labor, for different productivity levels.

\section{Transition with public debt expansions}

We perform two sets of exercises. In the first, a public debt expansion is used to transfer resources to households in a lump-sum fashion. In the second, which is summarized in Section 4.4, the public debt expansion is used to increase government purchases. The policies are unexpected by the households.

Technically, we set the simulation horizon to 800 quarters. We then iterate on the path of prices, the set of time-dependent policy functions and the time-dependent wealth and productivity joint distributions, under the assumption of perfect foresight, until we have a fixed point in these objects. Section B in the appendix gives a detailed account of the computation of the transition.

Below we report and explain the effects of the debt expansions on the borrowing constraint and on other variables. We also describe the consequences of the constraint's movement on the households' reaction. Finally, we show the implications on welfare of considering the borrowing limit as an endogenous variable.

\subsection{The dynamics of the borrowing limit, prices and aggregates}

This section highlights the credit tightening process generated by the transfers policy and how aggregates are affected. It also offers a decomposition exercise which helps us disentangle the effects generated by the shift of the borrowing limit from those generated by the price effects 
induced by the shift.

The transfers policy We simulate a debt expansion that finances an increase in transfers, denoted $\mathrm{Tr}$, that is uniform across agents. On impact, which we define to occur at $t=1$, transfers increase by $1 \%$ of steady-state output and then decay following an $\mathrm{AR}(1)$ with persistence 0.95, as estimated by Leeper et al. (2010). In order to postpone lump-sum taxation, denoted $\Gamma$, far into the future, we set the parameter $\phi$ in the fiscal rule (10) at a low level, 0.02, which is still large enough so as to ensure stability of the debt level. As a result, the Government debt-to-output ratio increases by a maximum of 12 percentage points around the $30^{\text {th }}$ quarter (3 percentage points in yearly terms) and then slowly comes back to its original steady-state level at $240 \%$, or $60 \%$ in yearly terms. The evolution of the fiscal variables is depicted in the two top panels of Figure 3.
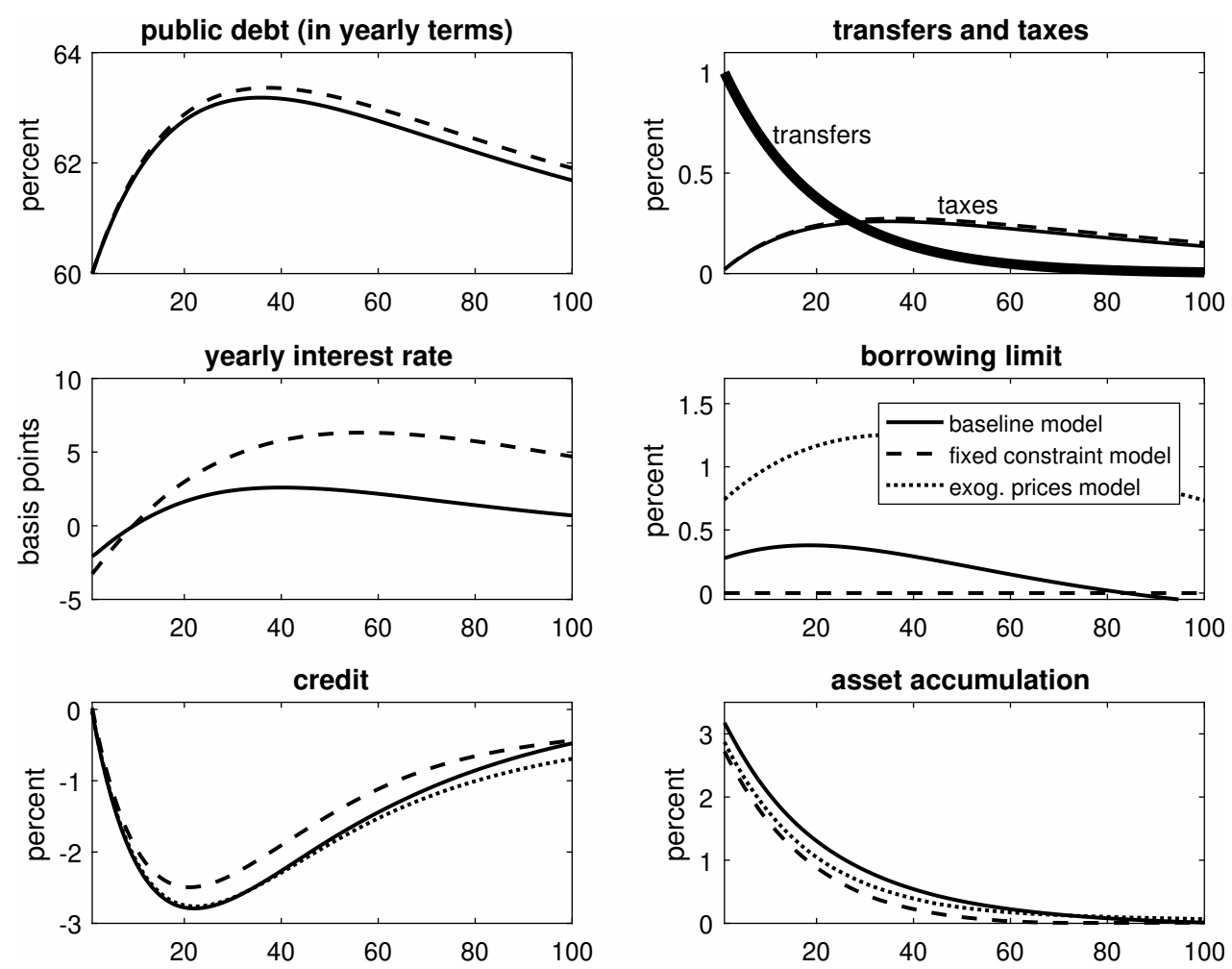

Figure 3: Selected reactions to the transfers policy. All variables are expressed in deviation from steady-state levels. The deviations for public debt, transfers, taxes and the borrowing limit are normalized by steady-state output. Positive deviations for the borrowing limit mean a tightening. Asset accumulation is the difference between the asset level in $t+1$ and the steady-state level, normalized by steady-state investment. The $\mathrm{x}$-axes are in quarters.

The credit tightening process Figures 3 and 4 present selected reactions to the abovedescribed transfers policy. In particular, solid lines are generated with what is called the "baseline model", where the borrowing limit is allowed to change endogenously and all markets clear at each moment. Dashed lines, instead, are drawn conditional on keeping the borrowing limit fixed throughout the transition, implying that the relevant borrowing constraint becomes $a^{\prime} \geq \underline{a}$, where $\underline{a}$ is the endogenously determined borrowing limit using the baseline model in the 
steady state. The latter specification is labeled the "fixed constraint model". The gap between the solid and the dashed lines represents the part of the reactions attributable to the dynamics of the borrowing limit.

Over time, issuing public debt positively impacts the interest rate. ${ }^{14}$ All else equal, this makes the option of staying in the market relatively worse than going to autarky, giving the borrowers a higher incentive to declare bankruptcy. Knowing that, lenders are willing to lend less, which endogenously tightens the household borrowing constraint, that is, reduces the maximum amount that can be borrowed. ${ }^{15}$ The tightening is persistent over time: ten years after the beginning of the debt expansion, the borrowing limit is still not back to its steady state. Quantitatively, the borrowing limit tightens by an average of $0.4 \%$ of steady-state quarterly output during the first five years of the debt expansion. Importantly, the dynamics of the interest rate is crucial for generating the tightening, which would not be possible in a partial equilibrium framework; see Section D.2 in the appendix.
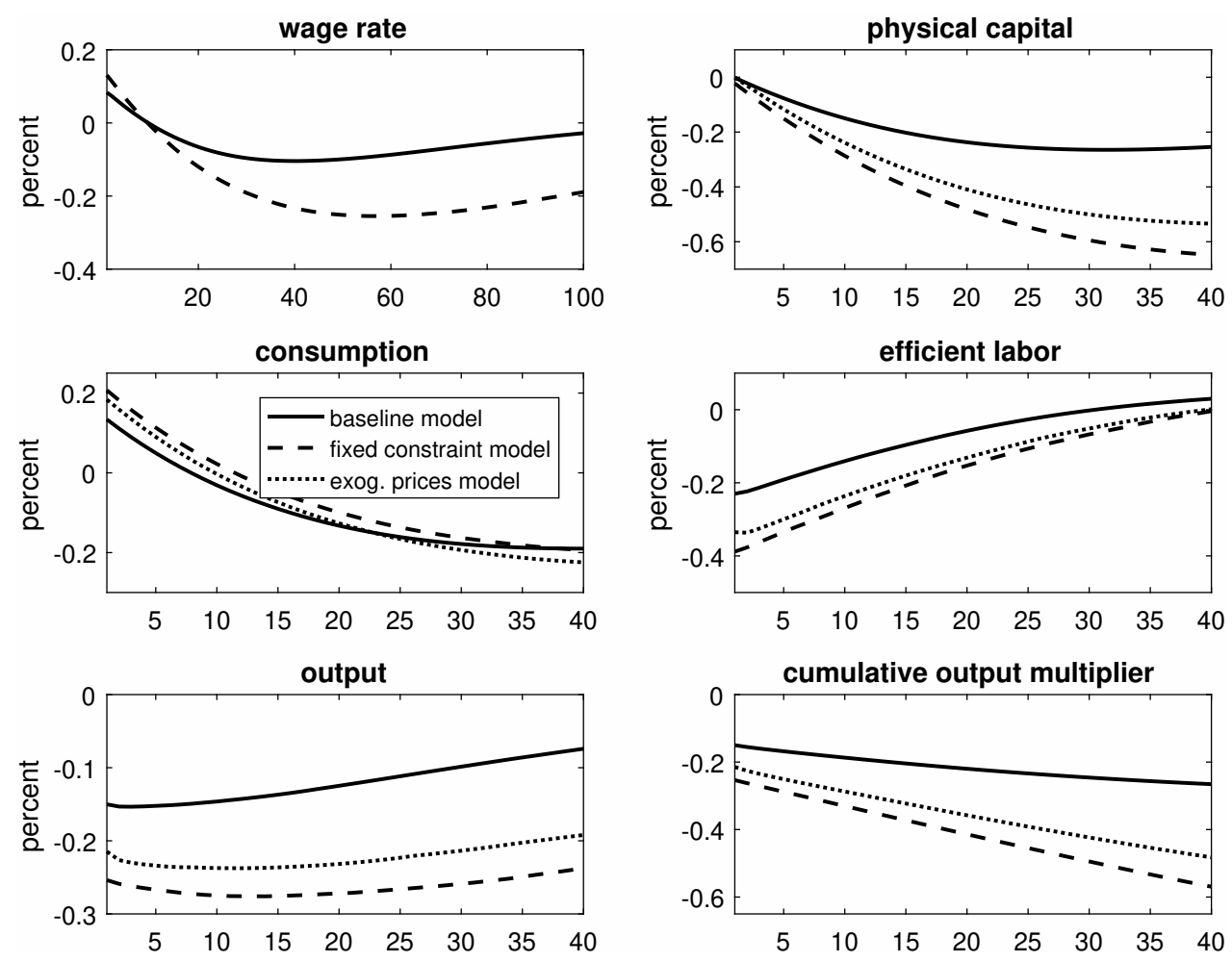

Figure 4: Aggregate effects of the transfers policy. All variables are expressed in deviation from steadystate levels. The cumulative output multiplier is calculated following Uhlig (2010); see footnote 17. The $\mathrm{x}$-axes are in quarters.

The tightening forces constrained agents to deleverage. At the same time, unconstrained

\footnotetext{
${ }^{14}$ One relevant observation here is that the interest rate decreases on impact, but after roughly two years it is already higher than its steady-state level, and reaches its peak in ten years. After that, it slowly comes back to the steady-state level. The initial fall in the interest rate is explained by the fall on impact of labor; details are given below. Another observation is that the elasticity of the interest rate to public debt obtained in our case is of the same order of magnitude of the elasticity obtained in Aiyagari and McGrattan (1998), despite the circumstance that they perform a steady-state analysis.

${ }^{15}$ Notice that the movement of the equilibrium and autarky value functions - which generates the tightening is carefully shown and explained in Section D.1 of the appendix. This section also shows the dynamics of the policy functions at the moment of the implementation of the fiscal policy.
} 
agents realize that, all else equal, their asset position will be closer to the borrowing limit; hence, their precautionary saving motive is reinforced. The unconstrained savers will save more, while the unconstrained borrowers will cut on their debt. The detailed reactions of both constrained and unconstrained households are reported in Section 4.2. As a result, the fall (increase) in credit (assets) is larger in the baseline model than in the fixed constraint model.

The transfers policy fosters agents' consumption and depresses labor; however, the tightening makes households consume (work) less (more) through deleveraging and precautionary saving motives. ${ }^{16}$ As for physical capital, the higher interest rate crowds it out; capital is crowded out less in the baseline model than in the fixed constraint model due to a lower interest rate in the former economy. Because of both the labor and the capital dynamics, output falls less in the baseline model. Specifically, the fixed constraint model generates a cumulative multiplier around -0.45 vis-à-vis -0.25 in the baseline economy, over a five-year horizon. ${ }^{17}$

In the presence of equilibrium defaults modeled after Chatterjee et al. (2007), one would argue that the effects on credit and consumption of this public debt expansion would not be qualitatively different from ours, as the increase in the interest rate would imply a larger discount in debt contracts, thus tightening the borrowing limit ceteris paribus. A share of households would prefer defaulting and consuming relatively more rather than paying back the principal. This effect should mitigate the fall in consumption. Like in our framework credit should fall because of both the increase in the borrowing costs and the tightening of the borrowing limit. Additionally, households finding it optimal to default as a consequence of the fiscal policy shock would contribute to the fall in total credit because they would not have access to borrowing for at least some of the following periods. Quantitatively it is hard to establish a meaningful mapping between a model with equilibrium defaults and the model in this paper in view of the very different calibrations, but the smaller amount of credit in Chatterjee et al. (2007) suggests that the effects would be smaller.

Decomposing the effects of the tightening As explained above, the gap between the dashed and the solid lines is generated by the dynamics of the tightening. Here we measure how much of this gap is due to the price effects generated by the shift of the limit, and due to the shift itself. In order to do that, we use counterfactuals, that is, we perform a new simulationdenoted the "exogenous prices model" and represented by the dotted lines in Figures 3 and 4 - which is the case where prices, public debt, taxes and transfers are kept at the values of the fixed constraint economy but the borrowing constraint, together with the individual policy functions, are allowed to vary. We hence compute off-equilibrium aggregates by directly

\footnotetext{
${ }^{16}$ Within otherwise standard incomplete-markets models, the sign of the labor reaction to a tightening can be negative. For example, Kehoe et al. (2016) show that such sign depends on the form of the household's utility function. Further, Huo and Ríos-Rull (2015) show that considering search frictions in some consumption markets suffices to generate a drop in employment as a result of tighter credit conditions.

${ }^{17}$ The output multiplier is a good indicator to evaluate the aggregate impact of a given policy because it relates the effects of the policy with the magnitude of the policy itself. Following Uhlig (2010), the output multiplier $t$ quarters after the policy implementation is calculated as $\sum_{k=0}^{t}\left(1+r_{s s}\right)^{-k} \hat{Y}_{k} / \sum_{k=0}^{t}\left(1+r_{s s}\right)^{-k} \hat{\operatorname{Tr}}_{k}$, where $\hat{Y}_{k}$ and $\hat{\operatorname{Tr}}_{k}$ represent the actual deviations of output and transfers from their steady states, respectively, with $r_{s s}$ being the steady-state real interest rate.
} 
aggregating the individual policy functions. ${ }^{18}$

The following simplified scheme helps visualize the step-by-step decomposition of the tightening during the transition:

(a) fixed constraint model: public debt $\uparrow \Rightarrow r \uparrow$;

(b) exogenous prices model: public debt $\uparrow \Rightarrow r \uparrow \Rightarrow$ borrowing limit tightens ;

(c) baseline model: public debt $\uparrow \Rightarrow r \uparrow \Rightarrow$ borrowing limit tightens $\Rightarrow r \downarrow$.

It follows that the gap between the households' reaction in (b) and (a) measures the part accounted for by the shift of the borrowing constraint alone. Further, the gap between the households' reaction in (c) and (b) measures the part generated by the price effects induced by the shift in the borrowing limit. Figure 4 shows that the price effects explain around two thirds of the aggregate reactions due to the tightening.

It is worth stressing the role of the interest rate for the dynamics of the borrowing limit. First, its rise, which is due to the public debt expansion, generates the tightening. Second, the tightening increases the households' desire to deleverage or increase asset holdings, which in turn exerts a downward pressure on the interest rate. This decrease in the rate then mitigates the initial tightening.

\subsection{Dynamics at the individual level and consequences for the ag- gregates}

In this section, we analyze the effects of the policy at a more disaggregated level by presenting the reactions of two groups of households, the constrained and the unconstrained. We show that unconstrained agents react non-trivially to the shift of the borrowing limit and this produces relevant aggregate effects.

Heterogeneous reactions Figure 5 shows the average reaction in assets, labor and consumption for both constrained (left column) and unconstrained households (right column). ${ }^{19}$

Let us focus on the reaction of the households under the fixed constraint model, which is represented by the dashed lines. Constrained households use the transfers received from the government to increase their consumption given that their marginal propensity to consume is the highest in the economy. Over time, they start decreasing consumption because of the higher future taxation. The dynamics of labor effort roughly mirrors that of consumption. Regarding

\footnotetext{
${ }^{18}$ This simulation is off-equilibrium in the sense that prices are not allowed to react to the shift of the borrowing constraint, but is different from the fixed prices simulation of Section D.2 where prices remain at their steady-state level.

${ }^{19}$ The reaction of labor in the first period of the transition for constrained households is calculated as $\int_{a \in \mathcal{V}(\underline{a})}\left(\frac{n_{1}(x, \theta)-n(x, \theta)}{n(x, \theta)}\right) d \theta$, where $n_{1}(x, \theta)$ is the labor policy function in the first period of the transition, $n(x, \theta)$ is the policy function in the steady state and $\mathcal{V}(\underline{a})$ is a tight neighborhood of $\underline{a}$ as defined in footnote 13. The reactions in the following periods are calculated in the same fashion. The computation is similar for the unconstrained with the appropriate change in the integration domain. Finally, the same logic is used to compute the heterogeneous responses for consumption and asset holdings.
} 

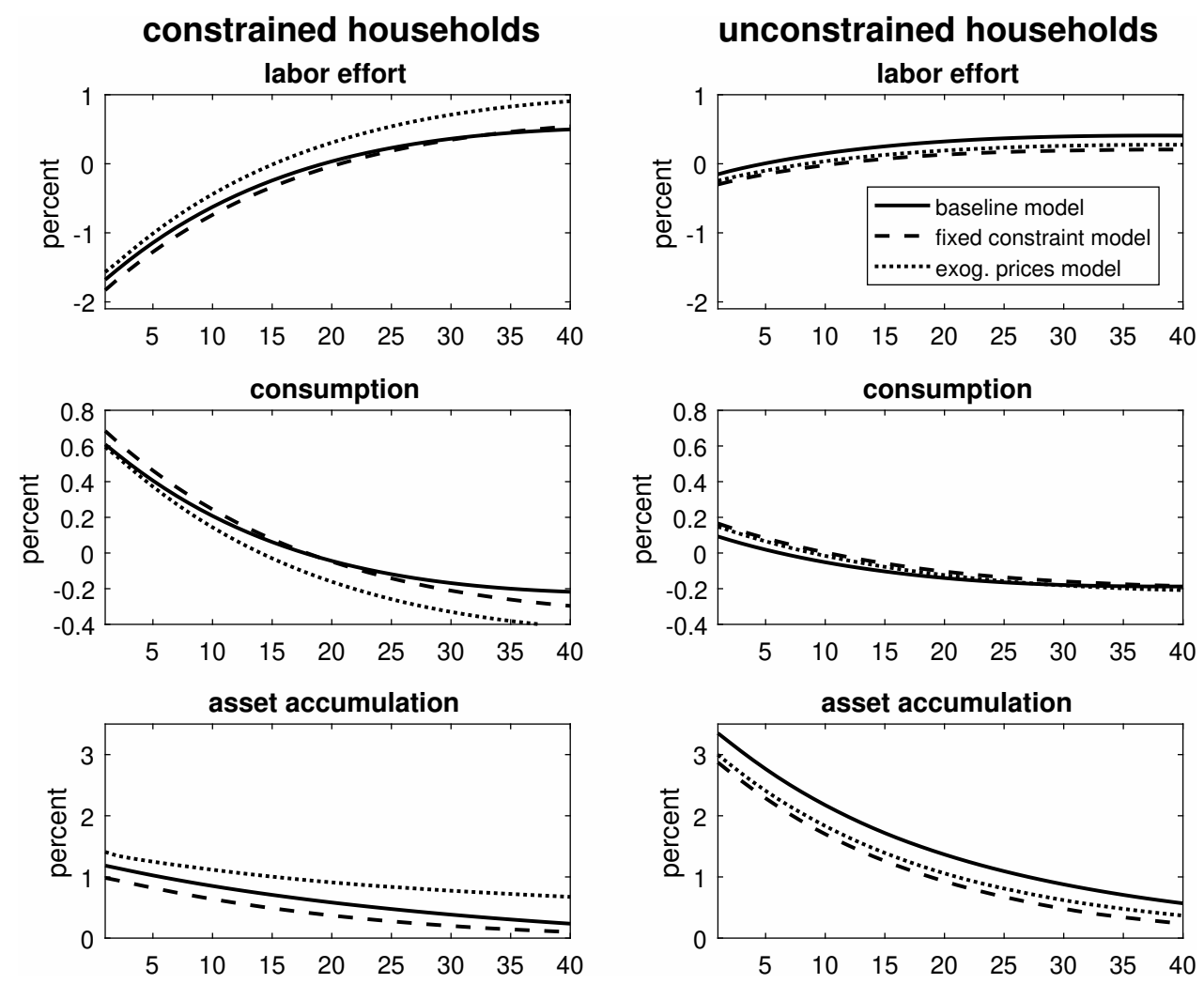

Figure 5: Heterogeneous effects of the transfers policy. The average reactions of constrained agents are on the left column. The average reactions of unconstrained agents are on the right column. All variables are expressed in deviation from steady-state levels. Asset accumulation is the difference between the asset level in $t+1$ and the steady-state level, normalized by steady-state investment. The $\mathrm{x}$-axes are in quarters. 
asset accumulation, households deleverage because they now rely more on the received transfers than on the (more expensive) borrowing for targeting the desired level of consumption.

In terms of consumption and labor, unconstrained households react to the transfers policy much less than the constrained. As a matter of fact, the unconstrained use a considerable part of the received transfers to buy assets (if they are lenders), or to decrease their indebtedness (if they are borrowers), in order to be able to pay the higher future taxes while keeping a smooth profile for consumption. The rise in saving occurs also because of the increase over time of the return on assets: as highlighted by Aiyagari and McGrattan (1998), this helps savers self-insure so that their asset position will be farther away from the borrowing constraint. ${ }^{20}$

What does the tightening of the borrowing constraint add to these reactions? Let us answer to this question in two steps. First, we analyze the consequences of the tightening depurated from its price effects by comparing the reactions of the exogenous prices model (dotted lines) with those of the fixed constraint model (dashed lines). As stated in Section 4.1, because of the shift in the borrowing limit constrained households must deleverage, which implies that their asset accumulation is stronger in the exogenous prices case than in the fixed constraint case. This extra deleveraging is obtained by cutting consumption and supplying more labor. Unconstrained agents behave similarly but with a much lower intensity: they do not have to adjust forcefully and mildly expand their asset holdings to hedge against the increased risk of becoming constrained in the future. Below we show that, even though the average reactions of the unconstrained are far smaller than those of the constrained, the behavior of the unconstrained is still crucial for determining the size of the effect of the borrowing limit shift on the aggregate reactions.

In the second step, we analyze the price effects generated by the tightening, which are illustrated by comparing the reactions of the baseline model (solid lines) with those of the exogenous prices model (dotted lines). It is worth noting that relatively lower (higher) interest (wage) rates exert substitution and income effects which can have contrasting impacts on the households' reactions. A particular effect seems to dominate in the case of constrained households: the lower interest rate dampens the tightening itself, so that this type of households needs to deleverage much less in the baseline model than in the exogenous prices model. In contrast, for unconstrained agents these price effects amplify the reactions obtained within the exogenous prices economy. In brief, the price effects dampen the reactions of constrained agents, while amplifying those of the unconstrained. ${ }^{21}$

The importance of the reaction of unconstrained households It is obvious that the price effects due to the shift of the borrowing limit influence the unconstrained agents' behavior. Less obvious is arguing that such behaviour is also affected by the shift itself. Table 3 reports the effects of the shift alone on the reactions to the fiscal policy of different groups of households: the constrained, the unconstrained, and the wealthiest 5\%. The table also reports the contribution

\footnotetext{
${ }^{20}$ Notice that the unconstrained borrowers will decrease their indebtedness also because of higher borrowing costs.

${ }^{21}$ This result holds even under the purchases policy; see Section E.2 in the appendix.
} 
of the reactions of each group to the aggregate reactions. ${ }^{22}$

As already stressed, constrained agents react the most to the movement in the borrowing limit. In particular, their average reactions in terms of labor and consumption are roughly five and ten times larger than those of the unconstrained and of the richest agents, respectively; in terms of asset accumulation, the corresponding proportions are about four and six times. However, the aggregate reactions are mostly determined by unconstrained households, which are responsible for roughly $70 \%$ of the aggregate reactions.

Table 3: Average reactions and contributions due to the shift of the borrowing constraint. The differences between the average reactions of the exogenous prices model and those of the fixed constraint model ("Diff.") for several groups of households are reported. The contributions of the reactions of each group of households to the aggregate reactions ("Contrib.") are also reported. All the figures represent an average over the first five years of the policy. All values are in percentage.

\begin{tabular}{lccccccccc}
\hline \hline & \multicolumn{2}{c}{ Constrained $(\approx 8 \%)$} & \multicolumn{2}{c}{ Unconstrained $(\approx 92 \%)$} & \multicolumn{2}{c}{ Wealthiest $5 \%$} & & \multicolumn{2}{c}{ Aggregate } \\
\cline { 2 - 4 } & Diff. & Contrib. & Diff. & Contrib. & Diff. & Contrib. & & Diff. & Contrib. \\
\hline Labor effort & 0.272 & 32 & 0.056 & 68 & 0.023 & 1.5 & & 0.075 & 100 \\
Consumption & -0.091 & 32 & -0.019 & 68 & -0.008 & 1.5 & & -0.025 & 100 \\
Asset accum. & 0.437 & 25 & 0.129 & 75 & 0.068 & 2.1 & & 0.157 & 100 \\
\hline \hline
\end{tabular}

The average reactions of the wealthiest households - a subset of unconstrained agents - are pretty small because they are very far from the borrowing limit. However, these reactions are not nil because, even for the richest households, the probability of becoming constrained in the future increases after the debt expansion, factoring out the price effects generated by the tightening.

Additional and robustness exercises In Section D.3 of the appendix we present a number of robustness and additional exercises targeted to the dynamics of the borrowing constraint. First, we perform our simulations within a model that uses an alternative borrowing limit, namely an endogenous ad hoc limit. Second, we simulate the economy using different steadystate levels of public debt. Third, we simulate an economy in which labor taxes adjust in order to finance the debt expansion, instead of lump-sum taxes. Fourth, we produce a version of the model with countercyclical markups that mimics the presence of price stickiness. Finally, we mention results related to changing the parameter of the fiscal rule, $\phi$. All these exercises deliver results which are similar to those obtained using our baseline specification.

In Section D.4 of the appendix we present the type of robustness exercises just mentioned but targeted to the magnitude of the aggregate effects generated by the tightening. They deliver results which are similar to those obtained using our baseline specification.

\footnotetext{
${ }^{22}$ The contribution of labor of constrained agents is the average reaction of these households multiplied by their respective population weight, for any quarter. These measures are then averaged out over a five-year horizon. The same logic applies to the other groups of households. The calculations for both consumption and asset accumulation are performed in the same fashion. Notice that summing up the contributions of unconstrained and constrained households, for a certain model variable, yields a total of 100 percent.
} 


\subsection{Welfare implications}

This section studies the effects of the debt-financed transfers policy on the households' welfare. In particular, we focus on how the welfare analysis changes whether or not we consider the endogenous borrowing constraint in the model. Figure 6 presents the welfare gains along the household wealth distribution for the baseline (solid line), the fixed constraint (dashed line) and the exogenous prices (dotted line) models. $^{23}$

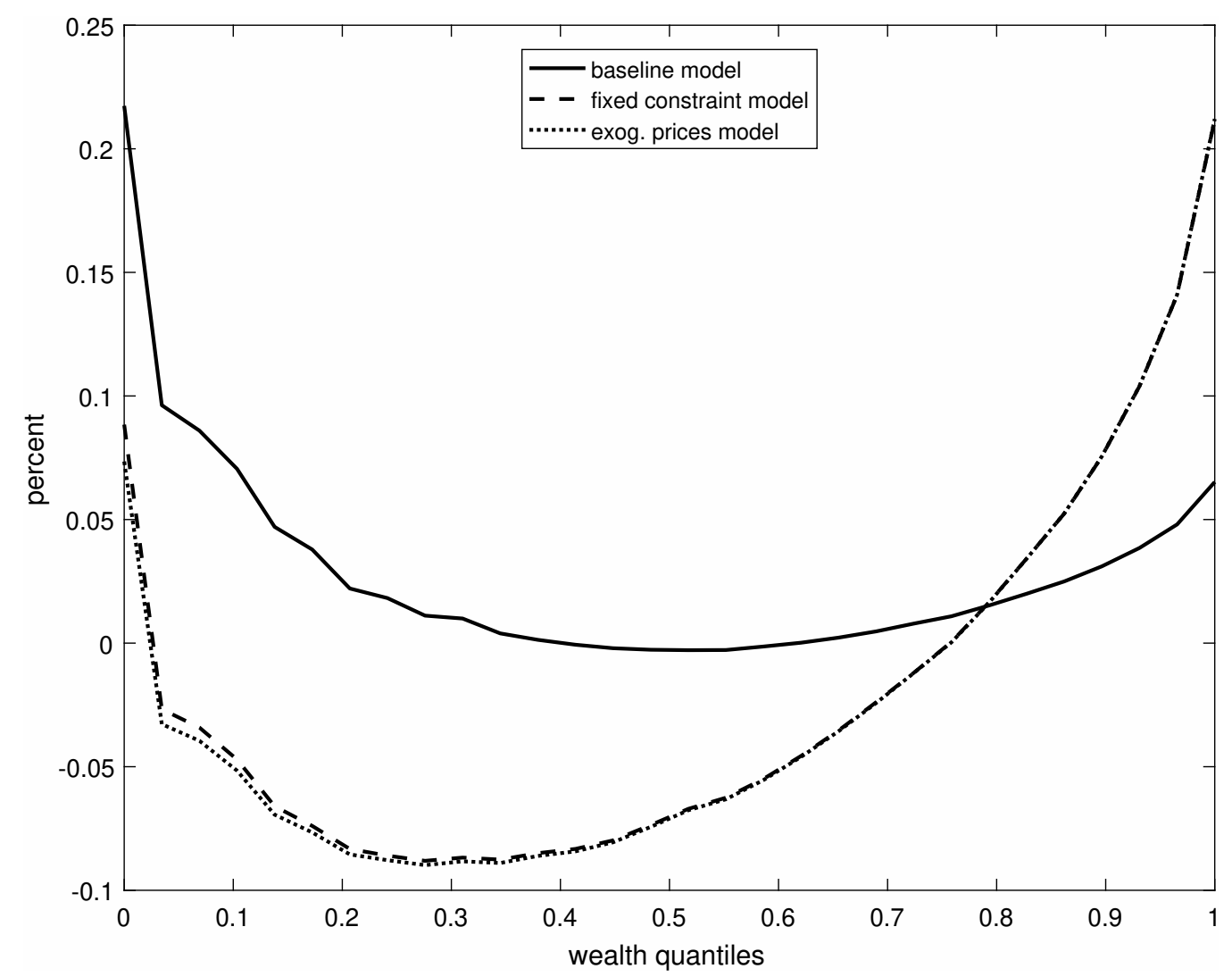

Figure 6: Welfare effects of the transfers policy by wealth quantiles. Positive values represent a welfare gain measured as the consumption-equivalent change relative to the initial steady state. See the definition in footnote 23.

Let us focus on the welfare effects of the policy in the fixed constraint economy. The policy produces positive effects for the households in the bottom $5 \%$ of the wealth distribution, a group composed of constrained households. These agents use the transfer to consume more and rely less on borrowing, which is costlier after the policy implementation. Other forces, like a higher future taxation, are not enough to nullify the welfare increase. The rest of the borrowers, together with the households up to roughly the fourth quintile of the distribution, suffer a welfare loss. This loss can be due to higher borrowing costs, lower wages and higher future taxation. For households in the top quintile of the distribution, the policy generates a

\footnotetext{
${ }^{23}$ To assess the welfare gain of a policy relative to a certain status quo we proceed as follows. For each point $(a, z)$ of the state grid, we compute the consumption-equivalent variation as the constant percentage change in consumption along the transition path such that, at the moment of the implementation of the policy, the agent is indifferent between staying in the status quo or switching to the economy under the policy. The welfare gain for a specific set of agents - such as for example agents with the same level of wealth, or agents within a given wealth range, or all agents - is computed by averaging out the consumption-equivalent variation over that set, using the measure of agents as weights.
} 
welfare gain. A plausible cause is the increase in the remuneration of the asset holdings, which represent their main source of income. Table 4 reports the political support and the average welfare gain associated with the policy. ${ }^{24}$ The majority of the households does not support the implementation of the transfer policy: only around $30 \%$ of the population is in favor.

Table 4: Political support to, and average welfare gain of, the transfers policy relative to the status $q u o$ (no policy implementation). Political support is the fraction of agents for whom the welfare gain of the policy change is positive. The average welfare gain is the average across all states of the state specific welfare gain, using the measure of agents as weight. All values are in percentage.

\begin{tabular}{lccccc}
\hline \hline & Political support & & \multicolumn{3}{c}{ Avg. welfare gain } \\
\cline { 2 - 2 } \cline { 5 - 6 } \cline { 5 - 6 } & & & Constrained & Unconstrained & Total \\
\hline Fixed constraint model & 30 & & 0.01 & -0.022 & -0.02 \\
Baseline model & 80 & & 0.13 & 0.02 & 0.03 \\
\hline \hline
\end{tabular}

How does considering the dynamics of the borrowing constraint influence the welfare results? The welfare associated with the baseline model is higher relative to the fixed constraint model for all households up to roughly the fourth quintile. For richer households, the opposite holds. The tightening can produce different effects on welfare. In principle, the shift of the borrowing limit forces constrained households to borrow less and, at the same time, limits the maximum quantity of borrowing for anyone else. This fact should produce welfare losses for all the households and, in particular, for the constrained. Looking at Figure 6, such shift does not seem to produce significant effects. Indeed, the dotted line is slightly below the dashed line only for the constrained. Again, the price effects generated by the tightening play the most prominent role. In particular, relatively higher (lower) wage (interest) rates represent a welfare gain for the borrowers (who can borrow cheaper) and the middle-class households (who mostly rely on their labor income) and a welfare cost for the rich (who mostly rely on their asset income). As a result, the majority of households (almost 80\%) would vote in favor of the implementation of the policy in the baseline economy; this can be seen in Table 4. In brief, under this specific transfers policy allowing for an endogenous borrowing constraint significantly alters the welfare results.

At first glance, our results on the effect of the tightening on welfare seem surprising. In fact, they concur with other findings in the literature. For example, Dávila et al. (2012) show that the competitive equilibrium of a heterogenous agent model with incomplete financial markets is constrained inefficient due to the presence of a pecuniary externality. That is, agents do not take into account that their own actions influence prices. Hence, a social planner can improve the households' welfare by choosing a policy function for each agent taking price effects into account. They show that, for the standard Aiyagari (1994) model, the planner wants agents to save more - with respect to what they do in the original decentralized economy - in order to increase (decrease) the wage (interest) rate. Wealth-rich agents suffer a welfare loss but the wealth-poor agents are better off. Since the effects are positive for agents with higher

\footnotetext{
${ }^{24}$ Political support is the fraction of agents for whom the welfare gain of the policy is positive. The average welfare gain is computed as explained in footnote 23 .
} 
marginal utility of consumption, social welfare increases. Farinha Luz and Werquin (2011) obtain a similar result performing a different analysis. They show that the Huggett (1993) economy, which does not consider capital accumulation, can be constrained inefficient as well. Hence, imposing a stricter borrowing limit can be welfare improving because it forces wealthpoor agents to save or deleverage more, depressing the interest rate. Finally, Obiols-Homs (2011) shows, using both an exchange economy and a Bewley-Huggett-Aiyagari-type model, that a loosening of the borrowing constraint can decrease the welfare of a sizeable fraction of wealth-poor households because of higher (lower) interest (wage) rates.

The relation between the households' welfare and the sign of the output multiplier is worth noting. Under the baseline model, the transfers policy delivers negative output multipliers with a majority of households supporting it. This suggests that fiscal multipliers and households' welfare changes are not necessarily positively correlated as discussed in Kolosova (2013) using a heterogenous agents model with ad hoc borrowing limits, and Bilbiie et al. (2014) using a standard New Keynesian representative agent model.

\subsection{The government spending stimulus}

We simulate a debt expansion that finances an increase in purchases, $G$, similar to that of the ARRA. We borrow the process for government spending from Uhlig (2010). On impact, the stimulus amounts to around $0.3 \%$ of output, reaching its maximum (around $0.8 \%$ of output) after 6-7 quarters. ${ }^{25}$ As in the transfers policy, we set the parameter $\phi$ in the fiscal rule (10) to 0.02 . The two top panels in Figure 7 show the evolution of the fiscal variables.

The purchases policy is fundamentally different from the transfers policy. The former, as shown in Figures 7 and 8, creates the so-called negative wealth effect in the economy, which, on average, induces agents to work more and consume less. However, the effects of the policy on the borrowing constraint are similar to those obtained with the transfers policy. That is, issuing public debt positively impacts the interest rate. All else equal, this creates a tightening of the borrowing constraint because the option of staying in the market becomes worse relative to going to autarky. The tightening is persistent over time and stimulates demand for assets that generates a downward pressure on the interest rate. Indeed, the interest rate is on average lower in the baseline model than in the fixed constraint model.

Quantitatively, the tightening of the borrowing limit in both the exogenous prices and the baseline models is larger than under the transfers policy. In particular, in the baseline model the borrowing limit tightens by more than $1 \%$ of steady-state output during the first years. This is due to the fact that the increase in the interest rate is higher under the purchases policy and the reaction of the value functions is structurally different from that of the transfers policy; see Section E.1 of the appendix.

Regarding the output effects, the baseline model delivers an impact output multiplier around

\footnotetext{
${ }^{25}$ Notice that the process in Uhlig (2010) is characterized by a zero increase of $G$ on impact, and a $0.3 \%$ output increase in the second period. We start in the second period of that process in order to avoid unbounded multipliers on impact. The $G$ path follows an $\operatorname{AR}(2)$ process, with the coefficients on the first and the second autoregressive terms being equal to 1.653 and -0.672 , respectively.
} 

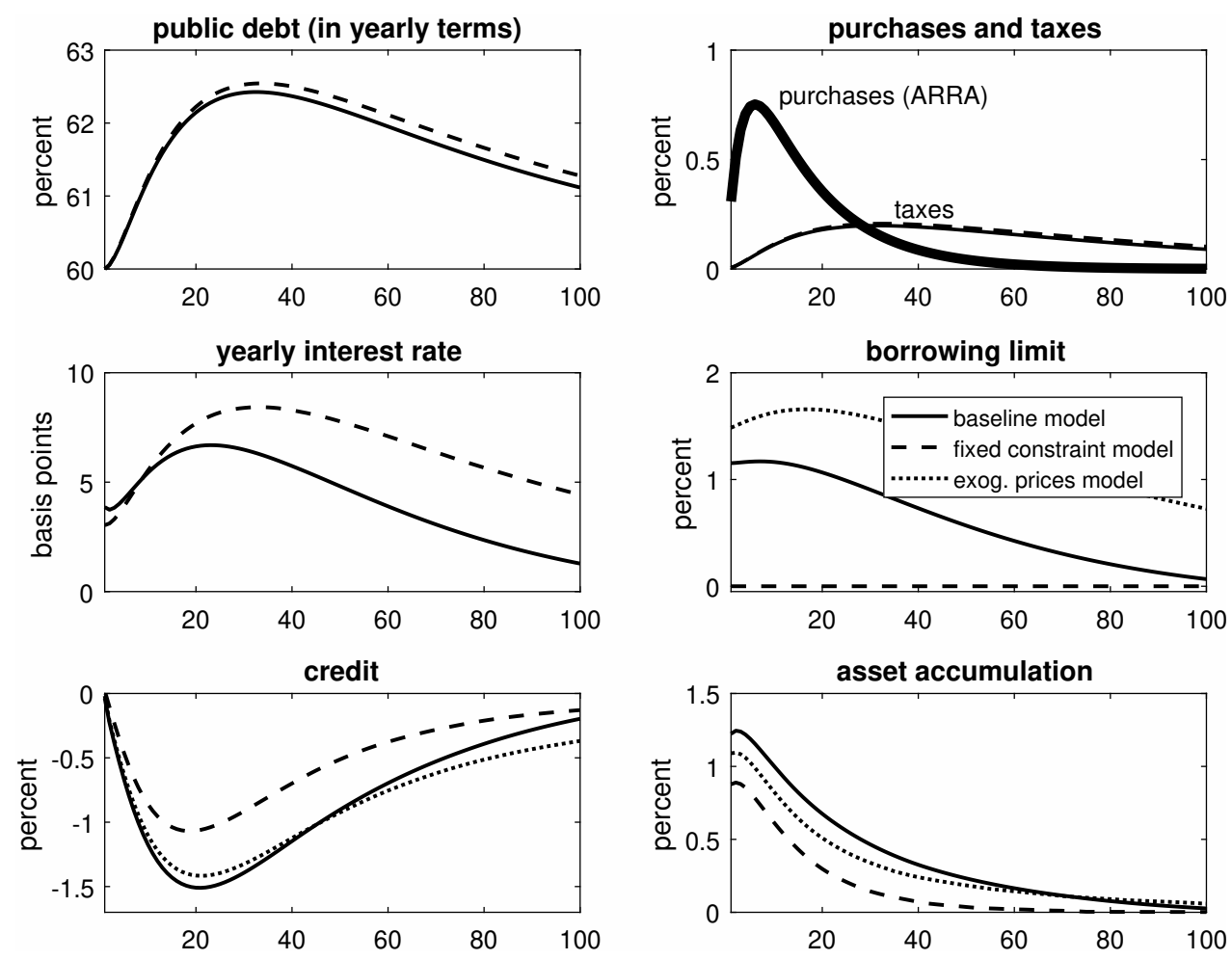

Figure 7: Selected aggregate effects of the purchases policy. All variables are expressed in deviation from steady-state levels. The deviations for public debt, transfers, taxes and the borrowing limit are normalized by steady-state output. Positive deviations for the borrowing limit mean a tightening. Asset accumulation is the difference between the asset level in $t+1$ and the steady-state level, normalized by steady-state investment. The $\mathrm{x}$-axes are in quarters.
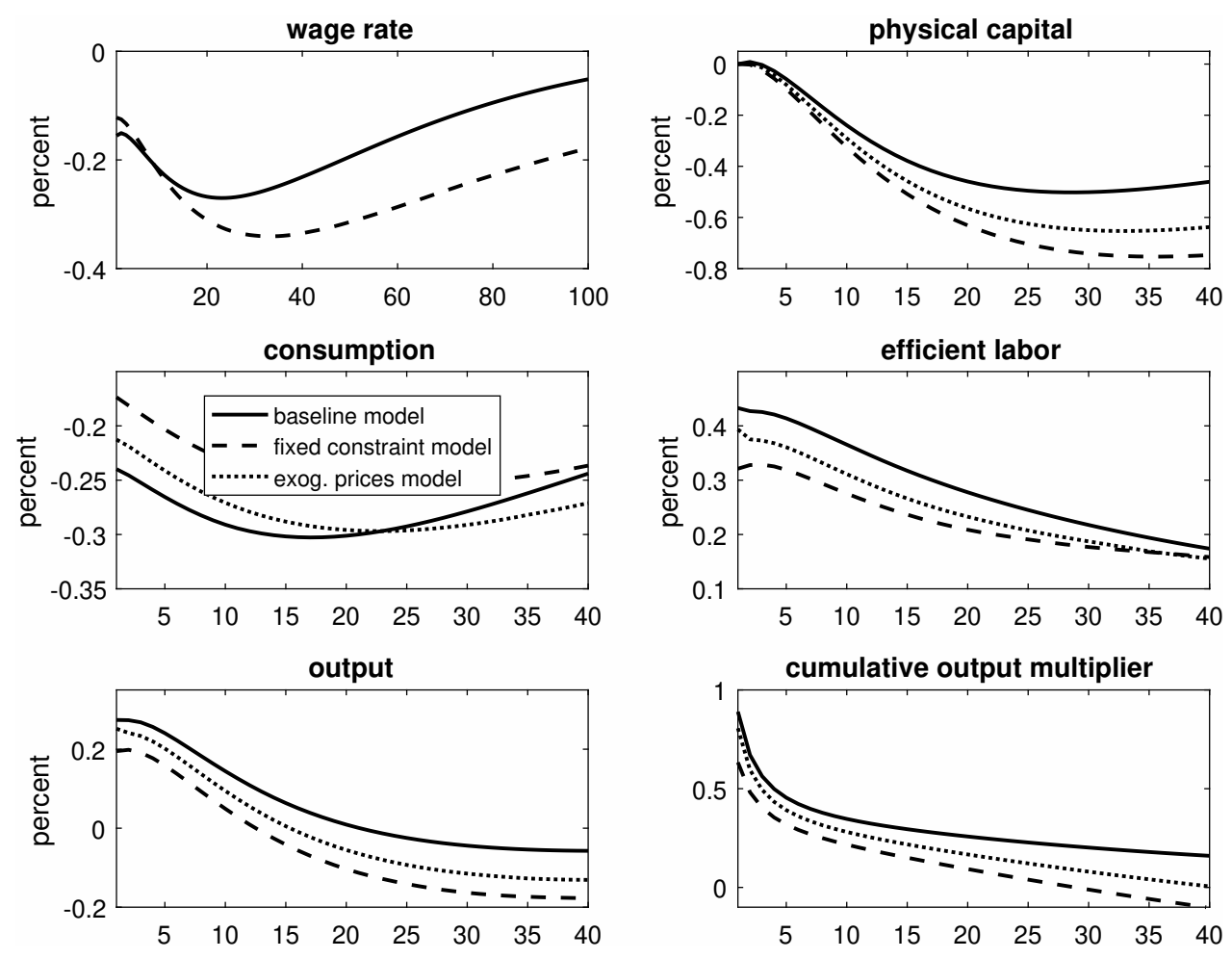

Figure 8: Aggregate effects of the purchases policy. All variables are expressed in deviation from steady-state levels. The cumulative output multiplier is calculated following Uhlig (2010); see footnote 17. The x-axes are in quarters. 
0.9 while the fixed constraint model generates a multiplier around 0.65. Around half of the effects generated by the tightening are due to price effects.

Additional exercises and robustness The appendix contains several sections with further results for the $G$ policy: Sections E.2 and E.3 show the heterogenous reactions and the welfare effects associated with the $G$ policy. Section E.4 presents the effects of the $G$ policy in a context where labor supply is inelastic.

Furthermore, a fixed prices version of the model is also simulated in which the interest rate is kept fixed at its steady-state value throughout the whole transition. As in the transfers case, the $G$ policy looses the borrowing constraint. The same set of robustness exercises as in Sections D.3 and D.4 is then performed. As in the case of the transfers policy, the robustness exercises under the purchases policy deliver results which are similar to those obtained under the baseline model. For ease of space, we omit the presentation of the fixed prices exercise together with the other robustness exercises. These results are all available upon request.

Section F presents an additional exercise with both the transfers and the government purchases policies whose aim is to assess how public debt expansions influence an economy in which households' financial conditions tighten and a recession is in place. Both policies contribute to a more marked fall in credit and a further tightening in the limit, while not producing significant effects on output.

\section{Conclusions}

This work shows that considering the endogeneity of the household borrowing constraint is important for carefully evaluating the dynamic effects of archetypal fiscal policies entailing government debt expansions, such as transfers to households and purchases of goods and services. To account for this, we use an incomplete-markets model featuring uncollateralized credit and borrowing constraints that allow for limited commitment in the repayment obligation of the borrower.

Issuing public debt creates a tension in the households' financial conditions. On the one hand, it helps relax the household borrowing constraint through a rise in the return on assets (Aiyagari and McGrattan, 1998) or a change of the collateral value (Angeletos et al., 2016). On the other hand, it tightens the constraint due to an increase in the borrowing costs. The literature has typically emphasized the first set of channels. We instead focus on the second channel and study the dynamic effects associated with the tightening. It affects the economy through two mechanisms: first, a reduction of the maximum quantity that households can borrow, which gives rise to deleveraging and precautionary motives; second, price effects induced by the movement in the borrowing limit. The price effects explain an important part of the effects generated by the tightening and induce heterogenous reactions across households which have significant political economy implications. It is evident that constrained agents react significantly to the tightening, but even unconstrained agents react non-trivially and it is the 
unconstrained's reaction that causes the tightening to produce relevant aggregate effects.

The fact that the calibrated endogenous borrowing constraint is binding for a non-negligible fraction of the households causes the Ricardian equivalence not to hold in the baseline model. However, we note that the dynamics of the borrowing limit can act both as a mitigating and as a reinforcing factor for the effects generated by specific fiscal policies. In particular, it dampens the rise of the interest rate, thus moving the economy closer to the Ricardian benchmark; at the same time, it reinforces the fall in credit and fosters labor supply which, in the case of the purchases policy, amplifies the output effects. All in all, even in the case in which the borrowing limit acts as a dampening factor, we show that important heterogeneous effectsstemming from the dynamics of the borrowing limit-remain at work. These effects cannot be ignored if we want to understand and correctly evaluate the impact of any fiscal policy.

We see three possible avenues for future research. First, our results are obtained using a model which considers only unsecured consumer credit and no defaults. As conjectured in Sections 1 and 4.1, our channel survives even if we consider a borrowing constraint characterized by collateralized credit and the possibility of defaults in equilibrium. However, it would be interesting to study how, and by how much, the inclusion these two features would change the present results. In this vein, Angeletos et al. (2016) provide interesting insights in a model where the households' wealth distribution is not a state variable of the problem. Second, government debt expansions generate movements in the household borrowing constraint that typically trigger heterogenous reactions among constrained and wealth-rich households. This fact can have implications for the level of the inequality in the economy that merit further inquiry. Third, it would be worth analyzing the implications of targeted policies, like transferring resources only to the poorest agents, for the dynamics of the borrowing constraint and compare these results with those obtained under the homogenous transfers policy.

\section{References}

Ábrahám, Á. and Cárceles-Poveda, E. (2010), 'Endogenous trading constraints with incomplete asset markets', Journal of Economic Theory 145(3), 974-1004.

Aiyagari, S. R. (1994), 'Uninsured idiosyncratic risk and aggregate saving', Quarterly Journal of Economics 109(3), 659-684.

Aiyagari, S. R. and McGrattan, E. R. (1998), 'The optimum quantity of debt', Journal of Monetary Economics 42(3), 447-469.

Alvarez, F. and Jermann, U. J. (2000), 'Efficiency, equilibrium, and asset pricing with risk of default', Econometrica 68(4), 775-797.

Angeletos, G.-M., Collard, F. and Dellas, H. (2016), Public debt as private liquidity: Optimal policy, Technical report, National Bureau of Economic Research. 
Antunes, A. A. and Cavalcanti, T. V. (2013), 'The welfare gains of financial liberalization: capital accumulation and heterogeneity', Journal of the European Economic Association 11(6), 1348-1381.

Arellano, C. (2008), 'Default risk and income fluctuations in emerging economies', American Economic Review 98(3), 690-712.

Athreya, K., Sánchez, J. M., Tam, X. S. and Young, E. R. (2015), 'Labor market upheaval, default regulations, and consumer debt', Review of Economic Dynamics 18(1), 32-52.

Baxter, M. and King, R. G. (1993), 'Fiscal policy in general equilibrium', American Economic Review 83(3), 315-334.

Bewley, T. (1977), 'The permanent income hypothesis: A theoretical formulation', Journal of Economic Theory 16(2), 252-292.

Bilbiie, F. O., Monacelli, T. and Perotti, R. (2013), 'Public debt and redistribution with borrowing constraints', Economic Journal 123(566), F64-F98.

Bilbiie, F. O., Monacelli, T. and Perotti, R. (2014), Is government spending at the zero lower bound desirable?, Technical report, National Bureau of Economic Research.

Brinca, P., Holter, H. A., Krusell, P. and Malafry, L. (2016), 'Fiscal multipliers in the 21st century', Journal of Monetary Economics 77, 53-69.

Buera, F. J. and Moll, B. (2015), 'Aggregate implications of a credit crunch: The importance of heterogeneity', American Economic Journal: Macroeconomics 7(3), 1-42.

Calvo, G. A. (1988), 'Servicing the public debt: The role of expectations', American Economic Review 78(4), 647-661.

Carroll, C. D. and Kimball, M. S. (1996), 'On the concavity of the consumption function', Econometrica 64(4), 981-992.

Castañeda, A., Díaz-Giménez, J. and Ríos-Rull, J.-V. (2003), 'Accounting for the U.S. earnings and wealth inequality', Journal of Political Economy 111(4), 818-857.

Challe, E. and Ragot, X. (2011), 'Fiscal policy in a tractable liquidity-constrained economy', Economic Journal 121(551), 273-317.

Chatterjee, S., Corbae, D., Nakajima, M. and Ríos-Rull, J.-V. (2007), 'A quantitative theory of unsecured consumer credit with risk of default', Econometrica 75(6), 1525-1589.

Christiano, L., Eichenbaum, M. and Rebelo, S. (2011), 'When is the government spending multiplier large?', Journal of Political Economy 119(1), 78-121.

Corsetti, G., Kuester, K., Meier, A. and Müller, G. J. (2013), 'Sovereign risk, fiscal policy, and macroeconomic stability', Economic Journal 123(566), F99-F132. 
Dávila, J., Hong, J. H., Krusell, P. and Ríos-Rull, J.-V. (2012), 'Constrained efficiency in the neoclassical growth model with uninsurable idiosyncratic shocks', Econometrica 80(6), 24312467.

Domeij, D. and Heathcote, J. (2004), 'On the distributional effects of reducing capital taxes', International Economic Review 45(2), 523-554.

Eggertsson, G. B. and Krugman, P. (2012), 'Debt, deleveraging, and the liquidity trap: A Fisher-Minsky-Koo approach', Quarterly Journal of Economics 127(3), 1469-1513.

Ercolani, V. and Pavoni, N. (2019), 'The precautionary saving effect of government consumption', The BE Journal of Macroeconomics (Frontiers) 19(1).

Farinha Luz, V. and Werquin, N. (2011), 'Constrained inefficiency in a Huggett model', mimeo Yale University.

Fernández-Villaverde, J. (2010), 'Fiscal policy in a model with financial frictions', American Economic Review, P\&P 100(2), 35-40.

Floden, M. and Lindé, J. (2001), 'Idiosyncratic risk in the United States and Sweden: Is there a role for government insurance?', Review of Economic Dynamics 4(2), 406-437.

Fulford, S. L. (2015), 'How important is variability in consumer credit limits?', Journal of Monetary Economics 72, 42-63.

Galí, J., López-Salido, J. D. and Vallés, J. (2007), 'Understanding the effects of government spending on consumption', Journal of the European Economic Association 5(1), 227-270.

Guerrieri, V. and Lorenzoni, G. (2017), 'Credit crises, precautionary savings, and the liquidity trap', Quarterly Journal of Economics 132(3), 1427-1467.

Hall, R. E. (2009), By how much does GDP rise if the government buys more output?, Technical report, National Bureau of Economic Research.

Heathcote, J. (2005), 'Fiscal policy with heterogeneous agents and incomplete markets', Review of Economic Studies 72(1), 161-188.

Holmstrom, B. and Tirole, J. (1998), 'Private and public supply of liquidity', Journal of Political Economy 106(1), 1-40.

Huggett, M. (1993), 'The risk-free rate in heterogeneous-agent incomplete-insurance economies', Journal of Economic Dynamics and Control 17(5), 953-969.

Huntley, J. and Michelangeli, V. (2014), 'Can tax rebates stimulate consumption spending in a life-cycle model?', American Economic Journal: Macroeconomics 6(1), 162-189.

Huo, Z. and Ríos-Rull, J.-V. (2015), 'Tightening financial frictions on households, recessions, and price reallocations', Review of Economic Dynamics 18(1), 118-139. 
Jappelli, T. (1990), 'Who is credit constrained in the U.S. economy?', Quarterly Journal of Economics 105(1), 219-234.

Kaplan, G. and Violante, G. L. (2014), 'A model of the consumption response to fiscal stimulus payments', Econometrica 82(4), 1199-1239.

Kaplan, G., Violante, G. L. and Weidner, J. (2014), 'The wealthy hand-to-mouth', Brookings Papers on Economic Activity .

Kehoe, P., Midrigan, V. and Pastorino, E. (2016), 'Debt constraints and the labor wedge', American Economic Review, P\&P 106(5), 548-553.

Kehoe, T. J. and Levine, D. K. (1993), 'Debt-constrained asset markets', Review of Economic Studies 60(4), 865-888.

Kiyotaki, N. and Moore, J. (1997), 'Credit cycles', Journal of Political Economy 105(2), 211248.

Kolosova, K. (2013), 'On the relationship between government spending multiplier and welfare'. Bocconi University, mimeo.

Kopecky, K. A. and Suen, R. (2010), 'Finite state Markov-chain approximations to highly persistent processes', Review of Economic Dynamics 13(3), 701-714.

Krueger, D. and Perri, F. (2005), 'Understanding consumption smoothing: Evidence from the U.S. consumer expenditure data', Journal of the European Economic Association 3(2-3), 340349.

Leeper, E. M., Plante, M. and Traum, N. (2010), 'Dynamics of fiscal financing in the United States', Journal of Econometrics 156(2), 304-321.

Ljungqvist, L. and Sargent, T. J. (2004), Recursive macroeconomic theory, MIT press.

Maddaloni, A. and Peydró, J.-L. (2011), 'Bank risk-taking, securitization, supervision, and low interest rates: Evidence from the euro area and the U.S. lending standards', Review of Financial Studies 24(6), 2121-2165.

McKay, A. and Reis, R. (2016), 'The role of automatic stabilizers in the U.S. business cycle', Econometrica 84(1), 141-194.

Obiols-Homs, F. (2011), 'On borrowing limits and welfare', Review of Economic Dynamics 14(2), 279-294.

Oh, H. and Reis, R. (2012), 'Targeted transfers and the fiscal response to the great recession', Journal of Monetary Economics 59, S50-S64.

Quadrini, V. and Ríos-Rull, J.-V. (1997), 'Understanding the U.S. distribution of wealth', Federal Reserve Bank of Minneapolis Quarterly Review 21(2), 22-36. 
Rendahl, P. (2016), 'Fiscal policy in an unemployment crisis', Review of Economic Studies 83(3), 1189-1224.

Röhrs, S. and Winter, C. (2015), 'Public versus private provision of liquidity: Is there a tradeoff?', Journal of Economic Dynamics and Control 53, 314-339.

Storesletten, K., Telmer, C. I. and Yaron, A. (2004), 'Consumption and risk sharing over the life cycle', Journal of Monetary Economics 51(3), 609-633.

Uhlig, H. (2010), 'Some fiscal calculus', American Economic Review, P\&P 100(2), 30-34.

Woodford, M. (1990), 'Public debt as private liquidity', American Economic Review, PESP 80(2), 382-388.

Zeldes, S. P. (1989), 'Optimal consumption with stochastic income: Deviations from certainty equivalence', Quarterly Journal of Economics 104(2), 275-298.

Zhang, H. H. (1997), 'Endogenous borrowing constraints with incomplete markets', Journal of Finance 52(5), 2187-2209. 


\section{Appendix}

\section{A A measure of the household borrowing limit and its relation with the interest rates}

Using individual credit card data from the credit reporting agency Equifax, prepared by the Federal Reserve Bank of New York, Fulford (2015) estimates the expected evolution of the borrowing limit by several individual characteristics, like geographical location and credit risk, and also across time (for more details, see Section 2 of Fulford, 2015). In particular, he estimates a quarterly series of the borrowing limit, in logs, for the period 1999q1-2013q4. Due to data availability issues, we recovered this series through a graphical procedure applied directly to Figure 4 of Fulford (2015), which contains the evolution over time of the borrowing limit. The outcome of the procedure (available upon request) is the solid line in Figure $9 .{ }^{26}$ Notice that while this definition uses a positive value for the borrowing limit-meaning that a smaller number implies a tightening - the notation used in our model (Section 2) implies that the borrowing limit is a negative value, that is, a tightening occurs when the absolute value of the limit decreases.

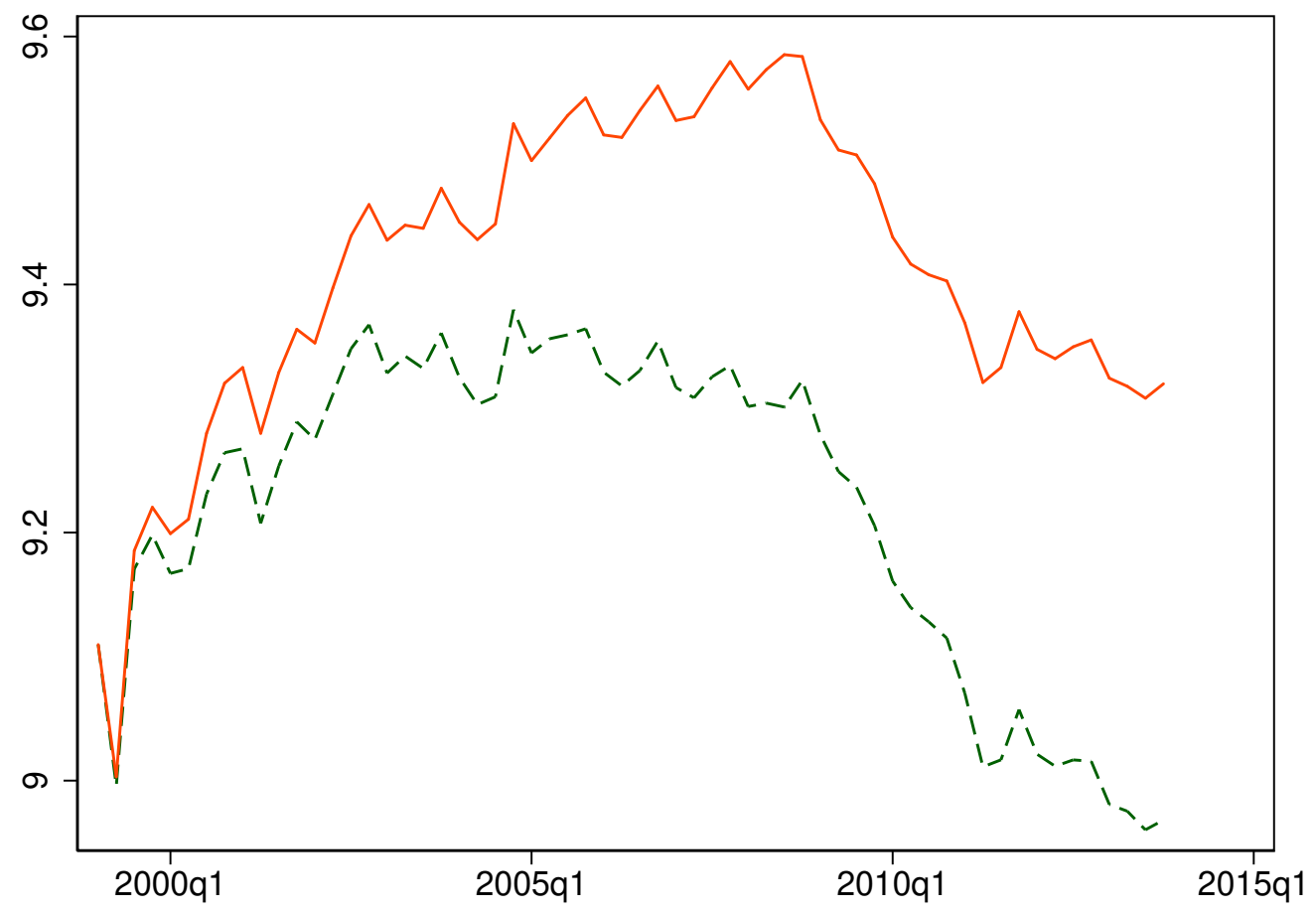

Figure 9: Borrowing limits in nominal and in real terms. The solid line represents the nominal borrowing limit derived by the authors in order to replicate Figure 4 in Fulford (2015). The dashed line represents the series of the borrowing limit deflated with the CPI. The time period is 1999q120013q4. The $\mathrm{y}$-axis is in logs; the $\mathrm{x}$-axis is in quarters.

In order to compute the borrowing limit in real terms, we took the exponential of the

\footnotetext{
${ }^{26}$ The measurement error of this procedure is estimated to be very small, at $0.1 \%$ of the dollar value of the borrowing limit.
} 
retrieved series of the borrowing limit and divided it by the Consumer Price Index (CPI). ${ }^{27}$ The outcome of this process, after taking logs again, is the dashed line in Figure 9.

Table 5: Regressions of the credit limit against interest rate and output. The log of the quarterly series of the borrowing limit is taken from Fulford (2015) and is deflated with the CPI. The series of the quarterly real rate (interest rate) is calculated as the difference between the rate charged by commercial banks on credit card plans and the quarterly average of monthly inflation expressed in annual terms, both taken from the FRED database. Output (GDP) is the log of the real GDP at quarterly frequency, taken from the FRED database. ${ }^{* * *}, * *, *$ identify p-values lower than $1 \%, 5 \%$, $10 \%$, respectively.

\begin{tabular}{lcccccc}
\hline \hline & \multicolumn{2}{c}{$\mathbf{1 9 9 9 q 1 - \mathbf { 2 0 0 7 q 4 }}$} & \multicolumn{2}{c}{$\mathbf{2 0 0 8 q 1 - \mathbf { 2 0 1 3 q 4 }}$} & \multicolumn{2}{c}{$\mathbf{1 9 9 9 q 1 - \mathbf { 2 0 1 3 q 4 }}$} \\
\hline constant & $9.77^{* * *}$ & $5.68^{* * *}$ & $9.04^{* * *}$ & $52.22^{* * *}$ & $9.33^{* * *}$ & $17.05^{* * *}$ \\
interest rate & $-0.04^{* * *}$ & $-0.03^{* * *}$ & 0.01 & $-0.02^{* * *}$ & -0.01 & $-0.03^{* * *}$ \\
GDP & & $0.41^{* *}$ & & $-4.43^{* * *}$ & & $-0.78^{* * *}$ \\
\hline \hline
\end{tabular}

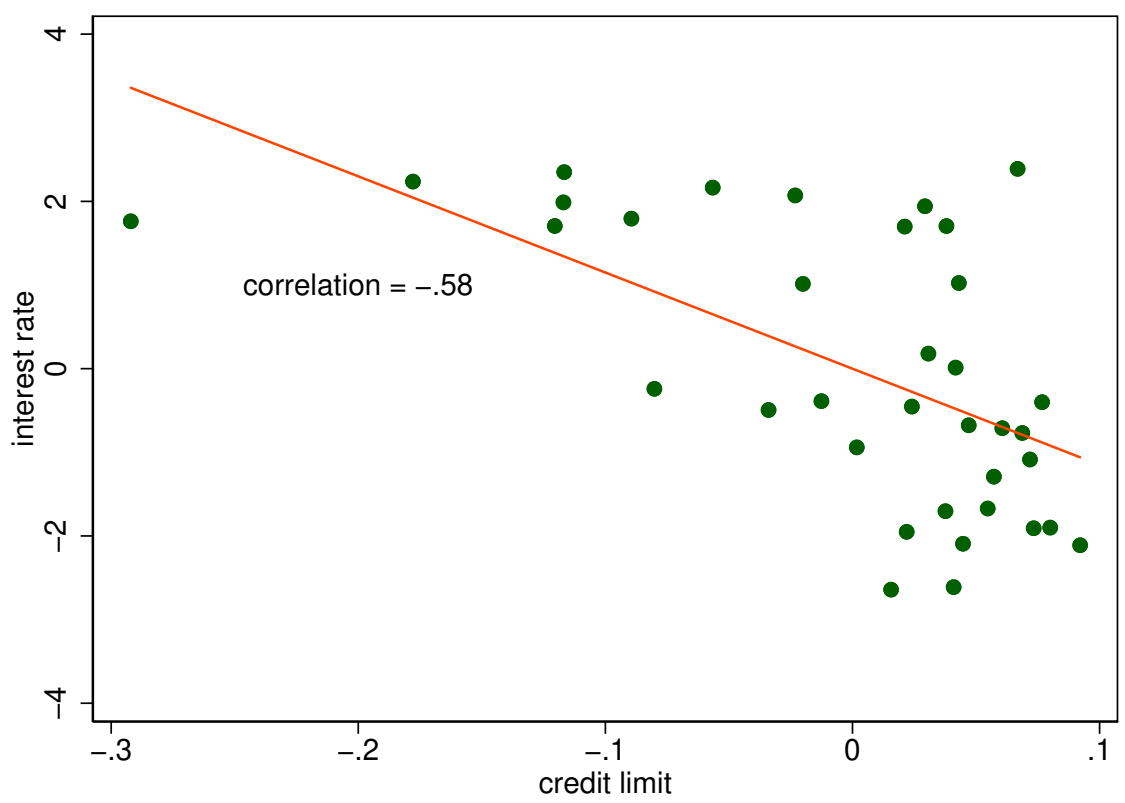

Figure 10: The borrowing limit and the risk-free interest rate for the U.S., in real terms, demeaned. The log of the quarterly series of the borrowing limit is taken from Fulford (2015). The series of the quarterly real rate is calculated as the difference between the quarterly effective federal funds rate and the quarterly average of monthly inflation expressed in annual terms, both taken from the FRED database. The time period is 1999q1-2007q4. The reported Pearson's correlation coefficient between the two variables is significant at $1 \%$. The straight line represents a linear fit to the two variables.

In order to get the correlation between the borrowing limit and the real interest rate we regress the former on the second, controlling for the state of the economy. As for the interest rate, we refer to the rate charged by commercial banks on credit card plans since the short-term risk-free rates had almost no variation for a large part of our sample, that is, after 2007. Table 5 presents the results of these regressions. The following two facts are worth noting. First, using the "normal times" sample (period 1999q1-2007q4) the coefficient associated to the interest rate

\footnotetext{
${ }^{27}$ The CPI is the quarterly "Consumer Price Index for All Urban Consumers: All Items", taken from the FRED database. We normalized to unity the observation in 1999Q1.
} 
is negative and significant irrespective of controlling for GDP or not. This means that increases in the interest rate tend to be associated to a tightening of the credit limit unconditionally. Second, both in what one would loosely call the "zero lower bound period" (2008q1-2013q4) and in the full sample the coefficient of the interest rate is negative and significant only if we control for real activity. The level of GDP seems to account well for the factors shifting the level of the borrowing limit in periods when output was more volatile and the policy rate was constrained at zero.

In Figure 1, Section 1, we present part of these results by reproducing the unconditional correlation between the credit limit and the interest rate on credit card plans, together with the scatter plot, during the "normal times" period. Notice that during this period, a rather strong negative correlation emerges even between the credit limit and the short-term risk-free interest rate; see Figure 10.

\section{B Computational procedure}

This section explains in detail the computational procedure for calculating both the stationary distribution and the transition of the model economy after a policy or parameter change.

\section{B.1 The solution method}

As explained in Section 3, the relevant borrowing limit in the model economy, $\underline{a}\left(\theta^{\prime}\right)$, is unique and parameterized in the lowest $z .^{28}$ The problem to solve is therefore:

$$
v(a, z, \theta)=\max _{c, n, a^{\prime}} u(c, n)+\beta \mathbf{E}\left[v\left(a^{\prime}, z^{\prime}, \theta^{\prime}\right) \mid z\right]
$$

subject to

$$
\begin{aligned}
c+a^{\prime} & =\left(1+r\left(1-\tau_{k} \mathcal{I}_{a \geq 0}\right)\right) a+w n z\left(1-\tau_{w}\right)+\operatorname{Tr}-\Gamma \\
a^{\prime} \geq \underline{a}\left(\theta^{\prime}\right) . &
\end{aligned}
$$

We use a direct solution method for solving problem (14). The problem is a mixedconstrained optimal control problem because of the coexistence of equality and inequality constraints. We will economize on notation and drop explicit reference to measure $\theta$. Consider the Lagrangian function:

$$
\begin{aligned}
\mathcal{L}\left(c, n, a^{\prime}\right) & =u(c, n)+\beta \mathrm{E}\left[v\left(a^{\prime}, z^{\prime}\right) \mid z\right]+ \\
& \left(\left(1+r\left(1-\tau_{k} \mathcal{I}_{a \geq 0}\right)\right) a+w n z\left(1-\tau_{w}\right)+\operatorname{Tr}-\Gamma-c-a^{\prime}\right) \lambda+\left(\underline{a}-a^{\prime}\right) \mu+\left(\bar{a}-a^{\prime}\right) \gamma
\end{aligned}
$$

\footnotetext{
${ }^{28}$ Despite we work with a unique borrowing limit, we should mention that the proposed solution method is robust to the consideration of borrowing limits contingent on different $z$ 's. Please, recall footnote 11.
} 
where we assume that there is an absolute upper level for asset holdings, $\bar{a}$. This will have to be confirmed once we solve the problem numerically. In practice it suffices to set it to a sufficiently high positive value. The necessary conditions for an optimum of the above problem are:

$$
\begin{aligned}
u_{c}(c, n)-\lambda & =0 \\
u_{n}(c, n)+\lambda w\left(1-\tau_{w}\right) z & =0 \\
\beta \mathrm{E}\left[v_{a}\left(a^{\prime}, z^{\prime}\right) \mid z\right]-\lambda-\mu-\gamma & =0 \\
\mu & \leq 0 \\
\left(\underline{a}-a^{\prime}\right) \mu & =0 \\
\gamma & \geq 0 \\
\left(\bar{a}-a^{\prime}\right) \gamma & =0 \\
\bar{a} & \geq a^{\prime}
\end{aligned}
$$

plus the two equations (15) and (16). Using an envelope result yields

$$
v_{a}(a, z)=\lambda\left(1+\left(1-\tau_{k} \mathcal{I}_{a \geq 0}\right) r\right) .
$$

Hence, equation (20) becomes

$$
\left.\beta \mathrm{E}\left[\lambda^{\prime}\left(1+\left(1-\tau_{k} \mathcal{I}_{a^{\prime} \geq 0}\right)\right) r^{\prime}\right) \mid z\right]-\lambda-\mu-\gamma=0
$$

where we have assumed without loss of generality that tax rates stay constant over time. Given the simplification of the notation, the previous expressions are relevant for the steady state and the transition.

\section{B.2 Numerical solution}

In general, our numerical procedure aims at precisely calculating the policy functions by iterating on the above first-order conditions and constraints, and then using them to compute the density measure across asset holdings and labor productivity. This method can be used in computing both the steady state and the transition with slight adaptations that will be described below.

We first set up a grid $\mathcal{A}$ on assets with overall negative and positive asset holdings limits $\underline{a}_{\min }$ and $\bar{a}$, and make sure that they are not binding in any of the calibrations. We set these bounds to -20 and 600 and use 250 points for $\mathcal{A}$. The grid oversamples negative holdings: a sampling scheme where about one fifth of the grid points are negative is used. The stochastic process of idiosyncratic productivity is modeled using Rouwenhorst's method (Kopecky and Suen, 2010). We use 7 points for $\mathcal{Z}$.

The procedure for calculating the steady state is conditional on some combination of the fiscal variables satisfying the intertemporal government budget described by equations (8)-(10). 
This means that $B, G, \operatorname{Tr}, \Gamma, \tau_{k}$ and $\tau_{w}$ must satisfy the steady-state relationship

$$
\Gamma+\tau_{k} r \int_{a \geq 0} a d \theta+\tau_{w} w N=G+\operatorname{Tr}+r B
$$

knowing that $\tau_{k}, \tau_{w}$, $\operatorname{Tr}$ and $G$ are exogenously given.

There are two levels of iterations. The inner iteration is on individual policy functions. The outer iteration, which will be indexed by $i$ in this section, is on the aggregate prices and quantities.

The measure $\theta$ can be defined in a grid considerably finer than $\mathcal{X}=\mathcal{A} \times \mathcal{Z}$ in the first dimension. Without loss of generality, assume a grid $\tilde{\mathcal{X}}=\tilde{\mathcal{A}} \times \mathcal{Z}$, where $\tilde{\mathcal{A}}$ is denser than $\mathcal{A}$ but contains all its elements. ${ }^{29}$

1. Start with a first guess for next period's aggregate capital, value function, autarky value, borrowing limit and consumption policy function, and a first guess for current period's aggregate labor supply, joint distribution of assets and shocks and the asset policy functions,

$$
\left(K_{\text {next }}^{0}, N^{0}, v_{\text {next }}^{0}(a, z), \underline{v}_{\text {next }}^{0}(z), \underline{a}_{\text {next }}^{0}, \theta^{0}, a^{0}(a, z), c_{\text {next }}^{0}(a, z)\right) .
$$

Set the outer iteration index $i$ to 0 .

2. Guess the level of debt for the next period and the current level of lump-sum taxes, $\left(B_{\text {next }}^{0}, \Gamma^{0}\right)$

3. If solving for the steady state, set $N_{\text {next }}^{i}=N^{i}$.

4. Compute prices $\left(r_{\text {next }}^{i}, w_{\text {next }}^{i}\right)$ using (6) and (7). If solving for the steady state, set $r^{i}=r_{\text {next }}^{i}$ and $w^{i}=w_{\text {next }}^{i}$.

5. Given $\underline{v}_{\text {next }}^{i}(z)$, compute the autarky value, $\underline{v}^{i}(z)$ for all values in $\mathcal{Z}$ using (3). The maximization problem in the expression is well-behaved and yields an interior solution in terms of $n$. Details for computing $n$ are given in step 6 .

6. Given policy function $a^{i}(a, z)$, solve equations (15), (18) and (19) to obtain policy functions

$$
\left(n^{i}(a, z), c^{i}(a, z), \lambda^{i}(a, z)\right) .
$$

The procedure consists of solving (15) and (18) with respect to $c$ and $\lambda$, then substituting these variables in the nonlinear equation (19) and solving it with respect to $n$ using the Newton-Raphson method.

7. Using equation (18), compute $\lambda_{\text {next }}^{i}(a, z)=u_{c}\left(c_{\text {next }}^{i}(a, z), \cdot\right)$, where the second argument

\footnotetext{
${ }^{29}$ In the solutions computed in the paper, the two grids are the same because $\mathcal{A}$ already contains a sufficiently large number of points. In even more numerically intensive applications one could decrease the number of points in $\mathcal{A}$ to a much lower number (say, 30) and keep a large number of elements for $\tilde{\mathcal{A}}$.
} 
is irrelevant given separability of the arguments of the utility function. Compute

$$
\left.\Phi(a, z)=\beta \mathrm{E}\left[\lambda_{\text {next }}^{i}\left(a^{i}(a, z), z^{\prime}\right)\left(1+\left(1-\tau_{k} \mathcal{I}_{a^{i}(a, z) \geq 0}\right)\right) r_{\text {next }}^{i}\right) \mid z\right]-\lambda^{i}(a, z)
$$

using linear interpolation where necessary.

8. Use equation (27) to set $\mu^{i}(a, z)=\Phi(a, z)$ in all points of set $S_{1}=\left\{(a, z) \in \mathcal{X}: a^{i}(a, z)<\right.$ $\left.\underline{a}_{\text {next }}^{i}+\epsilon_{1}\right\}$, for small $\epsilon_{1}>0$, and zero elsewhere.

9. Use equation (27) to set $\gamma^{i}(a, z)=\Phi(a, z)$ in all points of set $S_{2}=\left\{(a, z) \in \mathcal{X}: a^{i}(a, z)>\right.$ $\left.\bar{a}_{\text {next }}^{i}-\epsilon_{2}\right\}$, for small $\epsilon_{2}>0$, and zero elsewhere.

10. Partition grid $\mathcal{X}$ into five mutually exclusive sets:

$$
\begin{aligned}
& R_{1}=\left\{(a, z) \in S_{1}: \mu^{i}(a, z)>0\right\} \\
& R_{2}=\left\{(a, z) \in S_{2}: \gamma^{i}(a, z)<0\right\} \\
& R_{3}=\left\{(a, z) \in S_{1}: \mu^{i}(a, z) \leq 0\right\} \\
& R_{4}=\left\{(a, z) \in S_{2}: \gamma^{i}(a, z) \geq 0\right\} \\
& R_{5}=\mathcal{X} \backslash\left\{R_{1} \cup R_{2} \cup R_{3} \cup R_{4}\right\} .
\end{aligned}
$$

Increase $a^{i}(a, z)$ in all points of $R_{1}$; decrease $a^{i}(a, z)$ in all points of $R_{2}$; set $a^{i}(a, z)$ equal to $\underline{a}_{\text {next }}^{i}$ in all points of $R_{3}$; set $a^{i}(a, z)$ equal to $\bar{a}$ in all points of $R_{4}$; increase $a^{i}(a, z)$ in the points of $R_{5}$ such that $\Phi(a, z)>0$; and decrease $a^{i}(a, z)$ in the points of $R_{5}$ such that $\Phi(a, z)<0$. Set the values of $a^{i}(a, z)$ larger than $\bar{a}$ (if any) to $\bar{a}$ and the values smaller than $\underline{a}_{\mathrm{next}}^{i}$ (if any) to $\underline{a}_{\mathrm{next}}^{i}$.

11. If computing for the steady state, set $c_{\text {next }}^{i}(a, z)=c^{i}(a, z)$; compute $v^{i}$ iterating on expression (14) with policy functions $n^{i}(a, z)$ and $c^{i}(a, z)$.

12. Go back to stage 6 until changes in $a^{i}(a, z)$ in stage 10 are small enough for all points in $\mathcal{X}$; all the above necessary conditions should be satisfied within a small error.

13. Compute the borrowing limit for the current period by solving $v^{i}(a, z)=\underline{v}^{i}(z)$ in $a$ with linear interpolation and pick the tightest of these limits, $\underline{a}^{i}$.

14. Given the policy function $a^{i}(a, z)$, extend its domain to the denser grid $\tilde{\mathcal{X}}$ using interpolation; for ease of notation, this function will be denoted $a^{i}(\tilde{a}, z)$ at a generic point $(\tilde{a}, z) \in \tilde{\mathcal{X}}$. To compute next period's measure $\left(\theta^{i}\right)^{\prime}$ defined in set $\tilde{\mathcal{X}}$ we take into account the distance of next period's asset holdings to the nearest two points of the denser grid. To that effect, define the value in the denser grid of assets $\tilde{\mathcal{A}}$ immediately above the policy function as $a^{u}(\tilde{a}, z)=\min \left\{\tilde{b} \in \tilde{\mathcal{A}}: a^{i}(\tilde{a}, z) \leq \tilde{b}\right\}$ and similarly for the value immediately below, $a^{l}(\tilde{a}, z)=\max \left\{\tilde{b} \in \tilde{\mathcal{A}}: a^{i}(\tilde{a}, z) \geq \tilde{b}\right\}$. Further define the weights associated to 
these two points as

$$
w^{l}(\tilde{a}, z)=\left\{\begin{array}{cc}
\frac{a^{u}(\tilde{a}, z)-a^{i}(\tilde{a}, z)}{a^{u}(\tilde{a}, z)-a^{l}(\tilde{a}, z)} & \text { if } a^{u}(\tilde{a}, z) \neq a^{l}(\tilde{a}, z) \\
\frac{1}{2} & \text { otherwise }
\end{array}\right.
$$

and $w^{u}(\tilde{a}, z)=1-w^{l}(\tilde{a}, z)$.

The next period measure can be computed from the current period measure with generic density $\theta_{(\tilde{a}, z)}^{i}$ as:

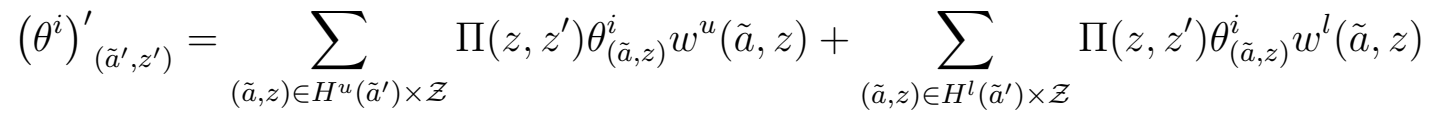

where $H^{u}\left(\tilde{a}^{\prime}\right)=\left\{(\tilde{a}, z) \in \tilde{\mathcal{X}}: a^{u}(\tilde{a}, z)=\tilde{a}^{\prime}\right\}$ and $H^{l}\left(\tilde{a}^{\prime}\right)=\left\{(\tilde{a}, z) \in \tilde{\mathcal{X}}: a^{l}(\tilde{a}, z)=\tilde{a}^{\prime}\right\}$.

15. Compute the desired level of capital in the next period and the supply of labor in the current period given by expressions (11) and (12), whose discrete counterparts are:

$$
\begin{aligned}
& K_{s}^{i}=\sum_{\tilde{\mathcal{X}}} a^{i}(\tilde{a}, z) \theta_{(\tilde{a}, z)}^{i}-B_{\text {next }}^{i} \\
& N_{s}^{i}=\sum_{\tilde{\mathcal{X}}} n^{i}(\tilde{a}, z) \theta_{(\tilde{a}, z)}^{i} .
\end{aligned}
$$

16. Set $B_{\text {next }}^{i+1}$ and $\Gamma^{i+1}$ using equations (8)-(10).

17. If $K_{\text {next }}^{i}-K_{s}^{i}, N^{i}-N_{s}^{i}, B_{\text {next }}^{i+1}-B_{\text {next }}^{i}$ and $\Gamma^{i+1}-\Gamma^{i}$ are small enough in absolute terms, one should have a solution for the problem and stop here.

18. Otherwise, set $K_{\text {next }}^{i+1}$ to a number between $K_{s}^{i}$ and $K_{\text {next }}^{i}$, and similarly for $N^{i+1}$. Set $\theta^{i+1}$ to $\left(\theta^{i}\right)^{\prime}, a^{i+1}(a, z)$ to $a^{i}(a, z), c_{\text {next }}^{i+1}(a, z)$ to $c^{i}(a, z), \underline{a}_{\text {next }}^{i+1}$ to $\underline{a}^{i}, \underline{v}_{\text {next }}^{i+1}(z)$ to $\underline{v}^{i}(z)$ and $v_{\text {next }}^{i+1}(a, z)$ to $v^{i}(a, z)$. Increment $i$ by one and go back to stage 3 .

Regarding the transition, we point out the following. The transition exercise consists of calculating the evolution of the economy starting with a certain distribution of assets and shocks $\theta^{\text {Init }}$ and the paths for the exogenous quantities, like transfers or government spending.

Set the simulation horizon, $T$, to a large number, say 800 periods. Instead of guesses for aggregate capital, labor supply, the policy and value functions, the autarky value, the fiscal variables, the joint distribution of assets and shocks, and the borrowing limit, we need to have a first guess for the entire path of those quantities. In practical terms, a good first guess for the paths of these quantities is, for all $T$ periods, their values at the final steady state.

We then have to proceed in the following way. Identify the iteration label $i$ with the time period $t+1$ and the results for the next iteration, denoted by $i+1$, with time $t$. The idea is to start from the end of the horizon and recursively proceed to the initial period. We start in moment $t$ equal to $T-1$, so that $i$ is 0 . Run steps $6-12$ above using the same computational routines as for the steady state. Then, update $t$ to $T-2$ and repeat this cycle until $t$ is 1 . The 
next part of the problem is to update the distributions of assets and shocks given the policy functions just calculated. Use the distribution $\theta^{\text {Init }}$ and the policy functions to update the entire path of the joint distribution and the other macro level variables, including the borrowing limit.

For each of the $T$ periods compare the computed aggregate capital with the guess, and likewise for aggregate labor, following the general idea of stage 17. Repeat the entire procedure until the differences between the computed aggregate capital and aggregate labor and their guesses are sufficiently small in all periods, and the changes in the endogenous fiscal variables between iterations are also small enough in all periods.

\section{Policy functions in the steady state}
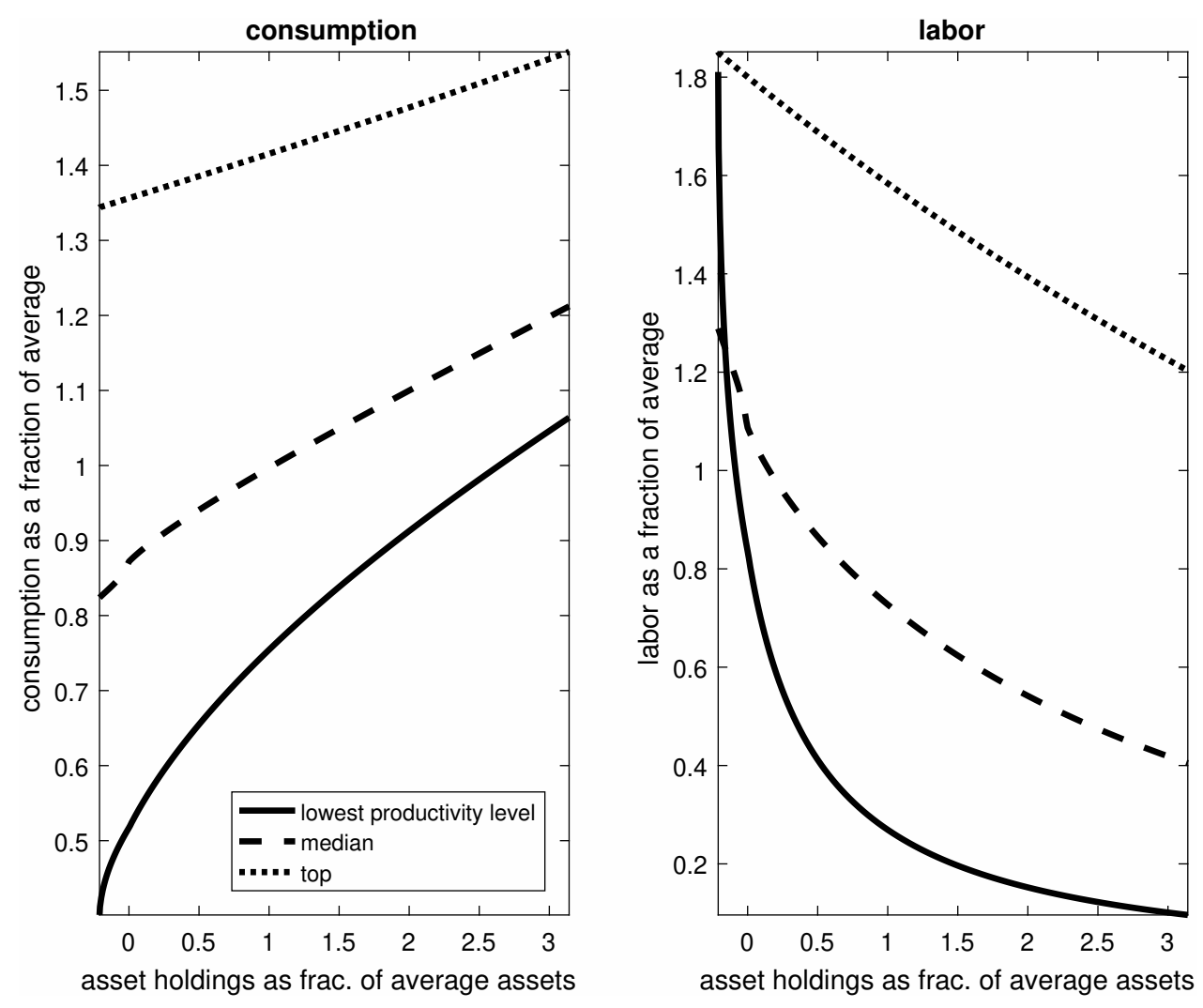

Figure 11: Consumption and labor policy functions in steady state, conditional on different levels of idiosyncratic productivity.

Figure 11 shows the agents' policy functions associated with consumption and labor for the lowest, the median and the highest productivity level. Focusing on the consumption policy function parameterized in the lowest productivity level, we see that it exhibits more curvature as wealth approaches the borrowing limit. This is typical in models with precautionary saving motives and borrowing limits (Zeldes, 1989; Carroll and Kimball, 1996). As expected, the curvature diminishes as the level of the idiosyncratic productivity increases. The labor policy functions mirror those of consumption; more specifically, borrowers and wealth-poor households at the lowest level of productivity are the most responsive in terms of labor. A marginal increase in their wealth produces a negative and large reaction in their labor supply. 


\section{Additional results for the transfers policy}

This section shows additional simulations together with several robustness exercises associated with the debt-financed transfers policy.

\section{D.1 The anatomy of the tightening and its effects on the policy functions}

Figure 12 shows the movement of the borrowing constraint as a result of the reaction of the equilibrium and autarky value functions (parameterized in the lowest $z$ ) to the transfers policy. Specifically, we show the movement of this constraint from its steady-state position (vertical solid line) to the new position in the first relevant period after the policy change (vertical dotted line). ${ }^{30}$ After the policy implementation, both value functions $v\left(x^{\prime}, \theta^{\prime}\right)$ and $\underline{v}\left(z^{\prime}, \theta^{\prime}\right)$ move up. Crucially, the increase in the borrowing cost affects (negatively) only the dynamics of $v\left(x^{\prime}, \theta^{\prime}\right)$ which, indeed, moves up by less than what $\underline{v}\left(z^{\prime}, \theta^{\prime}\right)$ does. This fact generates a movement of the borrowing constraint towards zero, or equivalently, a shift of the limit to the right.

Let us mention that the initial unexpected shift of the borrowing limit can in principle leave some households out of the capital grid given that capital is predetermined. Dealing with this issue would require some form of bankruptcy in equilibrium which, as already indicated, is a circumstance not considered in our model. However, right after the fiscal policy is implemented all households will perfectly know the dynamic of the borrowing limit, hence ensuring that their optimal asset choice is feasible.

Figure 13 compares policy functions in the baseline model and in the fixed constraint economy. Specifically, each line reports the difference between the labor, consumption and asset policy functions in the baseline model, and the respective policy functions in the fixed constraint model, for different levels of productivity. These values are calculated at the moment of the policy implementation, that is, at $t=1$.

The three decision rules differ across the two models. In particular, the resulting information is consistent with the households' reactions presented in the main text, that is, households work (consume) on average more (less) because of the tightening. They also tend to increase their wealth. However, for low productivity levels these differences are larger in absolute value as wealth approaches the borrowing limit. In contrast, for the highest productivity level these differences are pretty homogenous across wealth levels.

\section{D.2 Results with fixed prices}

We study the importance of the dynamics of the interest rate for the occurrence of the tightening. Figure 14 presents the effects of the transfers policy on the borrowing limit, within a fixed prices (off-equilibrium) version of the model. Specifically, we simulate the model while keeping the interest rate at its steady-state value throughout the whole transition. Keeping the

\footnotetext{
${ }^{30}$ If policy announcement and implementation occurs at time $t=1$, the first relevant period is $t=2$ because it is the moment for which the maximum amount of borrowing is defined.
} 


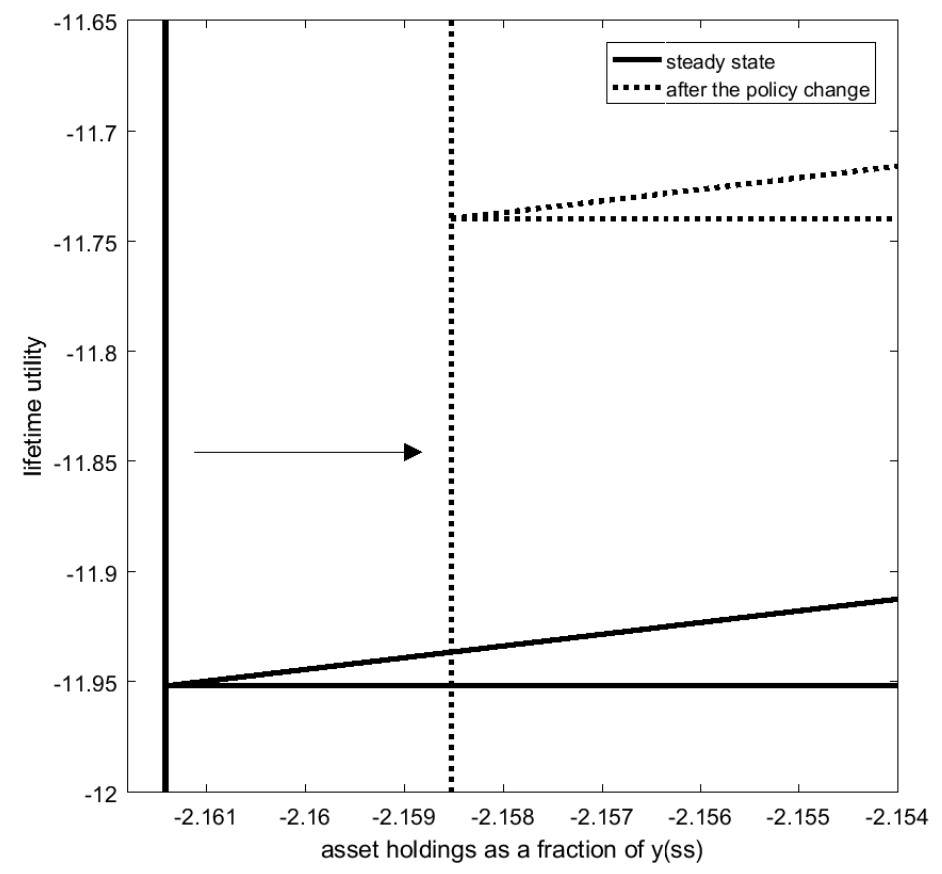

Figure 12: The movement of the borrowing constraint, $\underline{a}\left(\theta^{\prime}\right)$, conditional on the implementation of the transfers policy. The two flat lines correspond to the value functions in autarky, $\underline{v}\left(z^{\prime}, \theta^{\prime}\right)$, in the steady state (solid line) and in the first relevant period after the policy change (dotted line). The two lines with positive slope refer to the equilibrium value functions, $v\left(x^{\prime}, \theta^{\prime}\right)$, in the steady state (solid line) and in the first relevant period after the policy change (dotted line). The value functions are parameterized in the lowest productivity level. The steady-state borrowing limit is identified by the vertical solid line, while the borrowing limit after the change is represented by the vertical dotted line. $\mathrm{y}(\mathrm{ss})$ stands for steady-state output. 

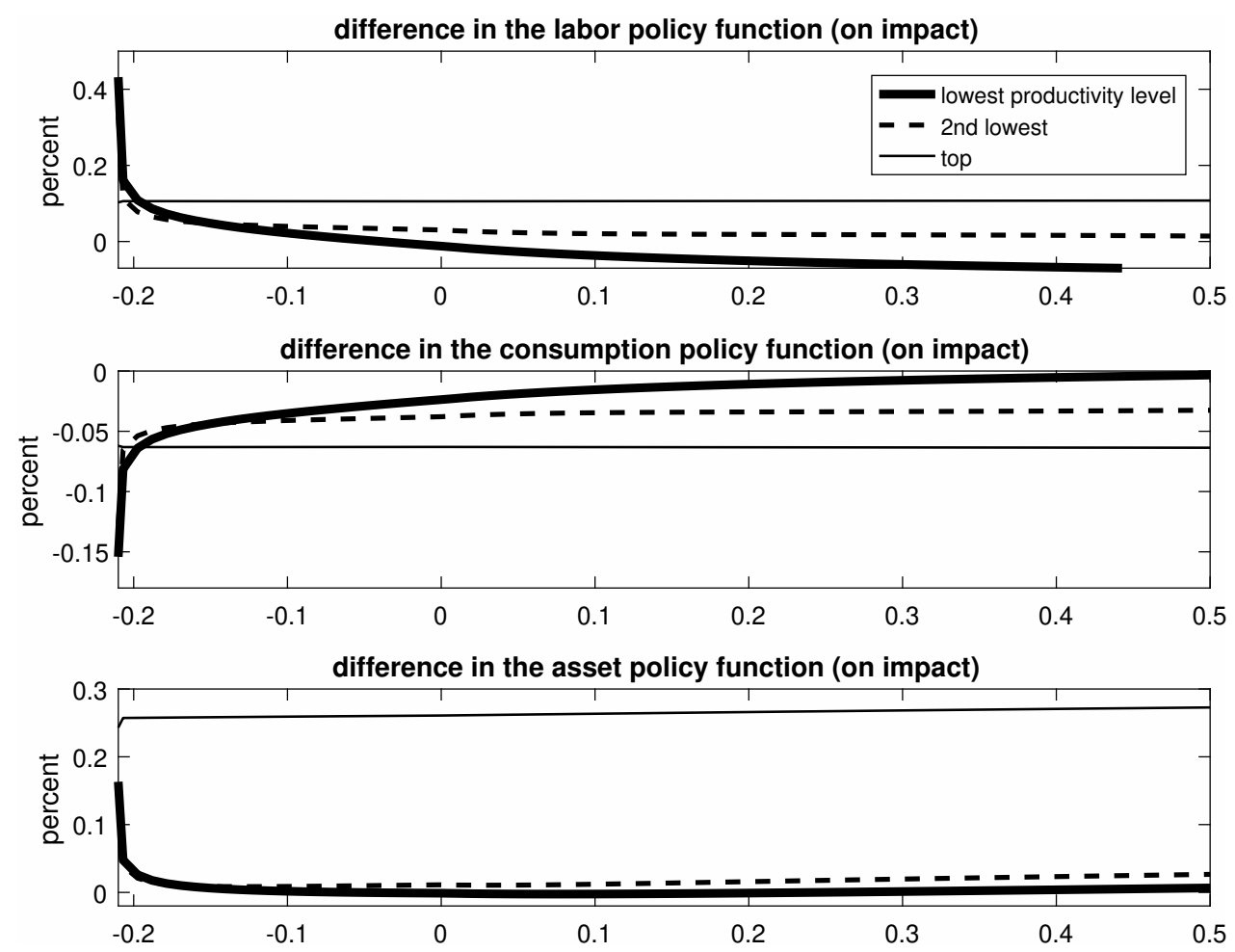

Figure 13: Effects of the transfers policy on labor, consumption and asset decision rules, conditional on different levels of productivity. Each line shows the difference between the policy function obtained in the baseline model and that obtained within the fixed constraint model, for a given productivity level, calculated at $t=1$. The $\mathrm{x}$-axes are asset holdings as a fraction of average assets.

interest rate constant implies also a constant wage rate. In practice, we iterate on policy functions conditional on factor prices kept at their steady-state levels. As a result - given the zero increase in the borrowing cost - the equilibrium value function moves up by more than in the baseline economy and this generates a loosening in the borrowing limit that is persistent over time. Hence, considering a partial equilibrium framework as opposed to a general equilibrium one reverts the sign of the reaction of the borrowing limit to the public debt expansion.

\section{D.3 Robustness exercises on the dynamics of the borrowing con- straint}

We now present a number of robustness simulations targeted to the dynamics of the borrowing constraint, under the transfers policy.

Figure 15 presents the results for four different simulations. First, in the top-left panel, we show a simulation where an endogenous ad hoc borrowing limit is used; this represents a modified version of the natural borrowing limit in Aiyagari (1994). Specifically, we let the borrowing limit be $\underline{a}=-\eta \frac{w}{r}$, where $\eta$ is parameterized so as to match the credit-to-output ratio in the data. ${ }^{31}$ The steady-state value of this alternative borrowing limit is the same we had using the original baseline model. Initially, the borrowing constraint loosens because it is mechanically affected by a fall in the interest rate on impact. After some quarters, the limit

\footnotetext{
${ }^{31}$ We recall that in the standard version of the natural borrowing limit $\eta$ would be the lowest level of the idiosyncratic productivity.
} 

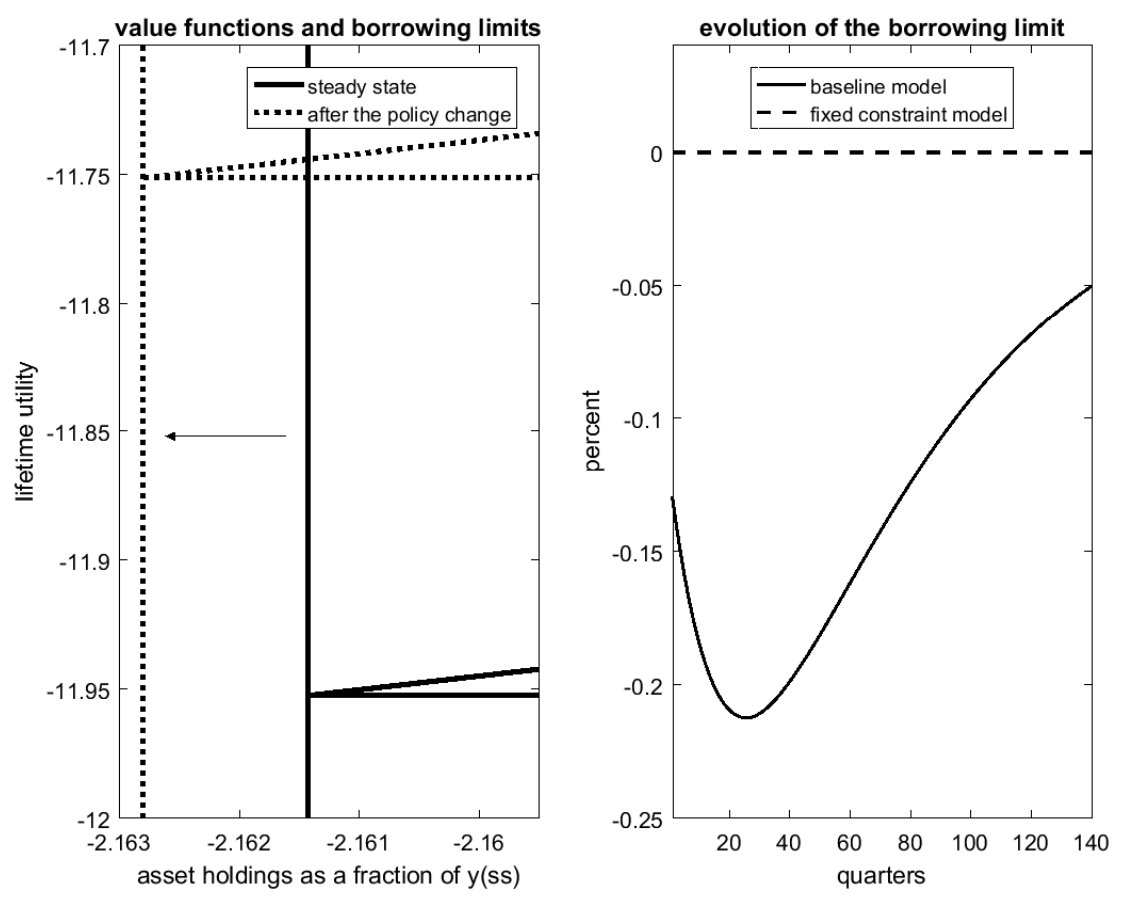

Figure 14: The movement of the borrowing constraint, $\underline{a}\left(\theta^{\prime}\right)$, conditional on the implementation of the transfers policy, under fixed prices. In the left panel, the two flat lines corresponds to the value functions in autarky, $\underline{v}\left(z^{\prime}, \theta^{\prime}\right)$, in the steady state (solid line) and in the first relevant period after the policy change (dotted line). The two lines with positive slope refer to the equilibrium value functions, $v\left(x^{\prime}, \theta^{\prime}\right)$, in the steady state (solid line) and in the first relevant period after the policy change (dotted line). The value functions are parameterized in the lowest productivity level. The steady-state borrowing limit is identified by the vertical solid line, while the borrowing limit after the change is represented by the vertical dotted line. In the right panel, the solid line corresponds to the evolution of the borrowing limit over time, while the dashed line identifies the constraint at its steady-state level. The borrowing limit is expressed in deviation from the steady-state level and normalized by steady-state output, y(ss). 
significantly tightens before slowly coming back to its steady-state level.

Second, we use different steady-state levels of public debt. In fact, in the baseline simulations we start from a steady state of debt-to-output ratio of $60 \%$ (in yearly terms). Here, we recalibrate our economy and produce two additional steady states, one with a debt-to-output ratio of $0 \%$, and the other with $120 \% .^{32}$ The top-right panel in Figure 15 shows the evolution of the borrowing constraint under the transfers policy starting with a zero public debt; this dynamics is similar to that obtained using the original calibration. The simulation in the case of a steady state of $120 \%$ for the debt-to-output ratio delivers similar results, which are available upon request.
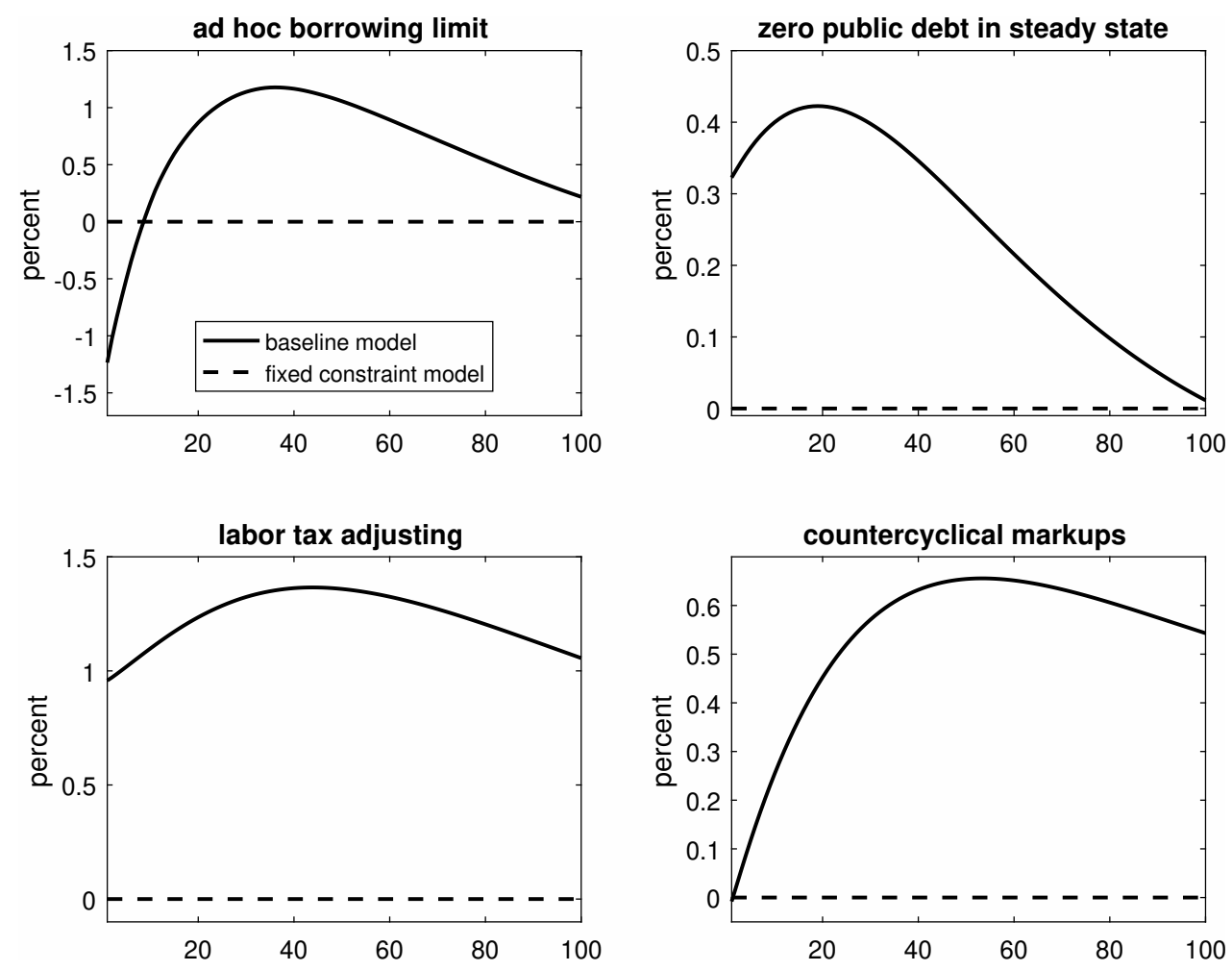

Figure 15: Evolution of the borrowing limit within alternative models, under the transfers policy. The top-left panel shows the simulation using the ad hoc borrowing limit, $-\eta \frac{w}{r}$. The top-right panel presents the simulation conditional on a steady-state level with zero public debt, in yearly terms. The bottom-left panel shows the simulation in which the public debt expansion is financed through an increase of the labor tax rate. The bottom-right panel presents the simulation with the countercylical markups. The borrowing limits are expressed in deviation from their steady-state level and normalized by steady-state output.

Third, we simulate a version of the model where an increase in the labor tax rate, $\tau_{w}$, as opposed to an increase in lump-sum taxes, finances the public debt expansion. The bottom-left panel in Figure 15 shows that a tightening occurs even under a different financing scheme.

Fourth, given that our model is characterized by flexible prices, we build a version with countercyclical markups in line with Hall (2009), which mimics the presence of price stickiness. ${ }^{33}$ As shown by Hall (2009), a model with countercyclical markups is able to replicate the typical

\footnotetext{
${ }^{32}$ In these new steady states we have the same tax rates and lump-sum taxation of the original calibration, but we set a different level of government purchases so that the fiscal primary balance is consistent with the chosen level of debt.

${ }^{33}$ Briefly, this version of the model considers an additional equation for the evolution of the markup $\kappa, \kappa=$
} 
reactions to fiscal shocks obtained in a model where price stickiness is properly modeled using, for example, a Calvo rule. The bottom-right panel in Figure 15 shows that even in this version a persistent tightening occurs.

Finally, we produce simulations with a different degree for the speed of debt adjustment, which means setting a different value for $\phi$ in the fiscal rule. For example, we set $\phi=0.05$ which is the value used by Uhlig (2010) and check that the simulation produces a tightening. This result is available upon request.

\section{D.4 Robustness exercises on the aggregate effects generated by the dynamics of the borrowing constraint}

Following the exercises in Section D.3, we check what are the effects produced by the tightening if (i) we use the alternative ad hoc borrowing limit, (ii) we start from a level of zero public debt, (iii) we use labor taxes to finance the debt expansion and, (iv) we use the version of the model with countercylical markups.
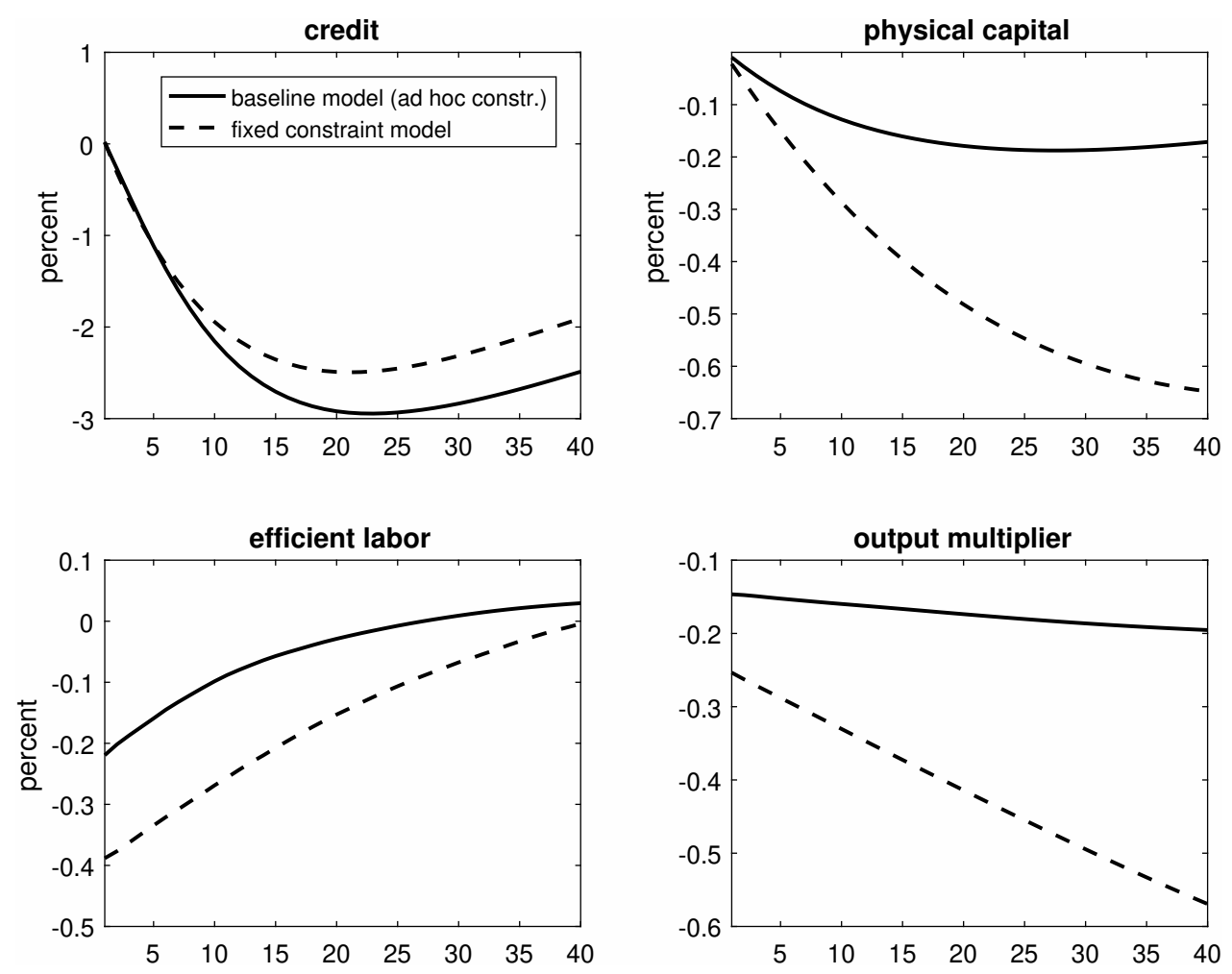

Figure 16: Aggregate effects of the transfers policy under the alternative borrowing constraint. Solid lines are generated with the model that uses the alternative borrowing limit, $-\eta \frac{w}{r}$; dashed lines are generated with the fixed constraint model. All variables are expressed in deviation from steady-state levels. The cumulative dynamic multipliers are calculated following Uhlig (2010). The x-axes are in quarters.

Regarding (i), Figure 16 shows the comparison between selected paths produced by the model with the endogenous ad hoc borrowing limit and those generated by the fixed constraint $\overline{\tilde{\kappa} Y^{-\omega}}$, where $\tilde{\kappa}$ is the markup in the steady state and a positive $\omega$ implies a countercylycal markup. Following Hall (2009), we set $\tilde{\kappa}$ and $\omega$ to 1.1 and 0.7 , respectively. Accordingly, (6) and (7) become $r^{K}=A \alpha\left(\frac{1}{\kappa}\right)\left(\frac{N}{K}\right)^{1-\alpha}$ and $w=A(1-\alpha)\left(\frac{1}{\kappa}\right)\left(\frac{K}{N}\right)^{\alpha}$, respectively. The resulting profits are evenly distributed among households. 

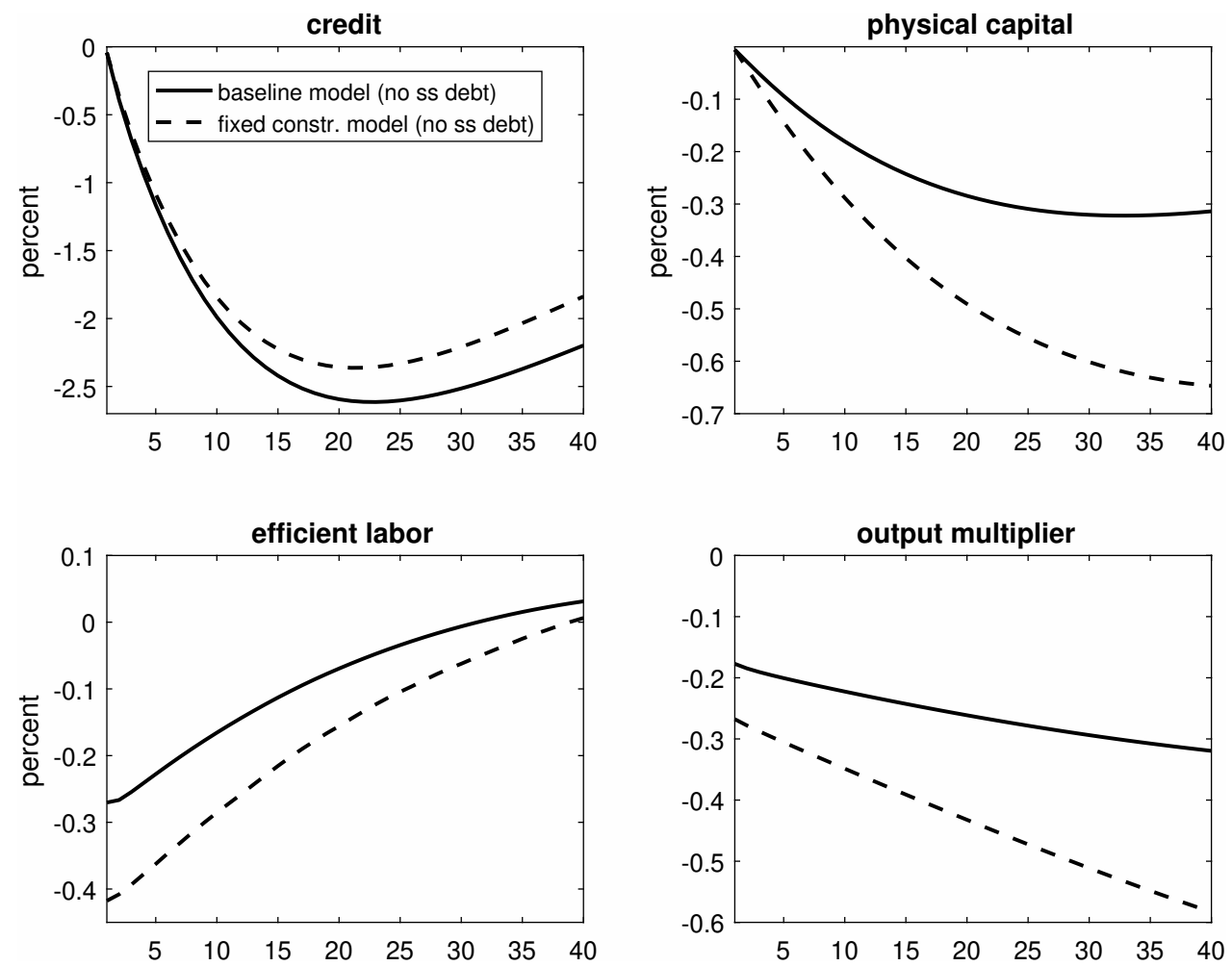

Figure 17: Aggregate effects of the transfers policy, conditional on zero public debt in steady-state. Solid lines are generated with the baseline model and dashed lines with the fixed constraint model. All variables are expressed in deviation from steady-state levels. The cumulative dynamic multipliers are calculated following Uhlig (2010). The x-axes are in quarters.
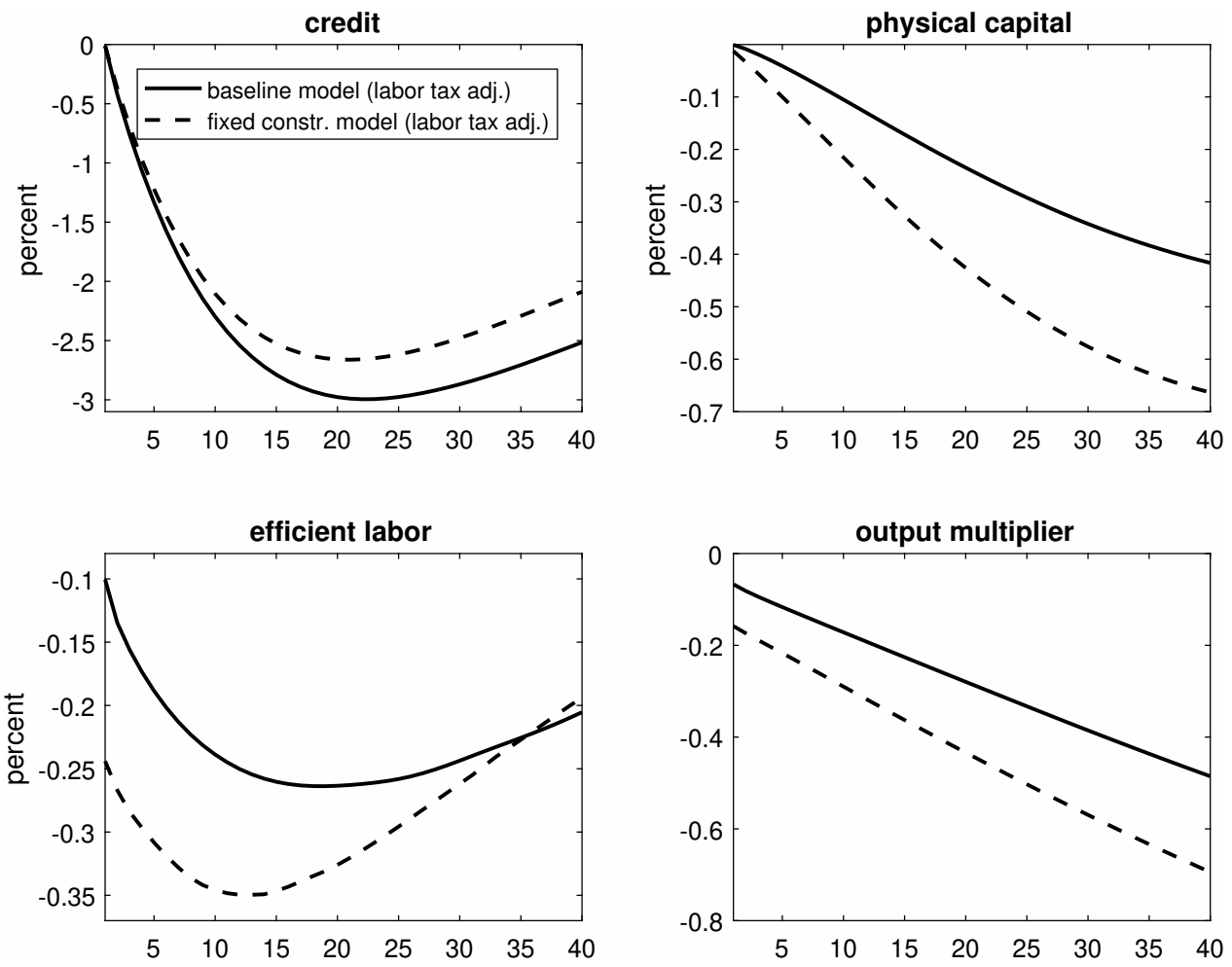

Figure 18: Aggregate effects of the transfers policy, conditional on the labor tax rate adjusting to finance the policy. Solid lines are generated with the baseline model and dashed lines with the fixed constraint model. All variables are expressed in deviation from steady-state levels. The cumulative dynamic multipliers are calculated following Uhlig (2010). The x-axes are in quarters. 

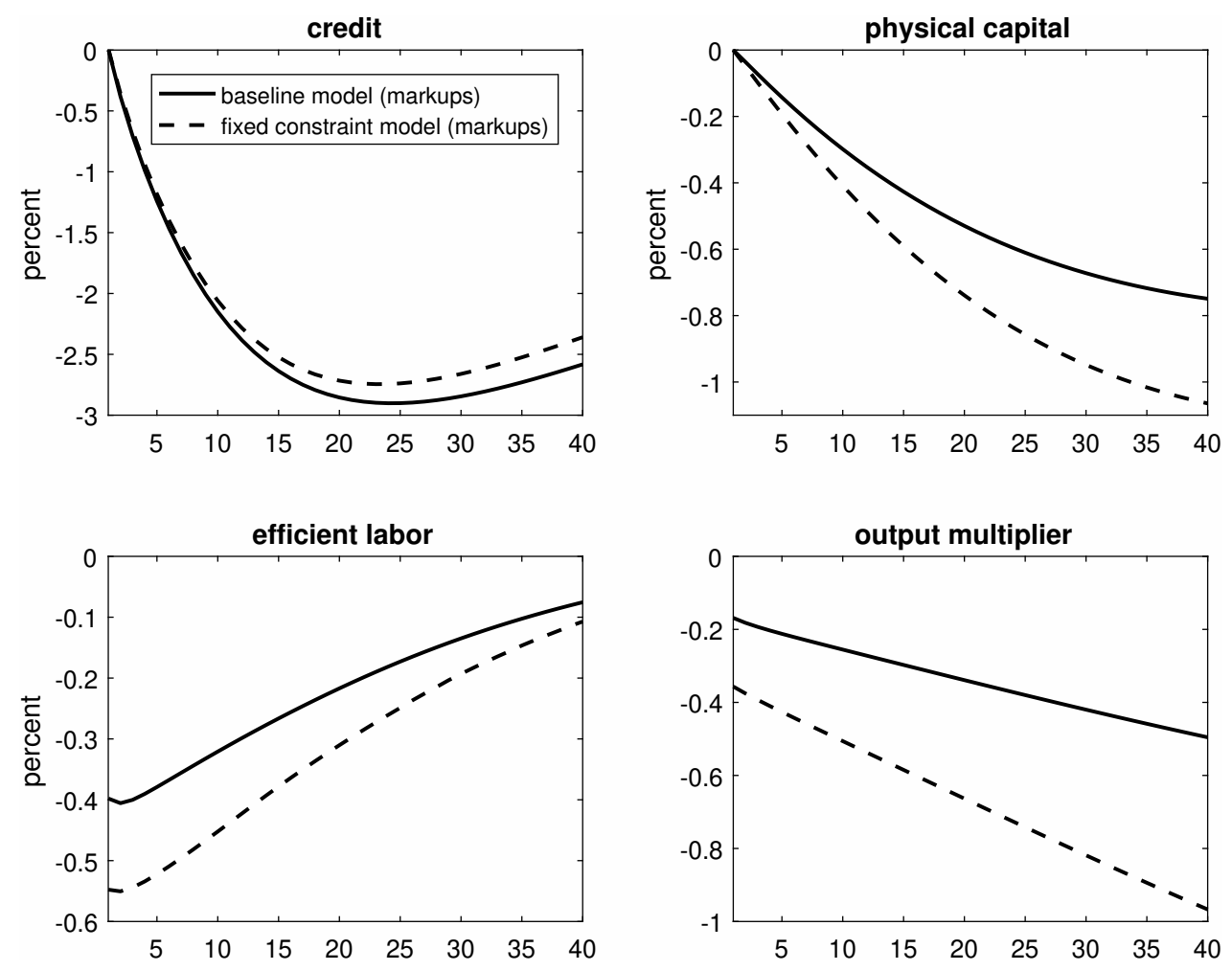

Figure 19: Aggregate effects of the transfers policy, conditional on the model version with countercylical markups. Solid lines are generated with the baseline model and dashed lines with the fixed constraint model. All variables are expressed in deviation from steady-state levels. The cumulative dynamic multipliers are calculated following Uhlig (2010). The x-axes are in quarters.

model. The effects generated by the tightening in Figure 16 are larger than those obtained in our baseline simulations using the rational borrowing constraints. This suggests that the effects generated by the dynamics of the household borrowing constraint are dampened if the borrowing limit depends not only on prices but also on the value functions, which are directly affected by the future path of all the model's variables.

Regarding the cases (ii), (iii), and (iv) which are represented in Figures 17, 18 and 19, respectively, the effects generated by the tightening have a similar magnitude to those produced within the baseline framework in Figure 4.

\section{E Further results for the government spending stimulus}

This section presents additional simulations associated with the $G$ policy.

\section{E.1 The anatomy of the tightening}

We already explained that the purchases policy is fundamentally different from the transfers policy, as the former induces agents to work more and consume less. Contrary to the transfers policy, Figure 20 shows that the purchases policy makes the autarky and the equilibrium value functions fall. Similarly to the transfers policy, the tightening eventually occurs because the increase in the borrowing cost affects only the dynamics of $v\left(x^{\prime}, \theta^{\prime}\right)$, which moves down more 


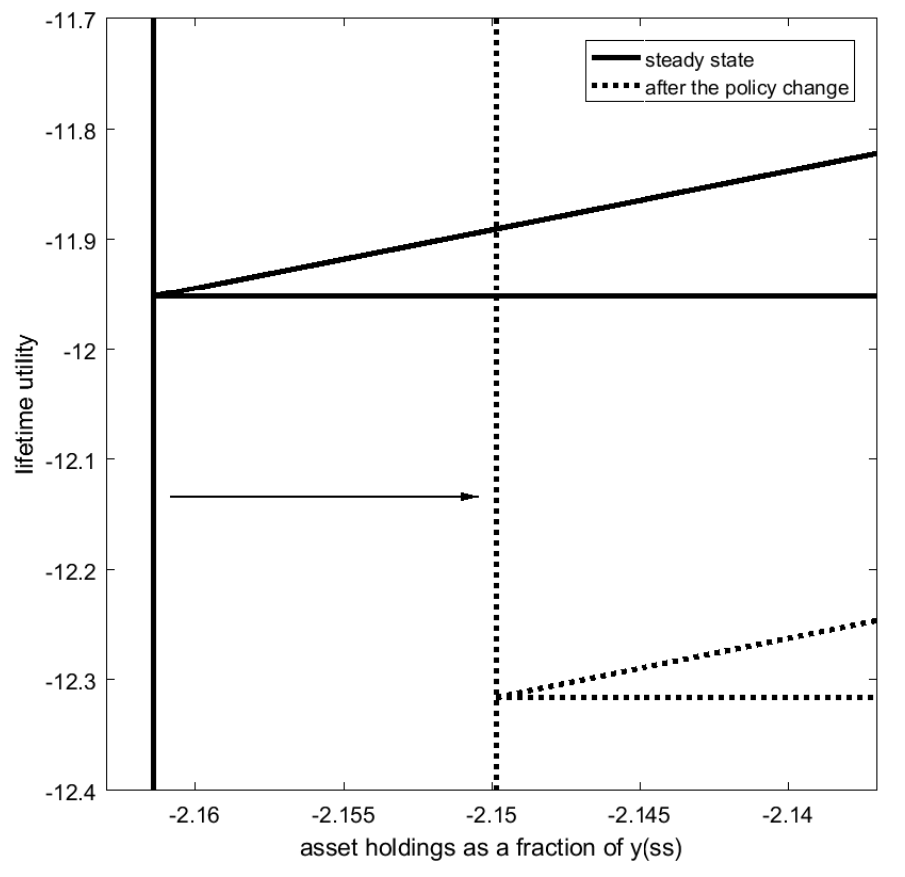

Figure 20: The movement of the borrowing constraint, $\underline{a}\left(\theta^{\prime}\right)$, conditional on the implementation of the purchases policy. The two flat lines correspond to the value functions in autarky, $\underline{v}\left(z^{\prime}, \theta^{\prime}\right)$, in the steady state (solid line) and in the first relevant period after the policy change (dotted line). The two lines with positive slope refer to the equilibrium value functions, $v\left(x^{\prime}, \theta^{\prime}\right)$, in the steady state (solid line) and in the first relevant period after the policy change (dotted line). The value functions are parameterized in the lowest productivity level. The steady-state borrowing limit is identified by the vertical solid line, while the borrowing limit after the change is represented by the vertical dotted line. $\mathrm{y}(\mathrm{ss})$ stands for steady-state output. 
than what $\underline{v}\left(z^{\prime}, \theta^{\prime}\right)$ does.

\section{E.2 Dynamics at the individual level}
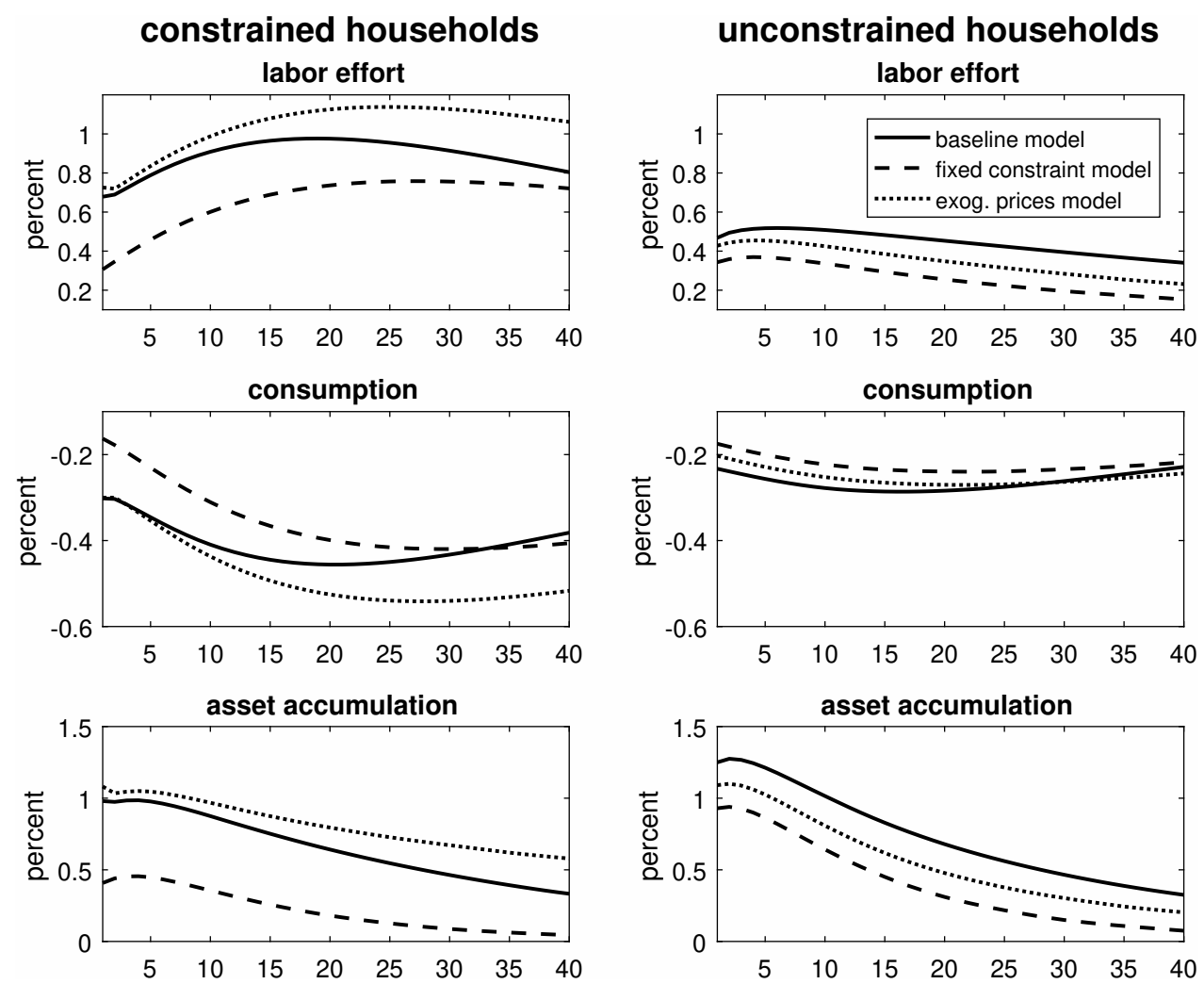

Figure 21: Heterogeneous effects of the purchases policy. The average reactions of constrained agents are on the left column. The average reactions of unconstrained agents are on the right column. All variables are expressed in deviation from steady-state levels. Asset accumulation is the difference between the asset level in $t+1$ and the steady-state level, normalized by steady-state investment. The $\mathrm{x}$-axes are in quarters.

Figures 21 show the heterogeneous reactions to the policy. The households' reactions generated by the tightening under the purchases policy are qualitatively similar to those generated under the transfers policy. However, on average, both the shift of the borrowing limit and the resulting price effects generate larger reactions vis-à-vis those induced by the transfers policy.

\section{E.3 Welfare}

Figure 22 presents the welfare gains along the household wealth distribution for the baseline (solid line), the fixed constraint model (dashed line), and the exogenous prices model (dotted line) under the purchases policy. To assess the welfare gains we follow the procedure described in Section 4.3.

Within the fixed constraint model, the government spending policy produces negative effects for almost all households along the wealth distribution. Only the richest households (top 10\%) experience a welfare gain, possibly because the higher yield more than compensates the negative effects coming from the future higher taxation. 


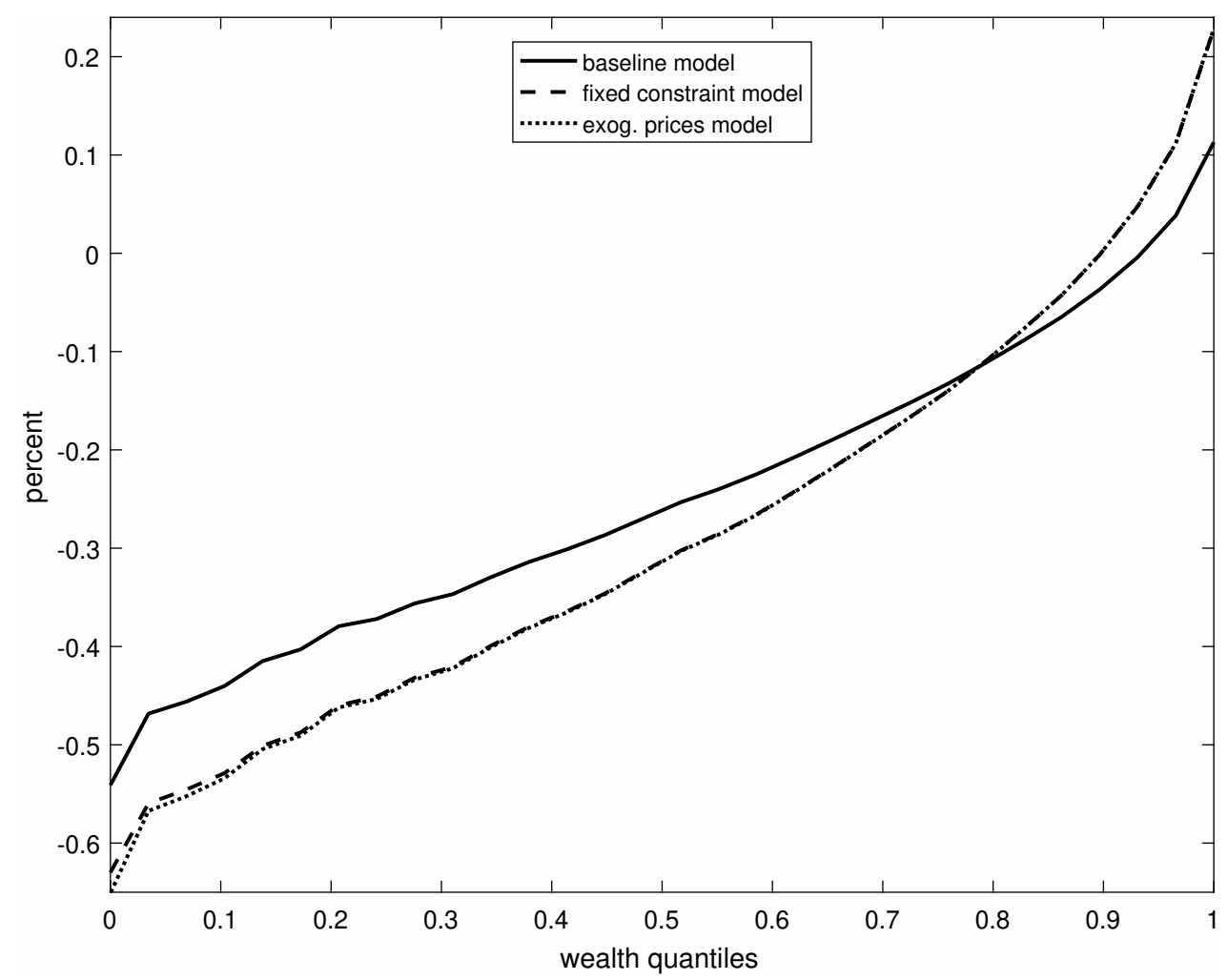

Figure 22: Welfare effects of the purchases policy by wealth quantiles. Positive values represent a welfare gain measured as the consumption-equivalent change relative to the initial steady state. See the definition in footnote 23.

The welfare associated with the baseline model is higher than that of the fixed constraint model for all households up until roughly the fourth quintile. Instead, for richer households the opposite holds. As in the transfers case, we explain this fact relying on the price effects generated by the tightening: relatively higher (lower) wage (interest) rates favor the constrained, the wealth-poor and the middle class households, but makes the richest households worse off.

\section{E.4 The government spending stimulus with inelastic labor supply}

In the main text, we show that labor supply reacts both to the fiscal policies and to the change in the borrowing limit, which would mean that not including elastic labor supply would likely bias the effects of the policies under scrutiny.

In order to highlight the bias, we run simulations of our baseline model version with inelastic labor supply. ${ }^{34}$ We focus on the $G$ policy under the inelastic labor case because of output effects. Figure 23 compares the simulation of our baseline model (solid lines) with the same model except for the fact that labor supply is inelastic (dashed lines), under the $G$ policy. The borrowing limit tightens more in the inelastic labor case because the increase in the interest rate is by far more persistent. The deeper tightening induces agents to deleverage more. Consumption goes down by a lot more in the inelastic labor case because the borrowing limit tightens more and

\footnotetext{
${ }^{34}$ In a nutshell, the exercise is conducted by assuming the instantaneous utility function $u(c)=\frac{c^{1-\sigma}-1}{1-\sigma}$ and recalibrating some of the parameters so as to obtain the same equilibrium interest rate and credit as a percentage of output.
} 

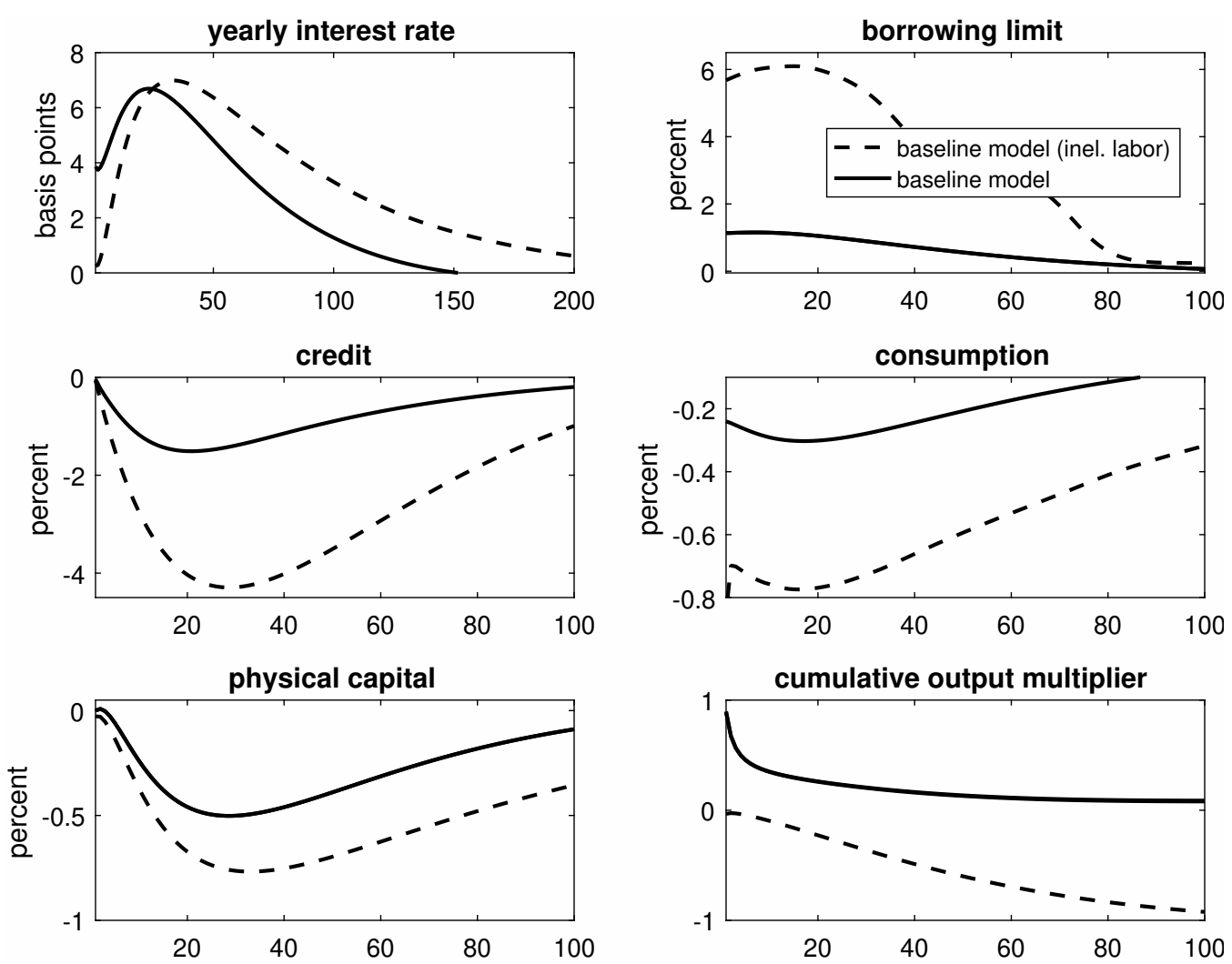

Figure 23: Selected reactions to the purchases policy. All variables are expressed in deviation from steady-state levels. The deviations for the borrowing limit are normalized by steady-state output. The cumulative output multiplier is calculated following Uhlig (2010). The x-axes are in quarters.

individuals have only the consumption margin to react to shocks. Notice the behavior of output in the inelastic labor economy: absent the labor reaction, the dynamics of output is driven by the behavior of capital, which does not allow output to positively react to the $G$ shock (not even initially), a feature that is at odds with the empirical evidence.

\section{F A crisis experiment}

The purpose of this section is to see how public debt expansions affect the agents' behavior during an economic crisis characterized by a fall in output and private credit.

In order to generate such scenario, we simultaneously simulate two exogenous changes. The first one, a decrease in the TFP, produces a fall in output; the second one, a decrease in the value of the penalty of choosing autarky, generates both a tightening and a fall in credit. More specifically, we simulate a negative technology change, modeled as a fall in $A$ as defined in Section 2.1. Process $A$ is deterministic and described by $A^{\prime}=1-\rho^{a}+\rho^{a} A$, where we set the initial level of $A$ to 0.965 and $\rho^{a}=0.85 .{ }^{35}$ There is also a temporary fall in the penalty for default through an increase in the parameter $\gamma$, modeled as $\gamma^{\prime}=\left(1-\rho^{\gamma}\right) \times 0.9516+\rho^{\gamma} \gamma$, where we set the initial level of $\gamma$ to 1 and $\rho^{\gamma}=0.95 .^{36}$

\footnotetext{
${ }^{35}$ We set the initial value of $A$ in order to roughly get a $4 \%$ fall in output. Such a fall is the same observed for the U.S. GDP during the Great Recession, specifically, between 2008:Q2 and 2009:Q2. Regarding $\rho^{a}$, we tried different values around 0.85 ; results hardly change.

${ }^{36} \mathrm{~A}$ lower value for penalty decreases the incentive for borrowers to pay back the principal; hence, lenders
} 
Within our baseline model specification, we unexpectedly implement the mentioned deterministic processes for $A$ and $\gamma$ at $t=1$. The solid lines in Figure 24 show selected paths implied by these changes. All else equal, the marginal product of capital decreases; the real interest rate and the capital stock fall. Households consume and work less. An initial fall in output of roughly $4 \%$ is generated. On impact, a tightening of the borrowing constraint obtains of more than $20 \%$ of steady-state output. The tightening, in turn, favors a fall in credit.

The effects generated by the above-mentioned changes can be seen as a "no intervention" scenario where the fiscal authority does not implement any discretionary policy. In order to see how the crisis is affected by the fiscal policies we proceed as follows. At the same time of the occurrence of the crisis, we simulate, in turn, the two debt expansions described in Sections 4.1 and 4.4. The dashed lines represent the variables' reactions to the crisis coupled with the debt-financed transfers policy. The dotted lines represent the variables' reactions to the crisis coupled with the debt-financed purchases policy. Though the quantitative effects of the two fiscal policies are somehow different, the qualitative effects show several similarities. For example, both policies produce a higher level of the borrowing cost when compared to the no intervention scenario, though a very mild increase occurs under the transfer policy. This is consistent with the fact that the implementation of the policies contributes to a further tightening of the borrowing limit, which is of a much smaller magnitude under the transfers policy. Both policies generate a fall in credit: five years after the start of the policies, the fall in credit is, on average, twice as large as that obtained in the no intervention case. ${ }^{37}$ Furthermore, physical capital is crowded out more if the fiscal policies are implemented. The $G$ policy makes consumption fall. Regarding output, the effects of both policies on its dynamics look modest.

will provide less funds in the credit market. This contributes to generate a tightening and a fall in credit.

${ }^{37}$ The tightening generated by the crisis has been so large that constrained or poor agents use part of the received transfers to deleverage, that is, cutting credit via buying assets. 

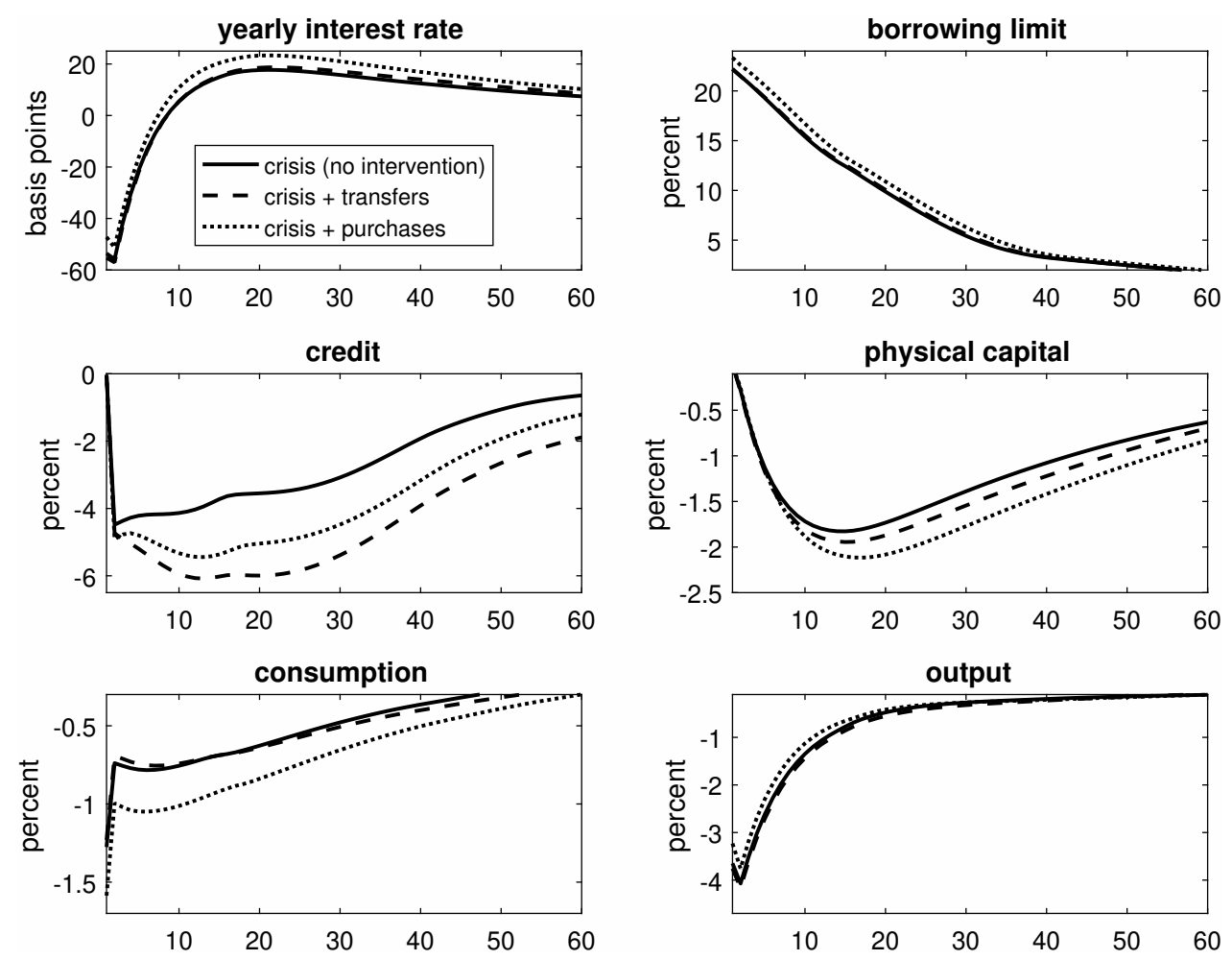

Figure 24: Selected aggregate effects in a crisis experiment. All paths are generated using the baseline version of the model. Solid lines represent the paths implied by the crisis, modeled as an unexpected TFP fall coupled with an unexpected decrease in the penalty of declaring autarky, without any intervention from the fiscal authority. Dashed lines are generated by the occurrence of both the crisis and the transfers policy. Dotted lines are generated by the occurrence of both the crisis and the purchases policy. All variables are expressed in deviation from steady-state levels. The deviations for the borrowing limit are normalized by steady-state output. The $\mathrm{x}$-axes are in quarters. 


\section{RECENTLY PUBLISHED “TEMI” (*)}

N.1246 - Financial development and growth in European regions, by Paola Rossi and Diego Scalise (November 2019).

N. 1247 - IMF programs and stigma in Emerging Market Economies, by Claudia Maurini (November 2019).

N.1248 - Loss aversion in housing assessment among Italian homeowners, by Andrea Lamorgese and Dario Pellegrino (November 2019).

N.1249 - Long-term unemployment and subsidies for permanent employment, by Emanuele Ciani, Adele Grompone and Elisabetta Olivieri (November 2019).

N. 1250 - Debt maturity and firm performance: evidence from a quasi-natural experiment, by Antonio Accetturo, Giulia Canzian, Michele Cascarano and Maria Lucia Stefani (November 2019).

N. 1251 - Non-standard monetary policy measures in the new normal, by Anna Bartocci, Alessandro Notarpietro and Massimiliano Pisani (November 2019).

N. 1252 - The cost of steering in financial markets: evidence from the mortgage market, by Leonardo Gambacorta, Luigi Guiso, Paolo Emilio Mistrulli, Andrea Pozzi and Anton Tsoy (December 2019).

N. 1253 - Place-based policy and local TFP, by Giuseppe Albanese, Guido de Blasio and Andrea Locatelli (December 2019).

N.1254 - The effects of bank branch closures on credit relationships, by Iconio Garrì (December 2019).

N. 1255 - The loan cost advantage of public firms and financial market conditions: evidence from the European syndicated loan market, by Raffaele Gallo (December 2019).

N. 1256 - Corporate default forecasting with machine learning, by Mirko Moscatelli, Simone Narizzano, Fabio Parlapiano and Gianluca Viggiano (December 2019).

N. 1257 - Labour productivity and the wageless recovery, by Antonio M. Conti, Elisa Guglielminetti and Marianna Riggi (December 2019).

N. 1258 - Corporate leverage and monetary policy effectiveness in the Euro area, by Simone Auer, Marco Bernardini and Martina Cecioni (December 2019).

N.1259 - Energy costs and competitiveness in Europe, by Ivan Faiella and Alessandro Mistretta (February 2020).

N.1260 - Demand for safety, risky loans: a model of securitization, by Anatoli Segura and Alonso Villacorta (February 2020).

N.1261 - The real effects of land use regulation: quasi-experimental evidence from a discontinuous policy variation, by Marco Fregoni, Marco Leonardi and Sauro Mocetti (February 2020).

N. 1262 - Capital inflows to emerging countries and their sensitivity to the global financial cycle, by Ines Buono, Flavia Corneli and Enrica Di Stefano (February 2020).

N. 1263 - Rising protectionism and global value chains: quantifying the general equilibrium effects, by Rita Cappariello, Sebastián Franco-Bedoya, Vanessa Gunnella and Gianmarco Ottaviano (February 2020).

N. 1264 - The impact of TLTRO2 on the Italian credit market: some econometric evidence, by Lucia Esposito, Davide Fantino and Yeji Sung (February 2020).

N.1265 - Public credit guarantee and financial additionalities across SME risk classes, by Emanuele Ciani, Marco Gallo and Zeno Rotondi (February 2020).

(*) Requests for copies should be sent to:

Banca d'Italia - Servizio Studi di struttura economica e finanziaria - Divisione Biblioteca e Archivio storico - Via Nazionale, 91 - 00184 Rome - (fax 003906 47922059). They are available on the Internet www.bancaditalia.it. 
Accetturo A., V. Di Giacinto, G. Micucci and M. Pagnini, Geography, productivity and trade: does selection explain why some locations are more productive than others?, Journal of Regional Science, v. 58, 5, pp. 949-979, WP 910 (April 2013).

ADAMOPOULOU A. and E. KAYA, Young adults living with their parents and the influence of peers, Oxford Bulletin of Economics and Statistics,v. 80, pp. 689-713, WP 1038 (November 2015).

Andini M., E. Ciani, G. De Blasio, A. D’Ignazio and V. Silvestrini, Targeting with machine learning: an application to a tax rebate program in Italy, Journal of Economic Behavior \& Organization, v. 156, pp. 86-102, WP 1158 (December 2017).

BARONE G., G. DE BLASIO and S. MOCETTI, The real effects of credit crunch in the great recession: evidence from Italian provinces, Regional Science and Urban Economics, v. 70, pp. 352-59, WP 1057 (March 2016).

Belotti F. and G. IlARDi Consistent inference in fixed-effects stochastic frontier models, Journal of Econometrics, v. 202, 2, pp. 161-177, WP 1147 (October 2017).

Berton F., S. Mocetti, A. Presbitero and M. Richiardi, Banks, firms, and jobs, Review of Financial Studies, v.31, 6, pp. 2113-2156, WP 1097 (February 2017).

Bofondi M., L. CARPinelli and E. SETte, Credit supply during a sovereign debt crisis, Journal of the European Economic Association, v.16, 3, pp. 696-729, WP 909 (April 2013).

Bokan N., A. Gerali, S. Gomes, P. JACQuinOt and M. PiSANI, EAGLE-FLI: a macroeconomic model of banking and financial interdependence in the euro area, Economic Modelling, v. 69, C, pp. 249280, WP 1064 (April 2016).

BRILli Y. and M. TONELlo, Does increasing compulsory education reduce or displace adolescent crime? New evidence from administrative and victimization data, CESifo Economic Studies, v. 64, 1, pp. 15-4, WP 1008 (April 2015).

BUONO I. and S. FORMAI The heterogeneous response of domestic sales and exports to bank credit shocks, Journal of International Economics, v. 113, pp. 55-73, WP 1066 (March 2018).

Burlon L., A. Gerali, A. NotarPietro and M. Pisani, Non-standard monetary policy, asset prices and macroprudential policy in a monetary union, Journal of International Money and Finance, v. 88, pp. 25-53, WP 1089 (October 2016).

CARTA F. and M. DE PHLIPPIS, You've Come a long way, baby. Husbands' commuting time and family labour supply, Regional Science and Urban Economics, v. 69, pp. 25-37, WP 1003 (March 2015).

CARTA F. and L. RIZZICA, Early kindergarten, maternal labor supply and children's outcomes: evidence from Italy, Journal of Public Economics, v. 158, pp. 79-102, WP 1030 (October 2015).

Casiraghi M., E. Gaiotti, L. Rodano and A. SECchi, A “Reverse Robin Hood"? The distributional implications of non-standard monetary policy for Italian households, Journal of International Money and Finance, v. 85, pp. 215-235, WP 1077 (July 2016).

CIANI E. and C. DEIANA, No Free lunch, buddy: housing transfers and informal care later in life, Review of Economics of the Household, v.16, 4, pp. 971-1001, WP 1117 (June 2017).

Cipriani M., A. Guarino, G. Guazzarotti, F. Tagliati and S. Fisher, Informational contagion in the laboratory, Review of Finance, v. 22, 3, pp. 877-904, WP 1063 (April 2016).

De Blasio G, S. De Mitri, S. D’Ignazio, P. Finaldi Russo and L. Stoppani, Public guarantees to SME borrowing. A RDD evaluation, Journal of Banking \& Finance, v. 96, pp. 73-86, WP 1111 (April 2017).

Gerali A., A. LocARno, A. NotARPIETRO and M. PISANI, The sovereign crisis and Italy's potential output, Journal of Policy Modeling, v. 40, 2, pp. 418-433, WP 1010 (June 2015).

LIBERATI D., An estimated DSGE model with search and matching frictions in the credit market, International Journal of Monetary Economics and Finance (IJMEF), v. 11, 6, pp. 567-617, WP 986 (November 2014).

LinAREllo A., Direct and indirect effects of trade liberalization: evidence from Chile, Journal of Development Economics, v. 134, pp. 160-175, WP 994 (December 2014).

NAtoli F. and L. SigAlotTi, Tail co-movement in inflation expectations as an indicator of anchoring, International Journal of Central Banking, v. 14, 1, pp. 35-71, WP 1025 (July 2015).

NuCCI F. and M. RigGI, Labor force participation, wage rigidities, and inflation, Journal of Macroeconomics, v. 55, 3 pp. 274-292, WP 1054 (March 2016).

RIGON M. and F. ZANETTI, Optimal monetary policy and fiscal policy interaction in a non_ricardian economy, International Journal of Central Banking, v. 14 3, pp. 389-436, WP 1155 (December 2017). 
SEGURA A., Why did sponsor banks rescue their SIVs?, Review of Finance, v. 22, 2, pp. 661-697, WP 1100 (February 2017).

AlbANESE G., M. CIOFFI and P. TOMMASINO, Legislators' behaviour and electoral rules: evidence from an Italian reform, European Journal of Political Economy, v. 59, pp. 423-444, WP 1135 (September 2017).

Aprigliano V., G. ArdizzI and L. MonTEForte, Using the payment system data to forecast the economic activity, International Journal of Central Banking, v. 15, 4, pp. 55-80, WP 1098 (February 2017).

ARNAUDO D., G. MICUCCI, M. RIGON and P. Rossi, Should I stay or should I go? Firms' mobility across banks in the aftermath of the financial crisis, Italian Economic Journal / Rivista italiana degli economisti, v. 5, 1, pp. 17-37, WP 1086 (October 2016).

BASSO G., F. D’AMURI and G. PERI, Immigrants, labor market dynamics and adjustment to shocks in the euro area, IMF Economic Review, v. 67, 3, pp. 528-572, WP 1195 (November 2018).

BAtini N., G. MelinA and S. Villa, Fiscal buffers, private debt, and recession: the good, the bad and the ugly, Journal of Macroeconomics, v. 62, WP 1186 (July 2018).

Burlon L., A. Notarpietro and M. Pisani, Macroeconomic effects of an open-ended asset purchase programme, Journal of Policy Modeling, v. 41, 6, pp. 1144-1159, WP 1185 (July 2018).

Busetti F. and M. CAIVANO, Low frequency drivers of the real interest rate: empirical evidence for advanced economies, International Finance, v. 22, 2, pp. 171-185, WP 1132 (September 2017).

CAppelletti G., G. GuAzZAROtTi and P. TOMmasino, Tax deferral and mutual fund inflows: evidence from a quasi-natural experiment, Fiscal Studies, v. 40, 2, pp. 211-237, WP 938 (November 2013).

CARDANi R., A. PACCAGNINI and S. VILla, Forecasting with instabilities: an application to DSGE models with financial frictions, Journal of Macroeconomics, v. 61, WP 1234 (September 2019).

Chiades P., L. Greco, V. Mengotto, L. Moretti and P. Valbonesi, Fiscal consolidation by intergovernmental transfers cuts? The unpleasant effect on expenditure arrears, Economic Modelling, v. 77, pp. 266-275, WP 985 (July 2016).

CIANI E., F. DAVID and G. DE BLASIO, Local responses to labor demand shocks: a re-assessment of the case of Italy, Regional Science and Urban Economics, v. 75, pp. 1-21, WP 1112 (April 2017).

CIANI E. and P. FISHER, Dif-in-dif estimators of multiplicative treatment effects, Journal of Econometric Methods, v. 8. 1, pp. 1-10, WP 985 (November 2014).

CIAPANNA E. and M. TABOGA, Bayesian analysis of coefficient instability in dynamic regressions, Econometrics, MDPI, Open Access Journal, v. 7, 3, pp.1-32, WP 836 (November 2011).

Coletta M., R. De Bonis and S. PIERMATteI, Household debt in OECD countries: the role of supply-side and demand-side factors, Social Indicators Research, v. 143, 3, pp. 1185-1217, WP 989 (November 2014).

Cova P., P. PAgAno and M. PISAni, Domestic and international effects of the Eurosystem Expanded Asset Purchase Programme, IMF Economic Review, v. 67, 2, pp. 315-348, WP 1036 (October 2015).

ERCOLANI V. and J. VAlLE E AZEVEDO, How can the government spending multiplier be small at the zero lower bound?, Macroeconomic Dynamics, v. 23, 8. pp. 3457-2482, WP 1174 (April 2018).

FERrero G., M. Gross and S. NerI, On secular stagnation and low interest rates: demography matters, International Finance, v. 22, 3, pp. 262-278, WP 1137 (September 2017).

FoA G., L. GAmbacorta, L. Guiso and P. E. Mistrulli, The supply side of household finance, Review of Financial Studies, v.32, 10, pp. 3762-3798, WP 1044 (November 2015).

Giordano C., M. MARINUCCI and A. Silvestrini, The macro determinants of firms' and households' investment: evidence from Italy, Economic Modelling, v. 78, pp. 118-133, WP 1167 (March 2018).

Gomellini M., D. Pellegrino and F. GifFoni, Human capital and urban growth in Italy,1981-2001, Review of Urban \& Regional Development Studies, v. 31, 2, pp. 77-101, WP 1127 (July 2017).

MAGRI S., Are lenders using risk-based pricing in the Italian consumer loan market? The effect of the 2008 crisis, Journal of Credit Risk, v. 15, 1, pp. 27-65, WP 1164 (January 2018).

Makinen T., A. MercatANTI and A. Silvestrini, The role of financial factors for european corporate investment, Journal of International Money and Finance, v. 96, pp. 246-258, WP 1148 (October 2017).

Miglietta A., C. Picillo and M. Pietrunti, The impact of margin policies on the Italian repo market, The North American Journal of Economics and Finance, v. 50, WP 1028 (October 2015). 
MONTEFORTE L. and V. RAPONI, Short-term forecasts of economic activity: are fortnightly factors useful?, Journal of Forecasting, v. 38, 3, pp. 207-221, WP 1177 (June 2018).

Neri S. and A. NOTARPIETRO, Collateral constraints, the zero lower bound, and the debt-deflation mechanism, Economics Letters, v. 174, pp. 144-148, WP 1040 (November 2015).

Pereda FERnANDEZ S., Teachers and cheaters. Just an anagram?, Journal of Human Capital, v. 13, 4, pp. 635-669, WP 1047 (January 2016).

RigGi M., Capital destruction, jobless recoveries, and the discipline device role of unemployment, Macroeconomic Dynamics, v. 23, 2, pp. 590-624, WP 871 (July 2012).

2020

COIBION O., Y. GORODNICHENKO and T. ROPELE, Inflation expectations and firms' decisions: new causal evidence, Quarterly Journal of Economics, v. 135, 1, pp. 165-219, WP 1219 (April 2019).

D'IGNAZIO A. and C. MENOn, The causal effect of credit Guarantees for SMEs: evidence from Italy, The Scandinavian Journal of Economics, v. 122, 1, pp. 191-218, WP 900 (February 2013).

RAINONE E. and F. VACIRCA, Estimating the money market microstructure with negative and zero interest rates, Quantitative Finance, v. 20, 2, pp. 207-234, WP 1059 (March 2016).

RIZZICA L., Raising aspirations and higher education. evidence from the UK's widening participation policy, Journal of Labor Economics, v. 38, 1, pp. 183-214, WP 1188 (September 2018).

\section{FORTHCOMING}

ARDUINI T., E. PATACCHINI and E. RAINONE, Treatment effects with heterogeneous externalities, Journal of Business \& Economic Statistics, WP 974 (October 2014).

Bologna P., A. Miglietta and A. Segura, Contagion in the CoCos market? A case study of two stress events, International Journal of Central Banking, WP 1201 (November 2018).

Bottero M., F. MEZZANOTTI and S. LENZU, Sovereign debt exposure and the Bank Lending Channel: impact on credit supply and the real economy, Journal of International Economics, WP 1032 (October 2015).

BRIPI F., D. LOSCHIAVO and D. REVELLI, Services trade and credit frictions: evidence with matched bankfirm data, The World Economy, WP 1110 (April 2017).

BRONZINI R., G. CARAMELLINO and S. MAGRI, Venture capitalists at work: a Diff-in-Diff approach at latestages of the screening process, Journal of Business Venturing, WP 1131 (September 2017).

BRONZINI R., S. MOCETTI and M. MONGARDInI, The economic effects of big events: evidence from the Great Jubilee 2000 in Rome, Journal of Regional Science, WP 1208 (February 2019).

CORSELlO F. and V. NISPI LANDI, Labor market and financial shocks: a time-varying analysis, Journal of Money, Credit and Banking, WP 1179 (June 2018).

Cova P., P. PAgAnO, A. NotarPietro and M. Pisani, Secular stagnation, R\&D, public investment and monetary policy: a global-model perspective, Macroeconomic Dynamics, WP 1156 (December 2017).

GerAli A. and S. NeRI, Natural rates across the Atlantic, Journal of Macroeconomics, WP 1140 (September 2017).

LiBERATI D. and M. LOBERTO, Taxation and housing markets with search frictions, Journal of Housing Economics, WP 1105 (March 2017).

LoschiAvo D., Household debt and income inequality: evidence from italian survey data, Review of Income and Wealth, WP 1095 (January 2017).

Mocetti S., G. RoMA and E. RuBOLINO, Knocking on parents' doors: regulation and intergenerational mobility, Journal of Human Resources, WP 1182 (July 2018).

PANCRAZI R. and M. PietrunTI, Natural expectations and home equity extraction, Journal of Housing Economics, WP 984 (November 2014).

Pereda Fernandez S., Copula-based random effects models for clustered data, Journal of Business \& Economic Statistics, WP 1092 (January 2017).

RAINONE E., The network nature of otc interest rates, Journal of Financial Markets, WP 1022 (July 2015). 